PNNL-13166

\title{
Polycube Oxidation and Factors Affecting the Concentrations of Gaseous Products
}

\author{
J. Abrefah \\ P. J. MacFarlan \\ R. L. Sell
}

April 2000

Prepared for

Fluor Hanford, Inc.

Work Supported by

the U.S. Department of Energy

under Contract DE-AC06-76RLO 1830

Pacific Northwest National Laboratory

Richland, Washington 99352 



\section{DISCLAIMER}

This report was prepared as an account of work sponsored by an agency of the United States Government. Neither the United States Government nor any agency thereof, nor any of their employees, make any warranty, express or implied, or assumes any legal liability or responsibility for the accuracy, completeness, or usefulness of any information, apparatus, product, or process disclosed, or represents that its use would not infringe privately owned rights. Reference herein to any specific commercial product, process, or service by trade name, trademark, manufacturer, or otherwise does not necessarily constitute or imply its endorsement, recommendation, or favoring by the United States Government or any agency thereof. The views and opinions of authors expressed herein do not necessarily state or reflect those of the United States Government or any agency thereof. 


\section{DISCLAIMER}

Portions of this document may be illegible in electronic image products. Images are produced from the best available original document. 


\section{Summary}

This report discusses tests conducted by Pacific Northwest National Laboratory (PNNL) to determine the effectiveness of directly oxidizing polycubes in a muffle furnace to stabilize them for interim storage. Polycubes, which are solid mixtures of high-density polystyrene and plutonium and uranium oxides, were used in the 1960 s for criticality studies to determine the hydrogen-to-fissile atom ratios for neutron moderation. The "cubes" varied in size, typically $1 / 2 \times 2 \times 2$ in. up to $2 \times 2 \times 2$ in., and were sealed with a coating of aluminum paint and/or tape (PVC or Shurtape). These solid forms provided simulated "solutions" that were easy to handle and contained the high concentrations of fissile materials required for testing.

Upon completion of the criticality studies, two methods were developed to reclaim the transuranic (TRU) oxides from the polymer matrix:

- burning the polycubes in air at about $873 \mathrm{~K}^{(\mathrm{a})}$

- heating the polycubes in the absence of oxygen and scrubbing the released monomer and other volatile organics with carbon tetrachloride. ${ }^{(b)}$

Neither of these methods was satisfactory in separating the TRU oxides from the polystyrene. Consequently, approximately 1600 polycubes were sent to the Hanford Plutonium Finishing Plant (PFP) for storage. Since then, the polycubes have degraded as a result of radiolytic decomposition of the polystyrene. In 1994, the stored polycubes were identified in the Plutonium Finishing Plant Plutonium Vulnerability Assessment as items requiring stabilization to support the Defense Nuclear Facility Safety Board Recommendation 94-1.

A baseline stabilization process was developed by Los Alamos National Laboratory (LANL) to pyrolyze the polycubes in argon at a temperature of $1023 \mathrm{~K}$, condensing all the pyrolyzates and treating them in a catalyst bed to oxidize them. The residue resulting from the pyrolysis process would then be oxidized in a muffle furnace at PFP to generate pure TRU oxides to meet the DOE dry storage requirement 3013.

The development work performed by LANL was based on pure polystyrene cubes obtained for the study. To verify the applicability of the pyrolysis process to the degraded polycubes stored at PFP, samples of the actual materials were tested at PNNL. The main purpose of the PNNL study was to determine whether the current baseline for stabilizing the polycubes at PFP will separate out the plutonium/uranium oxides. Tests were performed that showed successful treatment of the polycubes by the pyrolysis process.

In light of the complexity of the steps and the installation costs involved in the baseline process for stabilizing the polycubes, a parallel testing program was initiated to investigate the potential of direct oxidation in the PFP muffle furnaces. Scoping studies performed at PNNL and B\&W Hanford's Plutonium Process Support Laboratories (PPSL) provided preliminary data and analyses that supported

(a) Uppington, G. W., and L. E. Bruns. 1967. Polystyrene-PuO $\mathrm{O}_{2}$ Flowsheet and Start-up Procedure. ISO-989, General Electric, Richland, Washington.

(b) Felt, R. E. 1969. Plutonium Dioxide Recovery from Polystyrene Cubes by Distillation. ARH-1391, Atlantic Richfield Hanford Company, Richland, Washington. 
the direct oxidation process. ${ }^{\text {(a) }}$ However, two main issues, raised during a technical exchange meeting, had to be resolved to support a final decision to re-baseline the process:

- The effect of increasing polycube size (i.e., increased "surface area") on the flammable gas species generation rate was not clearly understood. It has not been determined whether the potential exists for increasing the estimated concentrations of the flammable gases in the off-gas stream to process a 400 -g degraded polycube (maximum size that is estimated to be processed) in the muffle furnace. The degradation of the polycubes may have increased the geometrical area enough that its reactivity during processing can cause flammable gas concentrations to reach values exceeding lower flammable limits.

- The carbon monoxide (one of the oxidation products) concentration in the processing off-gas stream was calculated using a mass balance concept. In the calculations, carbon in the polycube was assumed to be equally distributed between $\mathrm{CO}$ and $\mathrm{CO}_{2}$ during oxidation. Even though this exercise may have provided a conservative estimate of $\mathrm{CO}$ concentration, there were no data to verify the analytical results. The concern about $\mathrm{CO}$ was its flammability limit in the off-gas during oxidation.

These issues were addressed in the studies reported here. Two experimental programs were initiated using the Netzsch STA 409 TGA/DSC/MS (thermogravimetric/differential scanning calorimeter/mass spectrometer) system at PNNL's Radiochemical Processing Laboratory (RPL). The first test series involved oxidizing various sizes of polycube samples in air, with other controlling parameters such as temperature profile and reactant gas flow rate kept constant for all runs. The sample weight loss and the gases generated by both pyrolysis and oxidation were monitored to provide a basis for determining if increasing sample size affects flammable gas generation rates. The samples tested had irregular shapes, and determining their initial geometrical areas was not practical. One experiment was run with a powder polycube sample to provide data on the extreme effect of the increased surface area on the flammable gas generation rates.

A second series of test were performed to obtain mass spectrometer data for estimating the true carbon monoxide concentration in the off-gas stream. This test series again used different sample sizes, but instead of air, an argon/ 20 volume percent oxygen mixture was used as the reactant gas. A powder polycube sample was also tested in this series to verify the extreme effect of flammable gas generation rates.

The results of these tests showed that the highly degraded polycubes can be thermally stabilized in an air atmosphere without generating flammable gases in concentrations that exceed their lower flammable limits in the off-gas stream. The process usually started with an initial slow oxidation of the polycube sample. The slight weight loss was followed by a region within the temperature range of $550 \mathrm{~K}$ to $790 \mathrm{~K}$, where the polycube sample lost significant weight at a faster rate. The higher rate of weight loss was followed by a region where all the carbonaceous products generated by radiolysis and thermal decomposition were converted to $\mathrm{CO}$ and $\mathrm{CO}_{2}$, leaving in the crucible an end product of plutonium oxide $\left(\mathrm{PuO}_{2}\right)$ powder.

(a) Jones, S. A., G. S. Barney, and J. Abrefah. 1999. White Paper on Muffle Furnace Stabilization of Polycubes. 15F00-99-130, B\&W Hanford, Richland, Washington. 
The following conclusions may be drawn from the experimental data:

- The concentrations of the flammable gases in the off-gas stream increased with increasing polycube size, but the extrapolation of the linear increase to a $400 \mathrm{~g}$ polycube in the muffle furnace process gave concentrations below the lower flammable limits for each gas and the composite.

- The maximum percent rate of polycube weight loss was independent of size, and an average value of $0.87 \pm 0.14 \% / \mathrm{min}$ was obtained from the data.

- Tests using powder polycube samples showed no measurable effect of increasing surface area on the flammable gas generation rate.

- Oxidation of the carbonaceous residue generated by far the highest concentrations of $\mathrm{CO}$ and $\mathrm{CO}_{2}$ in the off-gas stream, but the $\mathrm{CO}$ constituted only a minor fraction of the oxidation products.

- The maximum rate of weight loss that increased with increasing polycube size occurred when the polycube thermally decomposed both by pyrolysis and oxidation reactions.

From this study, the following temperature/time profile for the direct oxidation process of polycubes in the muffle furnace is recommended:

- Heat at a rate of 4 to $5 \mathrm{~K} / \mathrm{min}$ to a temperature of about $573 \mathrm{~K}$, as the reaction is slow within this temperature range and only a low concentration of gases is generated.

- Slow down the heating rate to $3 \mathrm{~K} / \mathrm{min}$ up to a temperature of $773 \mathrm{~K}$ and hold it for about 5 hours. This will reduce the flammable gas generation rate.

- Continue the heatup rate at $3 \mathrm{~K} / \mathrm{min}$ up to $1273 \mathrm{~K}$, hold it for 3 hours and allow to cool down to ambient conditions. This will convert the carbon residue to $\mathrm{CO}$ and $\mathrm{CO}_{2}$ to generate a pure form of $\mathrm{PuO}_{2}$ powder.

The above temperature/time profile can be optimized to increase the overall efficiency of the direct oxidation process. For other TRU-bearing material for stabilization, the thermal processing steps developed for the polycubes may have to be investigated to determine the optimum method. 



\section{Contents}

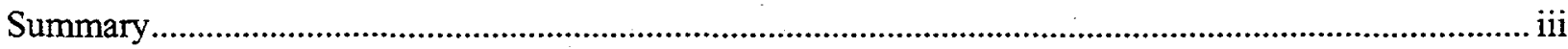

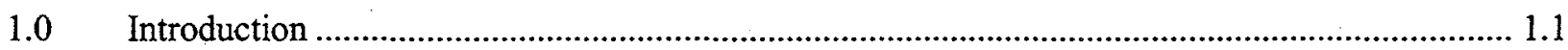

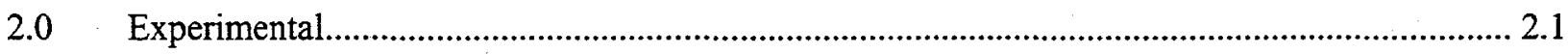

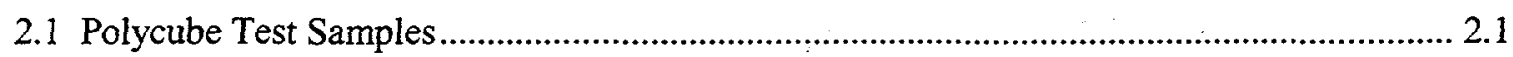

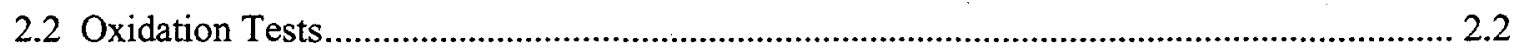

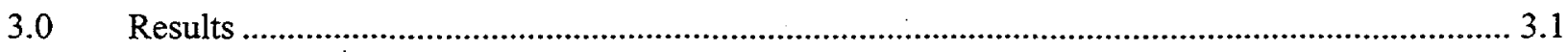

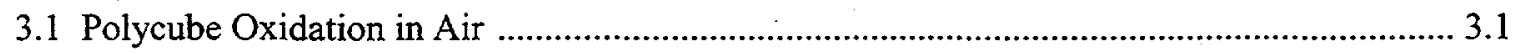

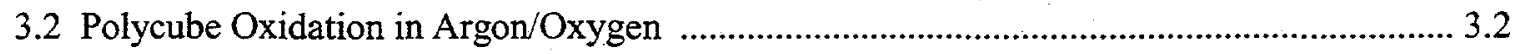

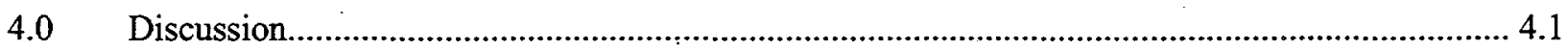

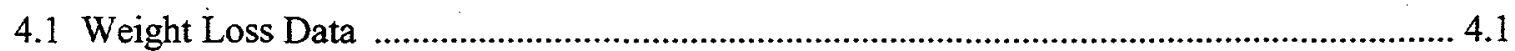

4.1.1 Pyrolysis/Oxidation Segment ......................................................................... 4.1

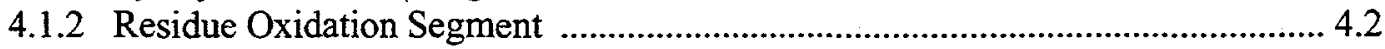

4.1.3 No Measurable Weight Change Segment ........................................................ 4.3

4.2 Maximum Flammable Species Concentrations in the Off-Gases for Stabilization of Polycubes in a Muffle Furnace .................................................................................................. 4.3

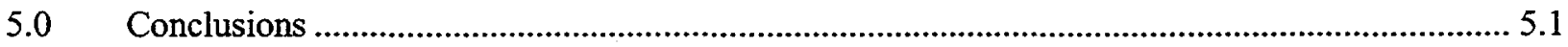

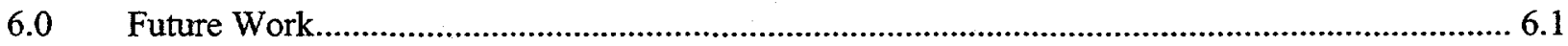

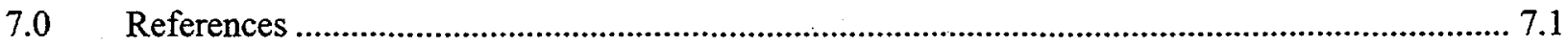

Appendix - Thermogravimetric and MS Data for Polycube Oxidation in Air

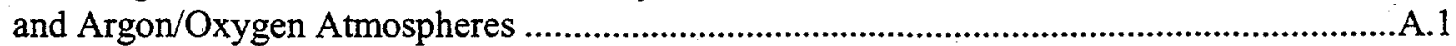




\section{Figures}

2.1 Polycube-1504 and -1481 Samples Sent to PNNL from PFP ............................................. 2.1

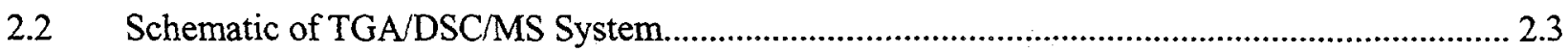

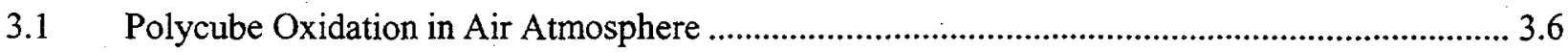

3.2 Polycube Oxidation in Argon/Oxygen Atmosphere ............................................................. 3.7

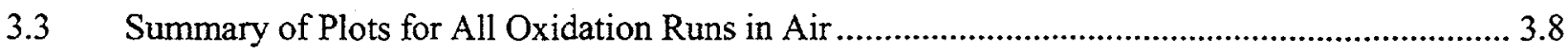

3.4 Summary of Plots for All Oxidation Runs in Argon/Oxygen ............................................... 3.9

4.1 Linear Dependence of Maximum Rate of Weight Loss on Polycube Initial Weight .................. 4.5

4.2 Maximum Percent Rate of Polycube Oxidation in Air and Argon/Oxygen Atmospheres .......... 4.5

4.3 Effect of Polycube Weight on the Maximum Generation Rate of Benzaldehyde ....................... 4.6

4.4 Major Flammable Products for Polycube Oxidation in Argon/Oxygen .................................. 4.6

4.5 Cumulative $\mathrm{CO}_{2}$ and $\mathrm{CO}$ Concentrations in the Off-Gas Stream......................................... 4.7

\section{Tables}

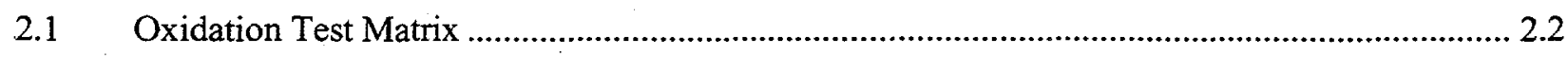

3.1 Summary Results for Polycube Oxidation, with Maximum Flammable Gas Generation Rates.. 3.4

3.2 Summary Results for Polycube Oxidation, with Cumulative Flammable Gas Yields ................ 3.5

4.1 Flammability in Air of Polycube Major Organic Products................................................. 4.3

4.2 Concentration of Flammable Species in Off-Gas Stream................................................... 4.4 


\subsection{Introduction}

The polycubes stored at the Hanford Plutonium Finishing Plant (PFP) have been identified in a Vulnerability Assessment as material that requires a stabilization process in support of the Defense Nuclear Facility Safety Board Recommendation 94-1. The baseline plan involves a pyrolysis process to separate out the plutonium and uranium oxides before the remaining material is packaged for interim storage, in accordance with the Record of Decision (ROD), issued June 25, 1996, for the Plutonium Finishing Plant Stabilization Final Environmental Impact Statement, DOE/EIS-0244-F.

The polycubes were manufactured at Hanford in the 1960s for use in criticality studies (Lewis and Meng 1996) to determine the hydrogen-to-fissile atom ratios for neutron moderation. A mixture of plutonium and/or uranium oxides and a polystyrene (vinyl benzene) matrix, cast into the shape of cubes, the polycubes simulated solutions containing high concentrations of fissile materials. The polycubes varied in size, typically $1 / 2 \times 2 \times 2$ in. up to $2 \times 2 \times 2$ in., and were sealed with a coating of aluminum paint and/or tape (PVC or Shurtape). The estimated 1600 polycubes (calculated 179,165 grams net weight) stored at PFP were packed in vented food cans with five to eight cubes per can to accommodate gas generation by radiolysis. Some polycube containers are suspected to contain loose material as well, left over from the forming process.

With a fairly high ${ }^{240} \mathrm{Pu}$ content, polycubes present a challenge for handling, as a result of the 7 to $8 \mathrm{R}$ contact dose rate. Significant hazards linked to unstabilized polycubes are associated with the polystyrene matrix, which generates hydrogen gas due to radiolysis. In addition, some cans of polycubes may contain fines. Because of insufficient data, hazards associated with the fines have not been assessed.

The composition of the polycubes requires they undergo a stabilization process that decomposes and separates the polystyrene from the plutonium/uranium oxides before thermal processing. The baseline process to stabilize the polycubes, developed by Los Alamos National Laboratory (LANL), was to first treat them in a pyrolysis furnace to decompose and vaporize the polystyrene, then transport the end product to one of the existing muffle furnaces at PFP, where the residual carbon would be oxidized and the residual plutonium/uranium oxides stabilized for interim storage.

As part of studies verifying the feasibility of using the pyrolysis process to stabilize the PFP polycubes, scoping studies were performed at Pacific Northwest National Laboratory (PNNL) and B\&W Hanford's Plutonium Process Support Laboratories (PPSL) to evaluate the potential of directly oxidizing the polycubes in a muffle furnace. The results of the scoping tests (Jones et al. 1999) indicated that the direct oxidation of polycubes will generate flammable gas species concentrations well below their lower flammable limits (LFL). However, two main issues need to be resolved before any further decisions on changing the baseline process to direct oxidation can be made:

- effect of polycube size (i.e., "initial surface area") on the flammable gas generation rate during thermal stabilization in air

- carbon monoxide (a flammable gas product) concentration in the off-gas stream.

The tests discussed in this report (two series of six runs) were conducted by PNNL to address those issues. Samples of actual polycubes from PFP were used in the experiments. The sample materials and 
experimental procedures are described in Section 2.0. The testing was conducted in PNNL's Radiochemical Processing Laboratory (RPL) using a Netzsch TGA/DSC/MS system. The first series of tests (Runs 35 through 40 ) were performed in dry air to determine the effect of increasing polycube sample sizes. The second series of tests (Runs 41 through 46) were performed in an argon/oxygen atmosphere to provide data on $\mathrm{CO}$ concentration, although the sample sizes for these runs were also increased to provide additional data for analyzing flammable gas generation. The results for the two testing campaigns are presented in Section 3.0 and discussed in Section 4.0. Conclusions and recommendations are given in Section 5.0, with future work outlined in Section 6.0. The appendix provides the complete set of data from both test series. 


\subsection{Experimental}

This section describes the polycube samples received from PFP and the experimental procedures used for the testing campaign. The oxidation tests were conducted using the Netzsch STA 409 TGADDSC/MS skimmer graphite furnace system installed in a glovebox at the RPL.

\subsection{Polycube Test Samples}

Two polycube samples (Figure 2.1), Polycube-1481 (traceable to Polycube 83-73-07-1481-B-3) with a Pu weight of $32 \mathrm{~g}$, and Polycube-1504 (traceable to Polycube 83-73-07-1504-A-1) with a Pu weight of about $33 \mathrm{~g}$, were shipped from PFP to PNNL for thermal stabilization studies. These polycubes had prior storage dimensions of $1 \frac{1}{2} \times 2 \times 2$ in. Samples for the experimental studies in this report were taken only from Polycube-1504. The weight of the test samples ranged from $0.1 \mathrm{~g}$ to $2.0 \mathrm{~g}$, and all the samples were generated by cleaving the polycube. Ten of the samples were fragments with irregular shapes, but certain selected dimensions were sketched and measured to provide a rough sample size. Two samples were in a powder form, which came from the friable material collected when the samples were cleaved.

(a)
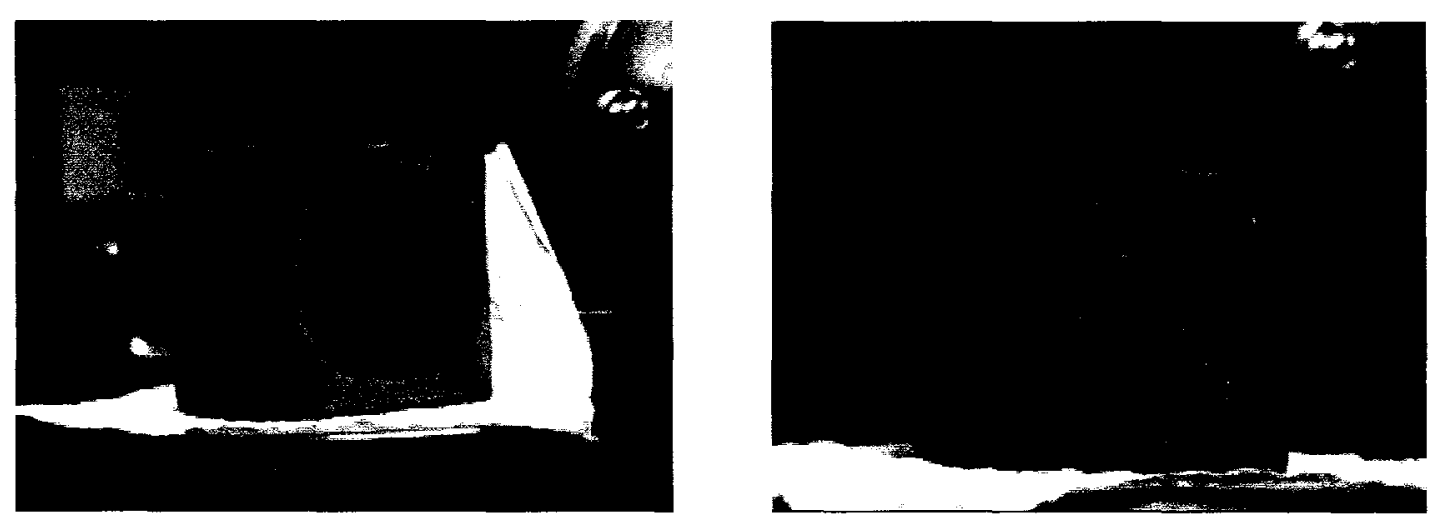

(c)

(b)
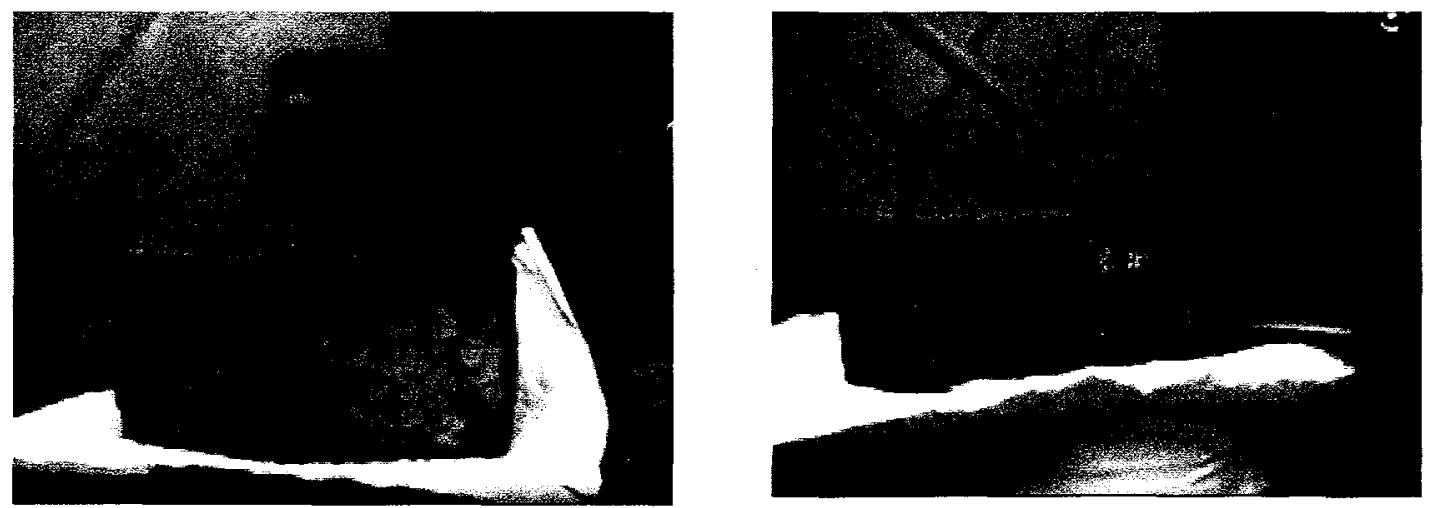

(d)

Figure 2.1. Polycube-1504 (a, b) and -1481 (c, d) Samples Sent to PNNL from PFP 


\subsection{Oxidation Tests}

A schematic representation of the testing system is shown in Figure 2.2. The system is made up of four chambers: an MS chamber, an intermediate chamber, a sample reaction chamber, and a balance chamber. The MS chamber houses the quadrupole mass spectrometer, and is pumped by a turbomolecular pump to a baseline pressure of about $10^{-7}$ Torr. The intermediate chamber separates the MS chamber from the atmospheric reaction chamber, and is pumped by a mechanical pump to a base pressure of about $10^{-3}$ Torr without a load. The sample chamber houses a thermogravimetric sample carrier, which contains the sample thermocouple (S-type) and connects to the analytical balance. Gas inlet and outlet lines are connected to this chamber for supplying the reactant gas.

A quartz crucible, with dimensions of $15 \mathrm{~mm}$ outside diameter, $12 \mathrm{~mm}$ inside diameter, a depth of $3.2 \mathrm{~mm}$, and a height of $4 \mathrm{~mm}$, is mounted at the end of the sample carrier. The sample chamber is resistively heated by graphite elements that are protected by a vacuum of about $10^{-3}$ Torr. The balance chamber houses the electrobalance and a gas inlet to the chamber that allows it to be purged by either ultra high purity helium or the reactant gas. The temperature of the balance chamber is maintained at ambient conditions by a series of heat shields in the sample chamber and water cooling at the joint that separates this chamber from the heated sample chamber.

A weighed polycube sample was loaded into the quartz crucible, and the system was sealed from the glovebox atmosphere. The sample chamber was then purged continuously by the reactant gas at a known flow rate measured by a mass flow controller. For these tests, the flow rate was about $150 \mathrm{cc} / \mathrm{min}$ when either the dry air or the argon/oxygen mixture was used as the testing atmosphere. The system was programmed to heat the polycube sample at a rate of about $4 \mathrm{~K} / \mathrm{min}$ to the maximum required temperature of about $1273 \mathrm{~K}$. The sample was held at about $1273 \mathrm{~K}$ for a period of about 4 hours, and then cooled at a rate of $20 \mathrm{~K} / \mathrm{min}$ to ambient conditions. The sample weight change and temperature were continuously monitored and recorded by a data acquisition system. The major organic species, in addition to the oxidation products such as water, mass/charge ratio $(\mathrm{m} / \mathrm{z})$ of 28 (i.e., carbon monoxide and/or nitrogen), and $\mathrm{CO}_{2}$, were monitored by the MS. The sample was weighed again after the run. Table 2.1 gives the test matrix.

Table 2.1. Oxidation Test Matrix

\begin{tabular}{|c|c|c|c|c|}
\hline $\begin{array}{c}\text { Polycube } \\
\text { Run \# }\end{array}$ & $\begin{array}{c}\text { Initial Sample } \\
\text { Weight (mg) }\end{array}$ & $\begin{array}{c}\text { Temperature } \\
\text { History }\end{array}$ & $\begin{array}{l}\text { Atmospheric } \\
\text { Condition }\end{array}$ & Description \\
\hline 35 & 650 & \multirow{6}{*}{$\begin{array}{l}\text { Ambient to } \\
1273 \mathrm{~K} \text { at a } \\
\text { Linear Ramp } \\
\text { Rate of } 4 \mathrm{~K} / \mathrm{min}\end{array}$} & \multirow{6}{*}{$\begin{array}{l}\text { Air Flowing at } \\
150 \mathrm{cc} / \mathrm{min}\end{array}$} & \multirow{6}{*}{$\begin{array}{l}\text { Size/Surface } \\
\text { Area Effect }\end{array}$} \\
\hline 36 & 240 & & & \\
\hline 37 & 540 & & & \\
\hline 38 & $400^{(a)}$ & & & \\
\hline 39 & 620 & & & \\
\hline 40 & 120 & & & \\
\hline 41 & 120 & \multirow{6}{*}{$\begin{array}{l}\text { Ambient to } \\
1273 \mathrm{~K} \text { at a } \\
\text { Linear Ramp } \\
\text { Rate of } 4 \mathrm{~K} / \mathrm{min}\end{array}$} & \multirow{6}{*}{$\begin{array}{l}\text { Argon } / 20 \% \\
\text { Oxygen Flowing } \\
\text { at } 150 \mathrm{cc} / \mathrm{min}\end{array}$} & \multirow{6}{*}{$\begin{array}{l}\text { Carbon } \\
\text { Monoxide } \\
\text { Generation Rate }\end{array}$} \\
\hline 42 & 400 & & & \\
\hline 43 & 620 & & & \\
\hline 44 & 280 & & & \\
\hline 45 & $330^{(a)}$ & & & \\
\hline 46 & 1560 & & & \\
\hline
\end{tabular}




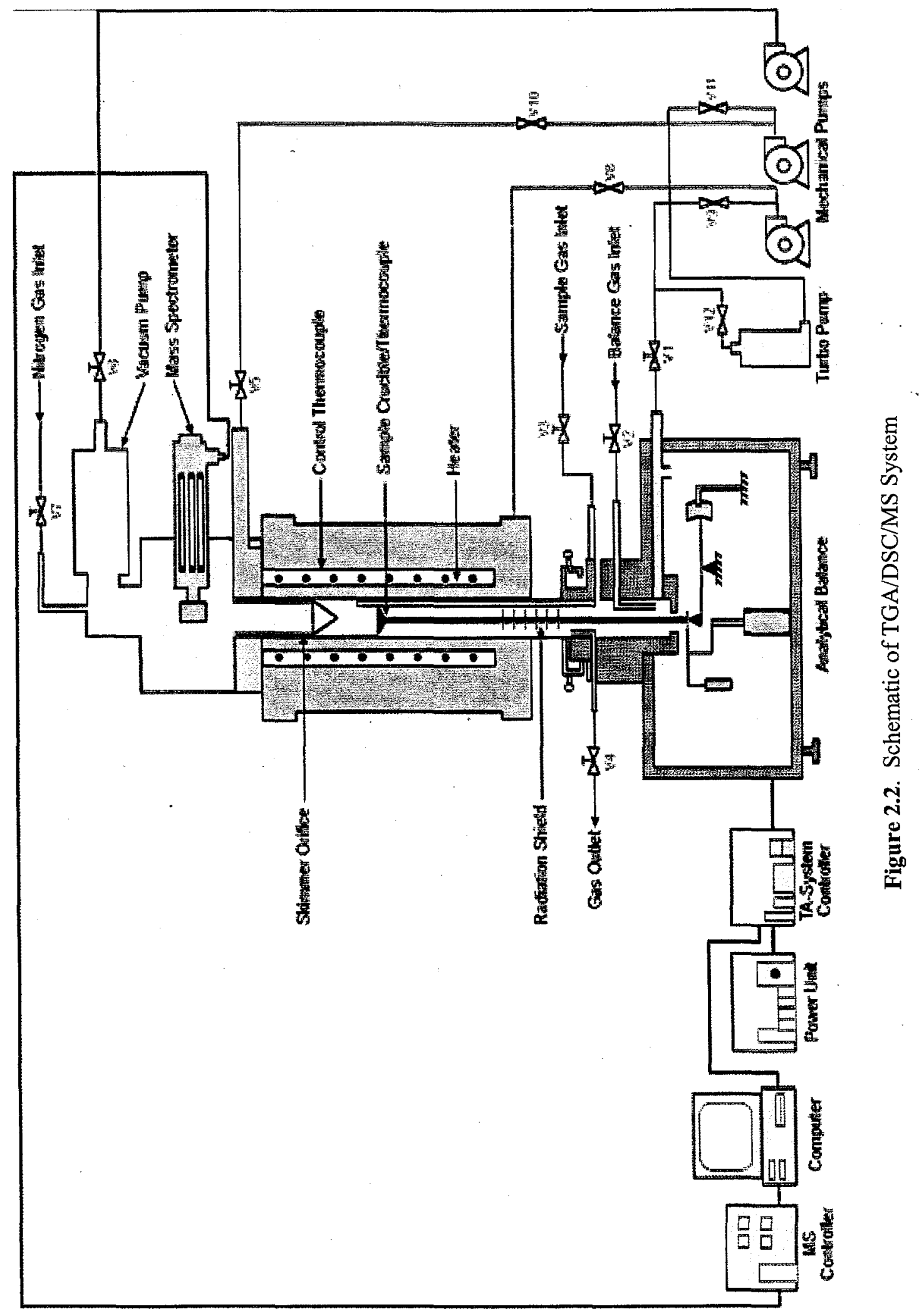




\subsection{Results}

The results of the polycube oxidation tests are presented here. Tables 3.1 and 3.2 give the summary results for the 12 runs, including maximum flammable gas species generation rates (Table 3.1) and cumulative yields (Table 3.2). Figures 3.1 and 3.2 display typical data for the two types of tests (Runs 37 and 42), and Figures 3.3 and 3.4 contain summary plots of all the runs. A complete set of plots is included in the appendix.

\subsection{Polycube Oxidation in Air}

The six experiments performed in air used polycube sample weights ranging from $120 \mathrm{mg}$ (Run 40) to $650 \mathrm{mg}$ (Run 35) to determine if increasing polycube size and/or initial geometric surface area affected the flammable gas species generation rate. Typical thermogravimetric and mass spectrometer data are shown in Figure 3.1 for Run 37. The data for all six runs (35 through 40) are plotted in Figures A.1 through A.14.

The weight loss trace and the temperature profile and MS signal intensity for an $\mathrm{m} / \mathrm{z}$ of 18 (i.e., water) for Run 37 are shown in Figure 3.1a. The polycube sample showed a slow decrease in weight after a temperature of about $373 \mathrm{~K}$ that persisted until the sample temperature reached about $550 \mathrm{~K}$. The slow weight loss was then followed by a significant weight loss in the temperature range of $550 \mathrm{~K}$ to $760 \mathrm{~K}$. The sample weight loss then slowed down to a region where the rate remained almost constant until all the carbonaceous compounds were oxidized. The sample displayed no significant weight change for the remaining period, even though the temperature was held at $1273 \mathrm{~K}$.

The weight loss data were differentiated to provide rate information for each run. All the samples went through a maximum rate of weight loss (Tables 3.1 and 3.2). In Figure 3.1b, the rate of weight loss for Run 37 is plotted together with the temperature profile and MS signal intensity for an $\mathrm{m} / \mathrm{z}$ of 28 . For Run 37 (Figure 3.1b), the maximum rate of weight loss was $3.35 \mathrm{mg} / \mathrm{min}$ and occurred at a temperature of about $660 \mathrm{~K}$. The MS signal for an $\mathrm{m} / \mathrm{z}$ of 28 came from two species in the off-gas stream, the major component being nitrogen from the reactant dry air and a small fraction due to the $\mathrm{CO}$ product from oxidation.

As shown in Figure 3.1c, the oxidation product with the highest concentration in the off-gas stream is $\mathrm{CO}_{2}$. The $\mathrm{CO}_{2}$ generation increased with increasing temperature to a maximum value at the highest temperature. It then remained almost at the same level at the constant temperature of $1273 \mathrm{~K}$ until all the organic and its residue were completely oxidized. After which, the $\mathrm{CO}_{2}$ concentration decreased to a background level.

Partial MS data for the flammable gas products are shown in Figures 3.1c through 3.1e. Detectable concentrations of these flammable species for the polycube occurred within the temperature range of about $510 \mathrm{~K}$ to $750 \mathrm{~K}$. All the flammable gas species showed a peak generation point. The peak (maximum) generation rates (arbitrary units) for the major flammable gases are also listed in Table 3.1. The temperatures at which the peak generation rates occurred for the major flammable gas species are listed below:

benzaldehyde

benzene
$635 \mathrm{~K}$

$633 \mathrm{~K}$ 
$\begin{array}{ll}\text { toluene } & 635 \mathrm{~K} \\ \text { styrene } & 629 \mathrm{~K} \\ \text { ethyl benzene } & 641 \mathrm{~K} \\ \text { alpha-methyl styrene } & 645 \mathrm{~K}\end{array}$

The summary plots for the air oxidation runs are illustrated in Figure 3.3. Figure 3.3a shows a comparison of weight loss by the polycube samples with increasing weight. The time to complete the oxidation process increased with increasing initial sample weight of the polycube. All the runs showed three distinct segments of weight change, excluding the initial slow weight loss region. These segments consisted of a region of rapid weight loss, region of a constant rate of weight change, and a region where the sample showed no measurable weight change.

The percent weight loss plots (Figure 3.3b) show almost the same percent weight loss by all the samples, except for the region where the samples lost weight at constant rate. There, the weight loss rate decreased with increasing sample weight. The total percent weight loss by the samples varied slightly from sample to sample, but on the average, the polycube samples lost about 72 weight percent during the oxidation process.

The time derivatives of the weight losses and the percent weight losses by polycube samples are shown in Figures $3.3 \mathrm{c}$ and $3.3 \mathrm{~d}$. Figure $3.3 \mathrm{c}$ shows the maximum rate of weight that increased with increasing the initial weight of the sample. The maximum rates for all runs occurred at about the same temperature. Figure 3.3d, on the other hand, shows the maximum percent rate of weight loss to be independent of sample size.

\subsection{Polycube Oxidation in Argon/Oxygen}

The oxidation runs performed in an argon/oxygen atmosphere used polycube sample sizes that ranged from 120 to $1560 \mathrm{mg}$. The results of a typical run are presented in Figure 3.2 (Run 42). The data for all the runs are shown in Figures A.15 (Run 41) through A.32 (Run 46). These experiments were run to simplify detection of $\mathrm{CO}$ in the off-gas.

The weight loss data for polycube thermal treatment in the argon/oxygen atmosphere were similar to the air oxidation data. The regions of varying rate of weight loss are illustrated for Run 42 in Figure 3.2b. The sample lost small but measurable weight up to a temperature of about $580 \mathrm{~K}$ that was followed by a region of significant weight loss within the temperature range of $580 \mathrm{~K}$ to $760 \mathrm{~K}$. This region was then followed by a period where the sample weight loss rate remained almost constant until the thermal treatment process of the polycube was complete. The maximum rate of weight loss in this run (Figure 3.2b) was about $2.8 \mathrm{mg} / \mathrm{min}$, and occurred at a temperature of about $667 \mathrm{~K}$. The maximum rates for all the runs, including the normalized maxima, are listed in Tables 3.1 and 3.2.

The MS signal intensities for the oxidation products, water, $\mathrm{CO}$, and $\mathrm{CO}_{2}$, for Run 42 are shown, together with the weight loss data, in Figure 3.2a, b, c. The signal for water (Figure 3.2a) has a background level comparable to the actual data from the polycube, which will make it difficult to analyze the water data for product concentration. However, the $\mathrm{CO}$ signal intensity (Figure $3.2 \mathrm{~b}$ ) is at a high enough level above background that it can be analyzed to determine $\mathrm{CO}$ concentration in the off-gas stream. 
Partial results for the flammable gaseous product signal intensities are plotted in Figure $3.2 \mathrm{~d}, \mathrm{e}, \mathrm{f}$, and the complete set of data is provided in Figures A.15 through A.32. The peak generation rate of the flammable organic species occurred at about the same temperature for the peak weight loss rate. The temperatures at which the peak generation rates for the major organic species occurred are listed below:

$\begin{array}{ll}\text { benzaldehyde } & 658 \mathrm{~K} \\ \text { styrene } & 629 \mathrm{~K} \\ \text { benzene } & 639 \mathrm{~K} \\ \text { ethyl benzene } & 658 \mathrm{~K} \\ \text { toluene } & 635 \mathrm{~K} \\ \text { alpha-methyl styrene } & 651 \mathrm{~K}\end{array}$

The peak generation rates for these major flammable products are included in Table 3.1. The cumulative yields for these gases were estimated by integration of the peaks, and the results are given in Table 3.2.

Summary plots for the argon/oxygen oxidation runs are presented in Figure 3.4. Figure 3.4a shows a comparison of the weight loss by the polycube samples with increasing weight. As in the air oxidation runs, the time required to complete the oxidation process increased with increasing initial sample weight. These runs also showed three distinct segments of weight change, similar to the results for the air oxidation tests.

The percent weight losses for these runs (Figure 3.4b) again show the same percent weight loss by all the samples, except where the samples lost weight at a constant rate. In this region the weight loss rate likewise decreased with increasing sample weight. On the average, the polycube samples lost about 73 weight percent during the oxidation process.

The time derivatives of the weight losses and the percent weight losses by polycube samples in the argon/oxygen runs are given in Figure 3.4c and d. Figure 3.4c shows the maximum rate of weight that increased with increasing initial sample weight. Like the air oxidation tests, the maximum rates for all runs occurred at about the same temperature, and the maximum percent rate of weight loss was independent of sample size (Figure 3.4d). 
Table 3.1. Summary Results for Polycube Oxidation, with Maximum Flammable Gas Generation Rates

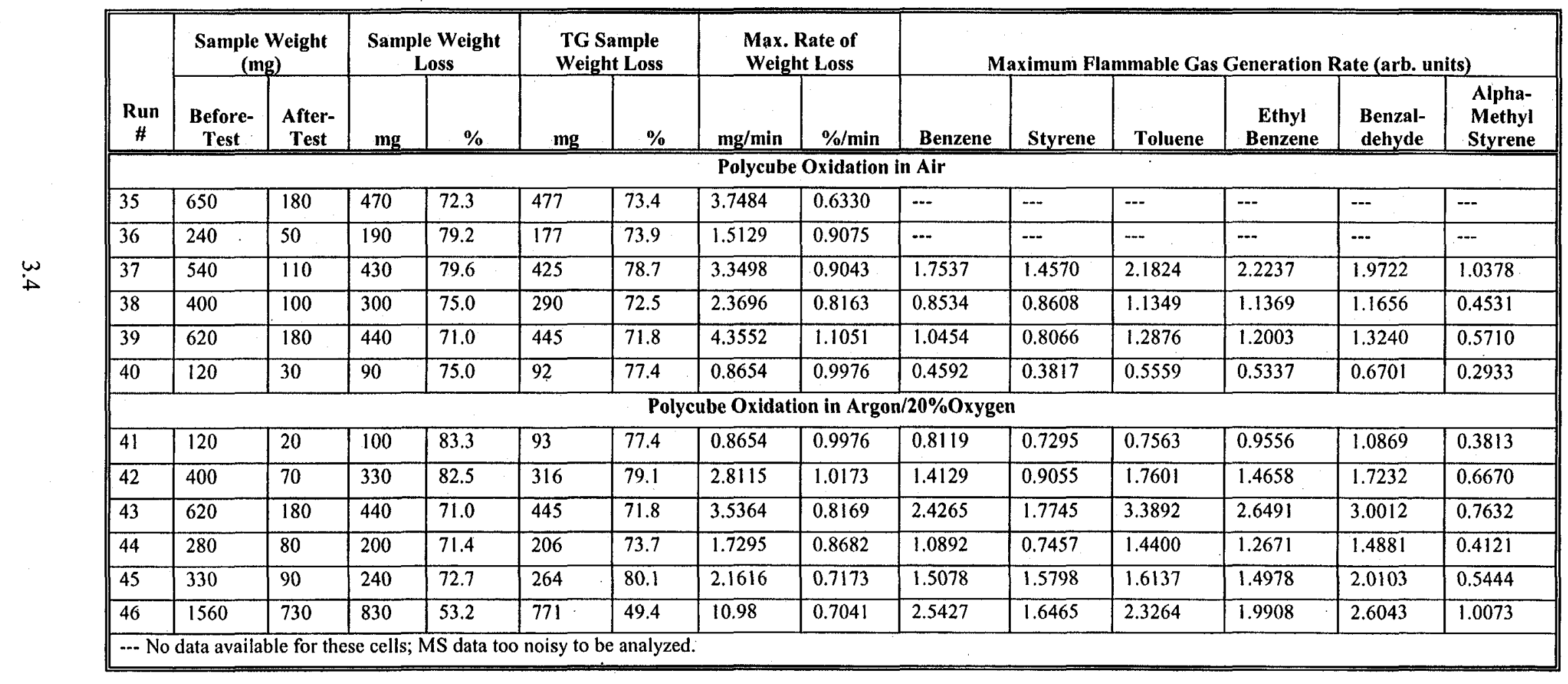


Table 3.2. Summary Results for Polycube Oxidation, with Cumulative Flammable Gas Yields

\begin{tabular}{|c|c|c|c|c|c|c|c|c|c|c|c|c|c|c|c|c|}
\hline \multirow[b]{2}{*}{$\begin{array}{c}\text { Run } \\
\#\end{array}$} & \multicolumn{2}{|c|}{$\begin{array}{c}\text { Sample Weight } \\
\text { (mg) }\end{array}$} & \multicolumn{2}{|c|}{$\begin{array}{c}\text { Sample } \\
\text { Weight Loss }\end{array}$} & \multicolumn{2}{|c|}{$\begin{array}{c}\text { TG Sample } \\
\text { Weight Loss }\end{array}$} & \multicolumn{2}{|c|}{$\begin{array}{l}\text { Max. Rate of } \\
\text { Weight Loss }\end{array}$} & \multicolumn{8}{|c|}{ Cumulative Flammable Gas Yield (arb. units) } \\
\hline & $\begin{array}{c}\begin{array}{c}\text { Before- } \\
\text { Test }\end{array} \\
\end{array}$ & $\begin{array}{c}\text { After- } \\
\text { Test }\end{array}$ & $\underline{\mathbf{m g}}$ & $\%$ & $\underline{\mathrm{mg}}$ & $\%$ & $\mathbf{m g} / \mathbf{m i n}$ & $\% / \min$ & Benzene & Styrene & Toluene & $\begin{array}{c}\text { Ethyl } \\
\text { Benzene } \\
\end{array}$ & $\begin{array}{l}\text { Benzal- } \\
\text { dehyde }\end{array}$ & \begin{tabular}{|c|} 
Alpa- \\
Methyl \\
Śtyrene \\
\end{tabular} & $\mathrm{CO}$ & $\mathrm{CO}_{2}$ \\
\hline \multicolumn{17}{|c|}{ Polycube Oxidation in Air } \\
\hline 35 & 650 & 180 & 470 & 72.3 & 477 & 73.4 & 3.7484 & 0.6330 & --- & --- & $\overline{---}$ & -- & --- & --- & $-\cdots$ & -- \\
\hline 36 & 240 & 50 & 190 & 79.2 & 177 & 73.9 & 1.5129 & 0.9075 & -- & -- & $\cdots$ & --- & -- & -- & -- & -- \\
\hline 37 & 540 & 110 & 430 & 79.6 & 425 & 78.7 & 3.3498 & 0.9043 & 27.06 & 11.62 & 33.63 & 25.00 & 25.53 & 4.83 & --- & 7914 \\
\hline 38 & 400 & 100 & 300 & 75.0 & 290 & 72.5 & 2.3696 & 0.8163 & 13.70 & 12.20 & 10.98 & 11.40 & 12.40 & 4.01 & -- & 4201 \\
\hline 39 & 620 & 180 & 440 & 71.0 & 445 & 71.8 & 4.3552 & 1.1051 & 17.21 & 5.14 & 16.94 & 13.91 & 13.17 & 4.05 & -- & 9154 \\
\hline 40 & 120 & 30 & 90 & 75.0 & 92 & 77.4 & 0.8654 & 0.9976 & 3.58 & 1.93 & 6.28 & 3.75 & 5.01 & 2.54 & -.-- & 1338 \\
\hline \multicolumn{17}{|c|}{ Polycube Oxidation in Argon $/ 20 \%$ Oxygen } \\
\hline 41 & 120 & 20 & 100 & 83.3 & 93 & 77.4 & 0.8654 & 0.9976 & 6.14 & 5.76 & 6.62 & 6.80 & 8.72 & 0.905 & 269.4 & 1501 \\
\hline 42 & 400 & 70 & 330 & 82.5 & 316 & 79.1 & 2.8115 & 1.0173 & 32.83 & 9.22 & 30.29 & 17.98 & 24.28 & 5.10 & 1848 & 14005 \\
\hline 43 & 620 & 180 & 440 & 71.0 & 445 & 71.8 & 3.5364 & 0.8169 & 47.55 & 17.86 & 58.07 & 35.65 & 41.75 & 8.41 & 6304 & 22707 \\
\hline 44 & 280 & 80 & 200 & 71.4 & 206 & 73.7 & 1.7295 & 0.8682 & 16.10 & 5.82 & 18.62 & 13.71 & 15.65 & 3.91 & 807 & 7894 \\
\hline 45 & 330 & 90 & 240 & 72.7 & 264 & 80.1 & 2.1616 & 0.7173 & 12.34 & 16.32 & 16.43 & 9.26 & 14.73 & 3.00 & 587 & 9213 \\
\hline 46 & 1560 & 730 & 830 & 53.2 & 771 & 49.4 & 10.98 & 0.7041 & 51.14 & 19.85 & 39.87 & 31.47 & 51.34 & 7.86 & 4182 & 2830 \\
\hline
\end{tabular}



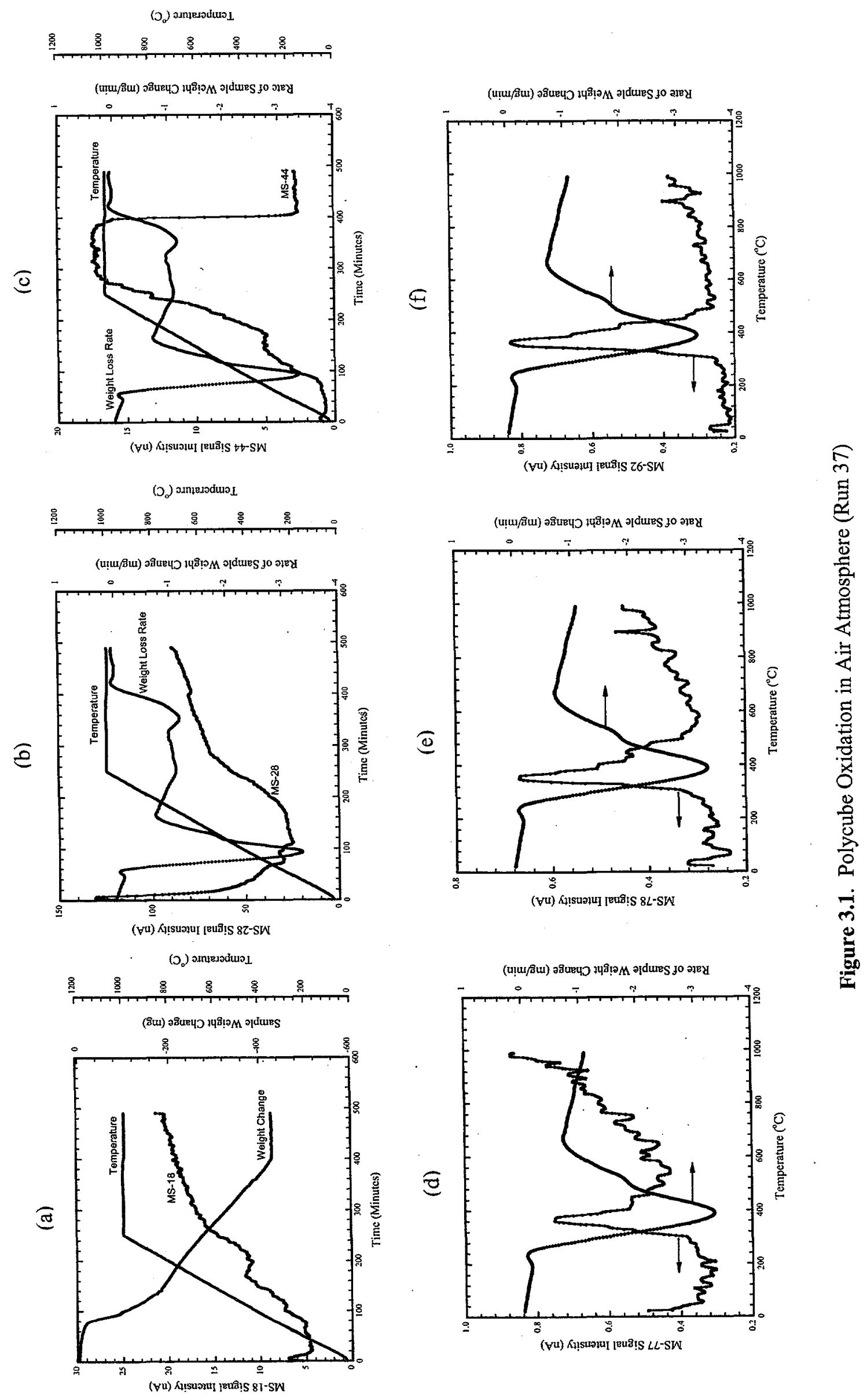
(a)

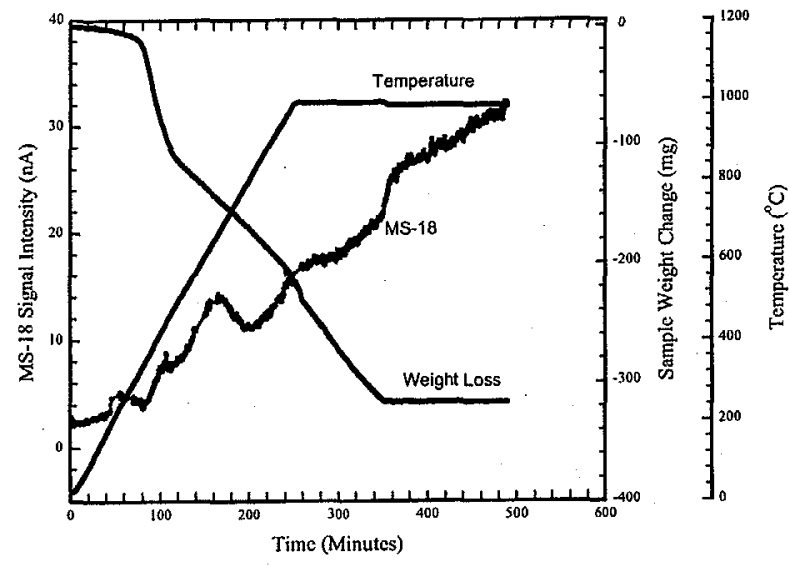

(d)

$\underset{\omega}{\omega}$

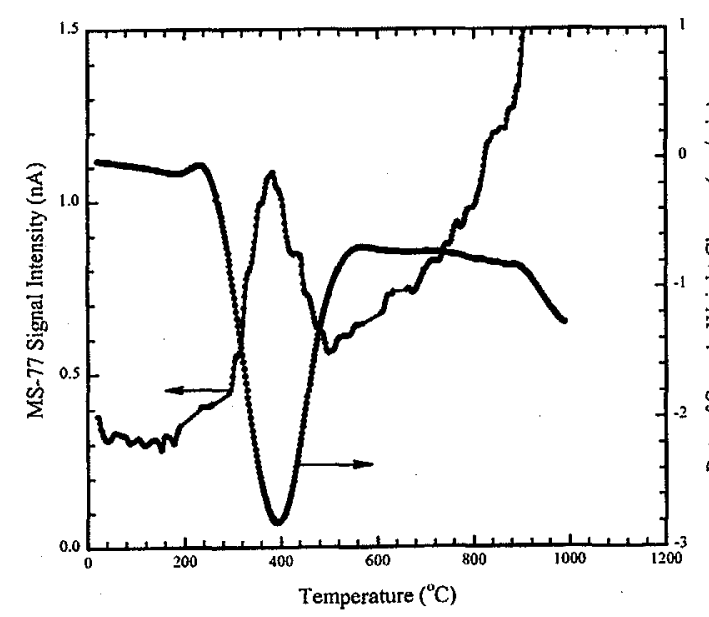

(b)

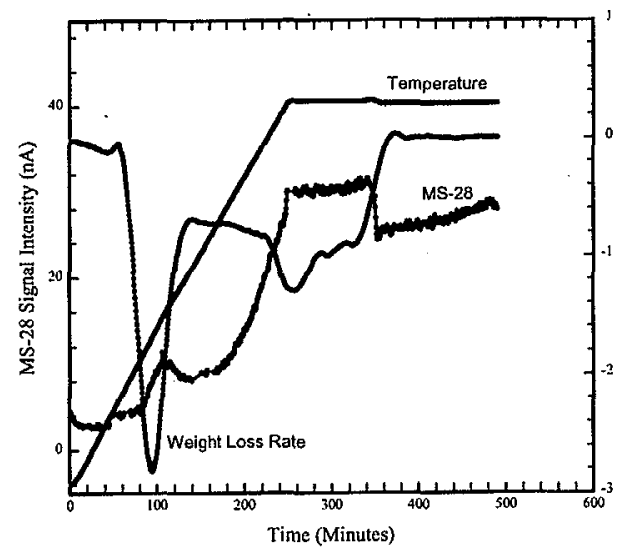

(e)

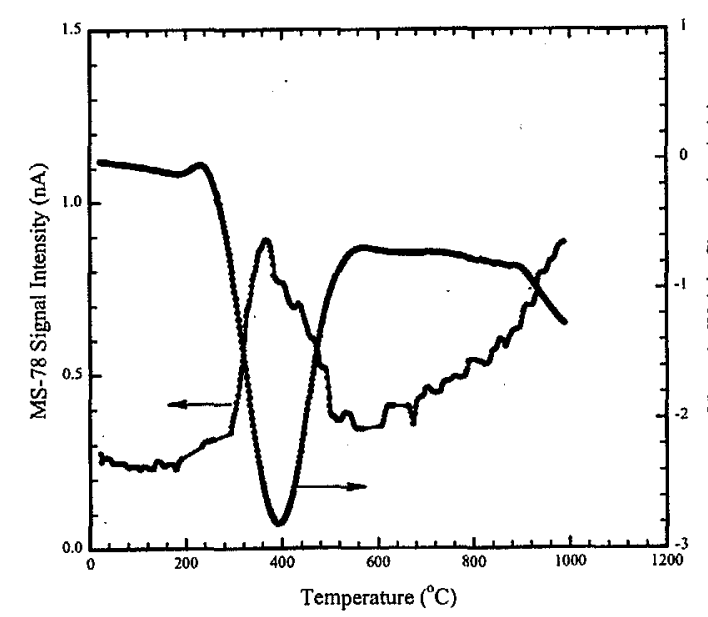

(c)

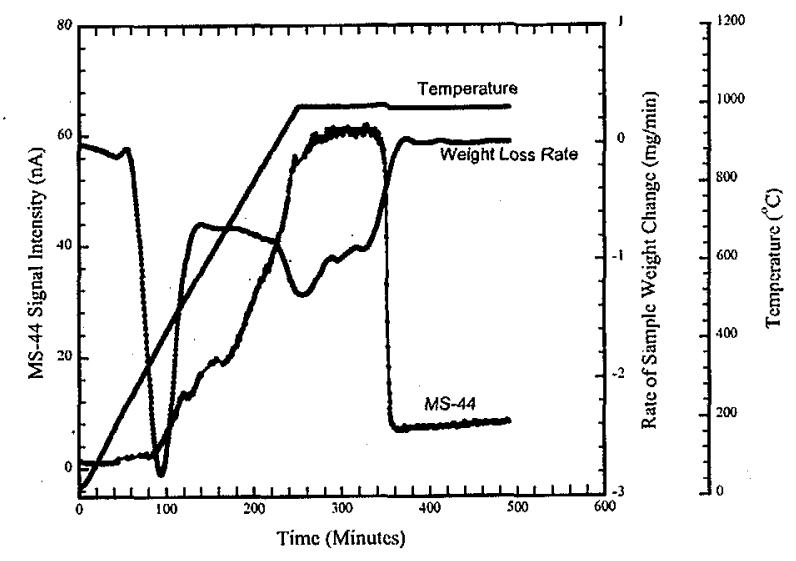

(f)

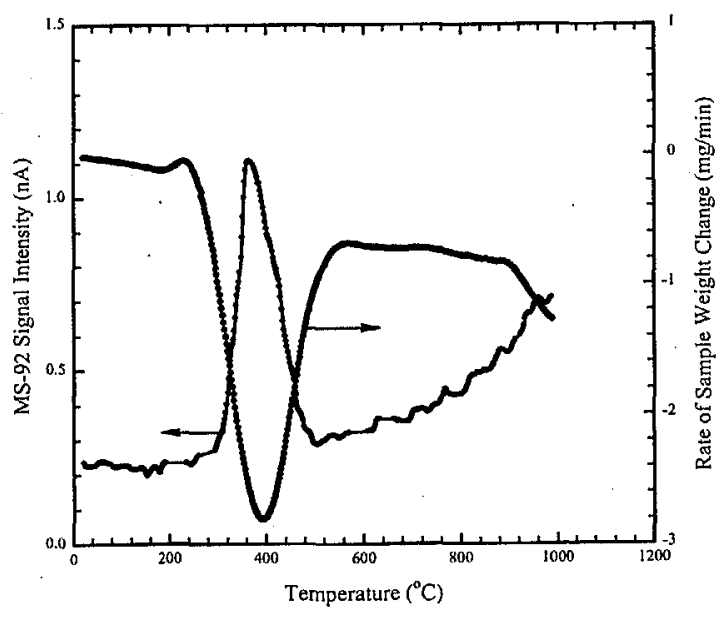

Figure 3.2. Polycube Oxidation in Argon/Oxygen Atmosphere (Run 42) 


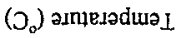

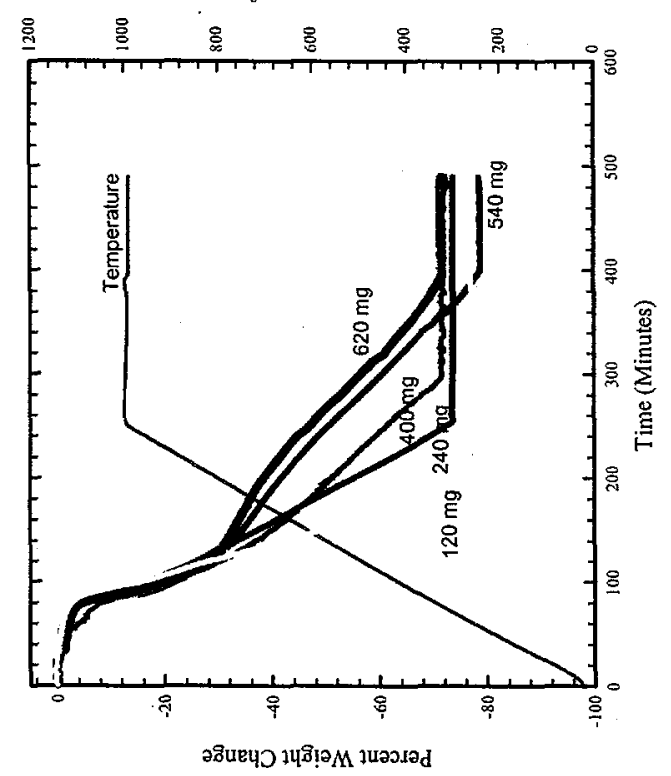

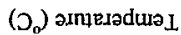

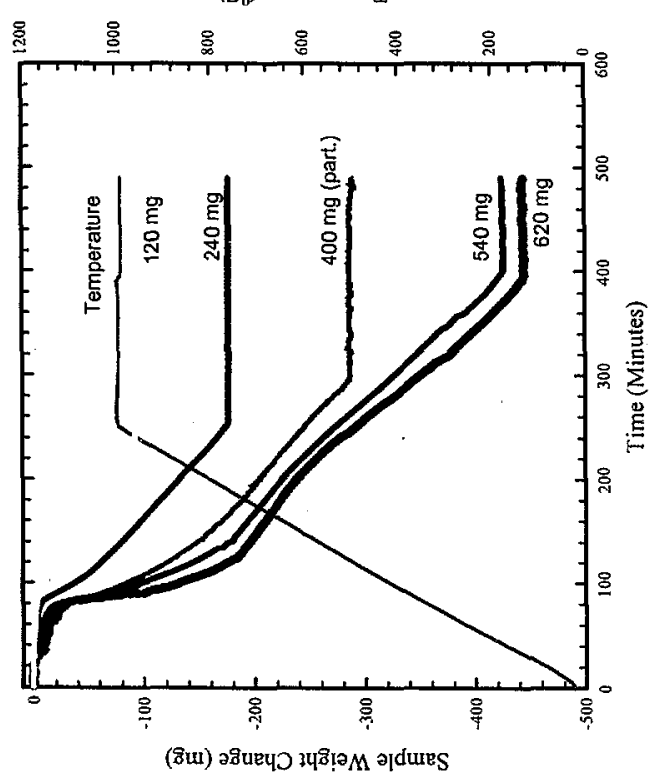

( $\left.{ }_{0}\right)$ adrutadua I

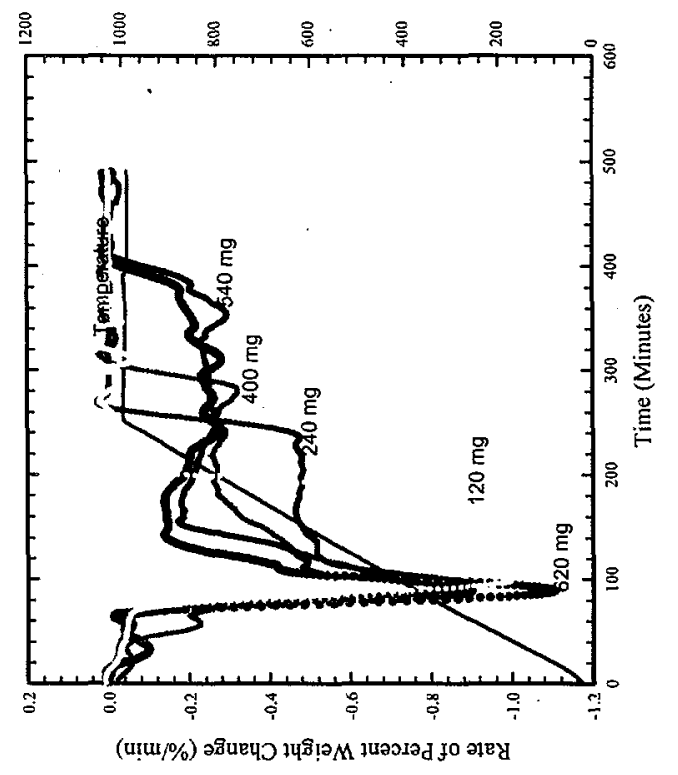

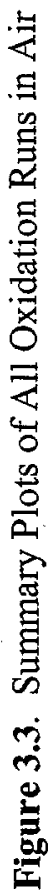

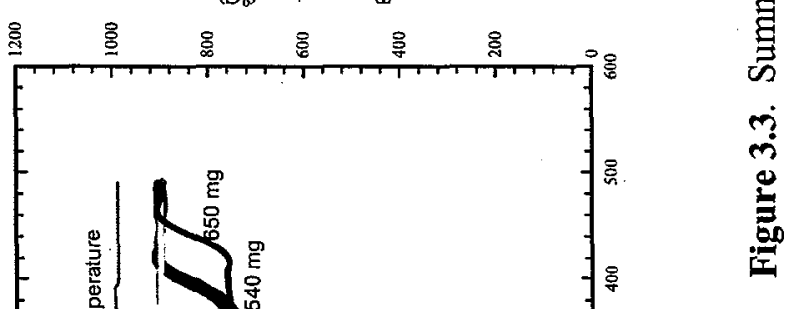




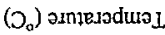

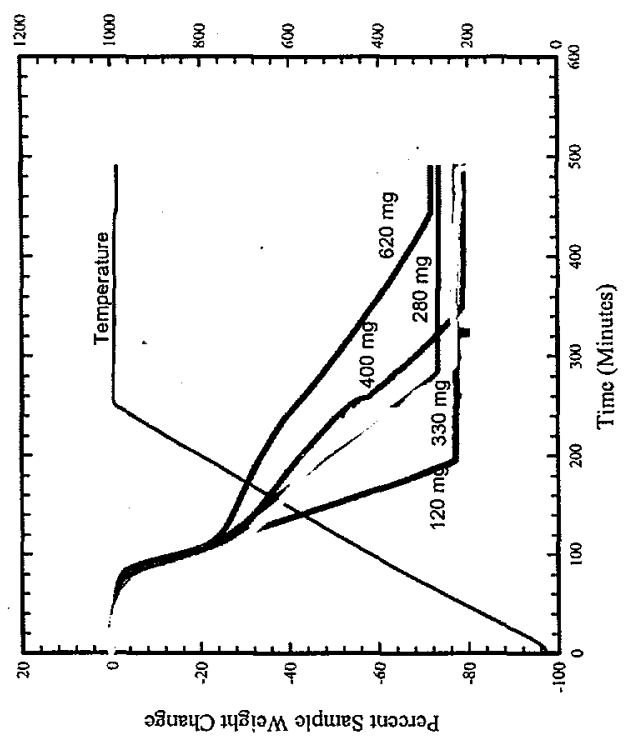

(D) armeroduว L

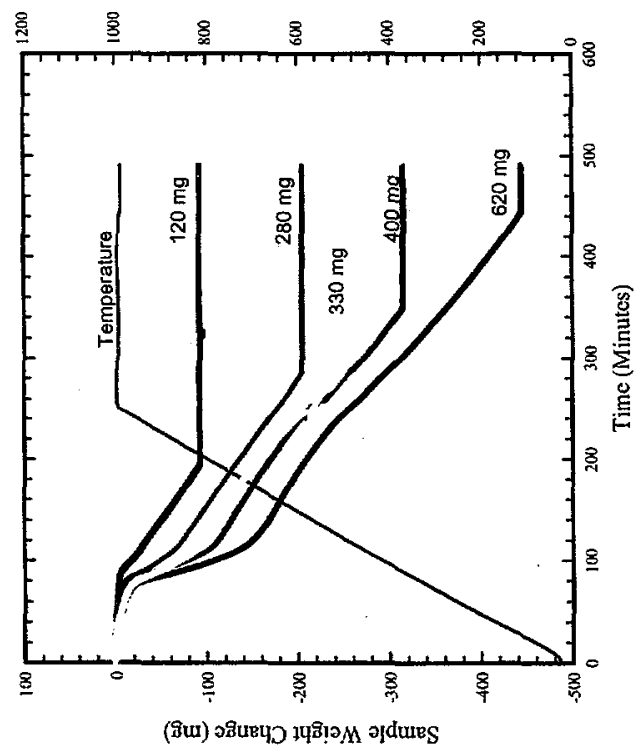

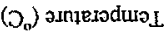

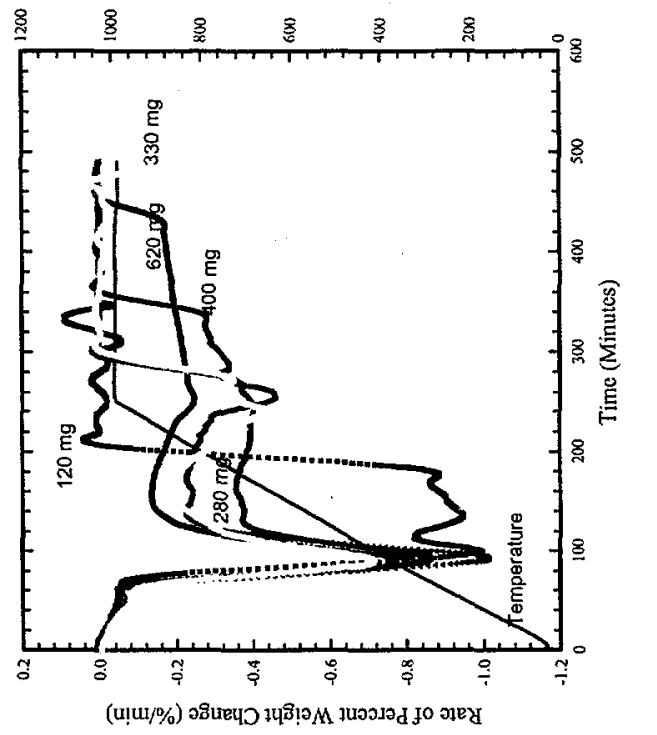

迥

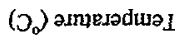

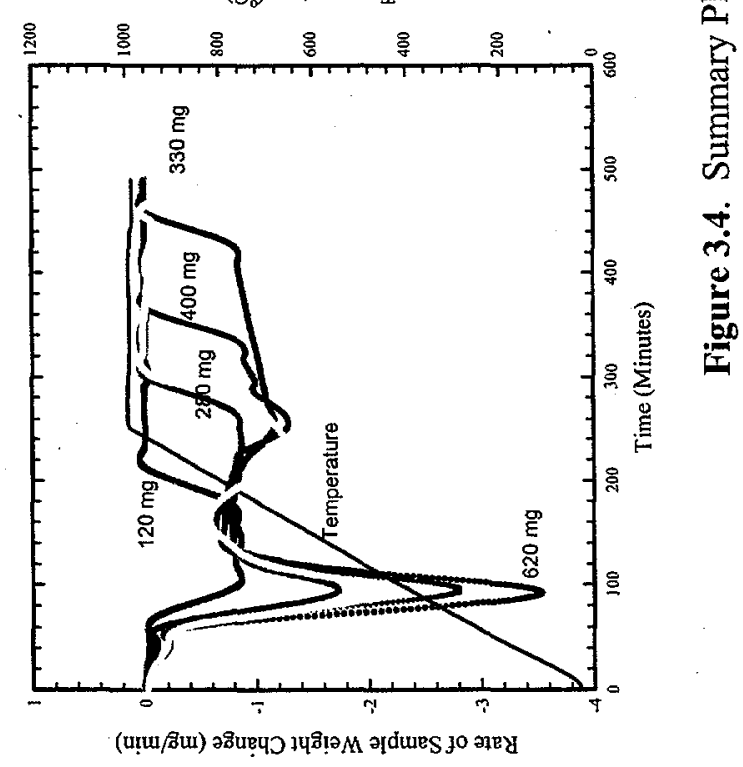




\subsection{Discussion}

The main objectives of the oxidation tests were to determine 1) the effect of increasing the polycube sample size on flammable gas species generation rates and 2) the concentration of $\mathrm{CO}$ in the off-gas stream. For the results discussed here, the weight loss data were subdivided into three main segments. Each segment was analyzed for the primary reaction of weight loss and the gaseous products that were monitored by the MS. The results were used to predict the flammable gas concentration for processing a $400-\mathrm{g}$ polycube in the muffle furnace.

\subsection{Weight Loss Data}

The three segments of weight loss data are discussed below:

- pyrolysis/oxidation ( $550 \mathrm{~K}$ to $790 \mathrm{~K}$ )

- residue oxidation (above $790 \mathrm{~K}$ )

- no measurable weight change at $1273 \mathrm{~K}$.

\subsubsection{Pyrolysis/Oxidation Segment}

In one region, the polycube samples lost weight through the thermal processes of pyrolysis (decomposition of the polystyrene to monomer species) and oxidation (reaction of the polystyrene with oxygen, generating $\mathrm{CO}, \mathrm{CO}_{2}$, and $\mathrm{H}_{2} \mathrm{O}$ ). For most runs, this region spanned the temperature range of about $550 \mathrm{~K}$ to $790 \mathrm{~K}$. As expected, the polycubes showed the maximum rate of the weight loss in this segment. The samples lost about 32 weight percent of their initial weight. The $\mathrm{PuO}_{2}$ fraction in Polycube- 1504 is estimated to be 30 weight percent (Abrefah and Sell 1999). Thus, about 70 weight percent of the samples tested were an organic phase, but only 32 weight percent can pyrolyze to contribute to the flammable gas generation. The results suggest that about 38 weight percent may have undergone radiolytic decomposition that results in mainly hydrogen loss and cross-linkages of C-C bonds. This fraction was removed from the polycube samples by the process of oxidation.

The maximum rates of weight loss by the samples in this region are listed in column 8 of Tables 3.1 and 3.2; column 9 lists the normalized maximum percent rates of weight loss. The data in columns 8 and 9 of Tables 3.1 and 3.2 are plotted on linear graphs in Figures 4.1 and 4.2, respectively. The maximum rate of weight loss increased linearly with increasing sample size, and the generalized linear regression line fit to the data yielded the equation

$$
\mathrm{Y}=7.03 \times 10^{-3} \mathrm{w}(\mathrm{mg})-0.20 \mathrm{mg} / \mathrm{min}
$$

where $\mathbf{w}$ is the initial polycube sample weight in $\mathrm{mg}$. The $\mathrm{r}^{2}$ for the fit was 0.99 with a standard error of 0.00026 on the slope. Using the above equation for processing a $400-\mathrm{g}$ polycube in the PFP muffle furnace, the maximum rate of weight loss expected is $2.8 \mathrm{~g} / \mathrm{min}$. This estimate assumes the bulk of the $400-\mathrm{g}$ polycube will be at the same temperature during heatup, and therefore predicts the upper bound value for the maximum rate of weight loss. During the muffle furnace processing, the heat transfer 
limitations will result in partial pyrolysis of the sample; hence, the actual maximum rate for the $400-\mathrm{g}$ polycube will be lower than the estimated value of $2.8 \mathrm{~g} / \mathrm{min}$.

The normalized maximum rates of percent weight loss plot in Figure 4.2 shows a large amount of scatter, but the general observation from the plots in Figures 3.3 and 3.4 is that the normalized maxima is independent of sample size for the range of samples tested. The normalized data were averaged to provide a best estimate that will be applicable to the polycubes during processing. The average value for the normalized maximum rate of percent weight loss was estimated to be $0.87 \pm 0.14 \% / \mathrm{min}$. Using this estimate, the maximum rate of weight loss by the $400-\mathrm{g}$ polycube will be $3.5 \pm 0.6 \mathrm{~g} / \mathrm{min}$. Again, this is the upper bound value as explained in the previous paragraph.

All the organic species, the products of pyrolysis, were generated in this segment. These products were identified by the MS (see Tables 3.1 and 3.2). The maximum concentrations of all the monitored organic products occurred at about the same temperature where the polycube samples showed the maximum rate of weight loss. This observation suggests that pyrolysis of the polycubes in this temperature segment is a major factor in the sample weight loss. For the organic flammable species monitored, the maximum concentrations increased with increasing polycube size (Figure 4.3). This observation may be true up to a certain maximum weight of polycube, where the effect of temperature diffusivity and distribution will limit the fraction of the polycube that will pyrolyze at any point in time. Therefore, an extrapolation of the data for these small samples to the whole polycube during the muffle furnace processing is expected to provide the upper bound concentrations for these flammable products. The cumulative yield for the flammable species (Figure 4.4) also shows a trend that increases with increasing polycube size. The pyrolysis of the virgin polystyrene using the same heating cycle generated styrene with the highest concentration in the off-gas stream (Abrefah and Sell 1999). The PFP polycube, on the other hand, always generated toluene, benzene, ethyl benzene, and benzaldehyde at a comparable concentration to that of styrene in the off-gas stream. The plausible explanation may be the cross linkages caused by radiation damage to the polystyrene matrix.

In addition to the regular pyrolysis flammable species, the oxidation of polycubes in air generates benzaldehyde as a major flammable gas. It is unclear whether the generation of this product occurs in the gas stream or on the solid surface.

\subsubsection{Residue Oxidation Segment}

During this segment of the test, the residues resulting from the pyrolysis and the radiolytic decomposition of the polystyrene reacted with oxygen to generate $\mathrm{CO}$ and $\mathrm{CO}_{2}$ as the main products. The total weight fraction of the residue was about 38 weight percent of the initial sample weight, as noted in Section 4.1.1. Since the $\mathrm{CO}$ component is a flammable gas product, its concentration in the off-gas stream is a safety issue that must be resolved. Assuming the same MS sensitivity for $\mathrm{CO}$ and $\mathrm{CO}_{2}$, the instant concentration ratio of $\mathrm{CO}_{2}$ to $\mathrm{CO}$ is about 2 for most of the runs except for Run 43. For Run 43, the $\mathrm{CO}_{2}$ to $\mathrm{CO}$ ratio is about unity in the segment where pyrolysis and oxidation reactions were occurring. The increase in the incomplete oxidation of the carbon char in this segment for the larger sample of $620 \mathrm{mg}$ may be due to the sudden release of the organic gaseous products that act as an additional barrier for oxygen diffusion to the sample surface. This suggests a potential for oxygen-starved oxidation to occur during processing the whole polycube, generating an increased fraction of $\mathrm{CO}$ in the gas stream. However, this effect could be minimized with increasing flow rate of the reaction gas (i.e., air). 
A reasonable background line was drawn to estimate the $\mathrm{CO}$ cumulative yield, but, due to the high background signal of nitrogen for the $\mathrm{CO}$ data, the error in estimating the total $\mathrm{CO}$ concentration could be as high as $50 \%$. The cumulative yield plotted in Figure 4.5 displays positive results of a smaller fraction of $\mathrm{CO}$ concentration in the off-gas stream. In fact, as the data in Table 3.2 suggest, the cumulative yield ratio of $\mathrm{CO}$ to $\mathrm{CO}_{2}$ is about 1 to 9 . That is, $\mathrm{CO}$ is only about $10 \%$ of the total gaseous product. This value is even lower than the LFL of CO, which is $12.5 \%$. These results indicate it is feasible to control the oxidation of the polycube with adequate oxygen gas flow to minimize the $\mathrm{CO}$ concentration in the offgas stream to far below its LFL.

\subsubsection{No Measurable Weight Change Segment}

In this segment the polycube sample showed no reaction with the oxidative atmosphere, suggesting that the organic phase and the resulting carbon residue have either been oxidized or pyrolyzed. The net product may be high purity $\mathrm{PuO}_{2} / \mathrm{UO}_{2}$ powder. The purity of the product cannot be determined without further analyses to quantify total carbon and other potential metal impurities in the final residue.

\subsection{Maximum Flammable Gas Concentrations in Off-Gases for Stabilization of Polycubes in a Muffle Furnace}

The objective of the calculation discussed here is to estimate the volume percent of flammable gases in the off-gas stream from thermal processing of a $400-\mathrm{g}$ polycube in an oxidizing atmosphere under production conditions expected in a muffle furnace. The calculated volume percent of flammable gases can be compared to the LFLs of the gases in air to determine if the gases could ignite during heating. For the purpose of this calculation, an airflow rate of $2.0 \mathrm{scfm}(56 \mathrm{l} / \mathrm{min})$ is assumed to go through the muffle furnace.

For safe operation of the muffle furnace during the oxidation of polycubes in dry air, the concentrations of the flammable species resulting from polycube pyrolysis should be below the LFL limits in column 3 of Table 4.1.

Table 4.1. Flammability in Air of Polycube Major Organic Products

\begin{tabular}{||l|c|c|c|c|}
\hline $\begin{array}{c}\text { Chemical } \\
\text { Species }\end{array}$ & $\begin{array}{c}\text { Flashpoint } \\
\text { (C) }\end{array}$ & $\begin{array}{c}\text { Lower } \\
\text { Flammable } \\
\text { Limit (\%) }\end{array}$ & $\begin{array}{c}\text { Upper } \\
\text { Flammable } \\
\text { Limit (\%) }\end{array}$ & $\begin{array}{c}\text { Autoignition } \\
\text { Point ( } \mathbf{C} \text { ) }\end{array}$ \\
\hline \hline Styrene & 31 & 1.1 & 6.1 & 490 \\
\hline Benzene & -11 & 1.2 & 7.8 & 498 \\
\hline Toluene & 4 & 1.2 & 7.1 & 480 \\
\hline Ethyl Benzene & 15 & 0.8 & 6.7 & 432 \\
\hline Benzaldehyde & 64 & 1.4 & 12.3 & 192 \\
\hline
\end{tabular}

The calculation requires data on the composition of the off-gases (both oxidation products and pyrolysis products) from MS measurements and estimates of the rates of weight loss of the polycube during heating. The MS data used here are from Section 4.1.1 for actual polycube samples. The rate of weight loss from the data for the 12 runs using samples taken from Polycube-1504 was used in the calculations. As noted in Section 4.1.1, the average maximum percent weight loss rate was estimated to be about 
$0.87 \% / \mathrm{min}$. For a $400 \mathrm{~g}$ polycube, this weight loss rate would be about $3.5 \mathrm{~g} / \mathrm{min}$. The same distribution of products for both the oxidation and pyrolysis used by Jones et al. (1999) is used in this calculation. In Jones et al., the oxidation products accounted for about $46 \%$ of the total weight loss of the polycube and about $54 \%$ for pyrolysis. Here, converting to weight loss rate, the flammable gaseous products accounted for about $1.89 \mathrm{~g} / \mathrm{min}$ rate of weight loss for the $400-\mathrm{g}$ polycube. The distribution of the flammable products in the off-gas stream was estimated using the maximum concentration data for Run 43 in Table 3.1. The resulting distribution in Table 4.2 is converted to volume percent in the air flow rate of $2.0 \mathrm{scfm}(56 \mathrm{l} / \mathrm{min})$.

Table 4.2. Concentration of Flammable Species in Off-Gas Stream

\begin{tabular}{||l|c|c|c|}
\hline \multirow{2}{*}{ Species } & Percent Flammable & \multicolumn{2}{c|}{ Concentration in the Off-Gas Stream } \\
\cline { 3 - 4 } & Gas (Test Data) & g/min & Vol. Percent at STP \\
\hline Benzene & 18.6 & 0.35 & 0.18 \\
\hline Styrene & 13.4 & 0.25 & 0.10 \\
\hline Toluene & 25.3 & 0.48 & 0.21 \\
\hline Ethyl Benzene & 20.0 & 0.38 & 0.14 \\
\hline Benzaldehyde & 22.7 & 0.43 & 0.16 \\
\hline
\end{tabular}

The individual flammable species concentrations in Table 4.2 are significantly lower than their respective LFLs, but the total concentration of all the flammable species, about 0.79 , is slightly lower than the lowest LFL in Table 4.1. The appropriate composite LFLs for the mixtures can be calculated using the Le Chatelier's rule:

$$
\text { Composite LFL (volume percent) }=\frac{100}{C_{1} / L F L_{1}+C_{2} / L F L_{2}+\ldots+C_{i} / L F L_{i}}
$$

where the C's are the percentages of the total fuel volume. The composite LFL for the mixture of styrene, benzaldehyde, ethyl benzene, toluene, and benzene in Table 4.2 is estimated to be 1.11 volume percent. Conclusively, the total flammable species concentration in the off-gas stream during the processing of the polycube is below the composite LFL. The linear extrapolation of the maximum rate of weight loss data (Figure 4.1) will give an even lower estimate of the flammable species concentrations. 

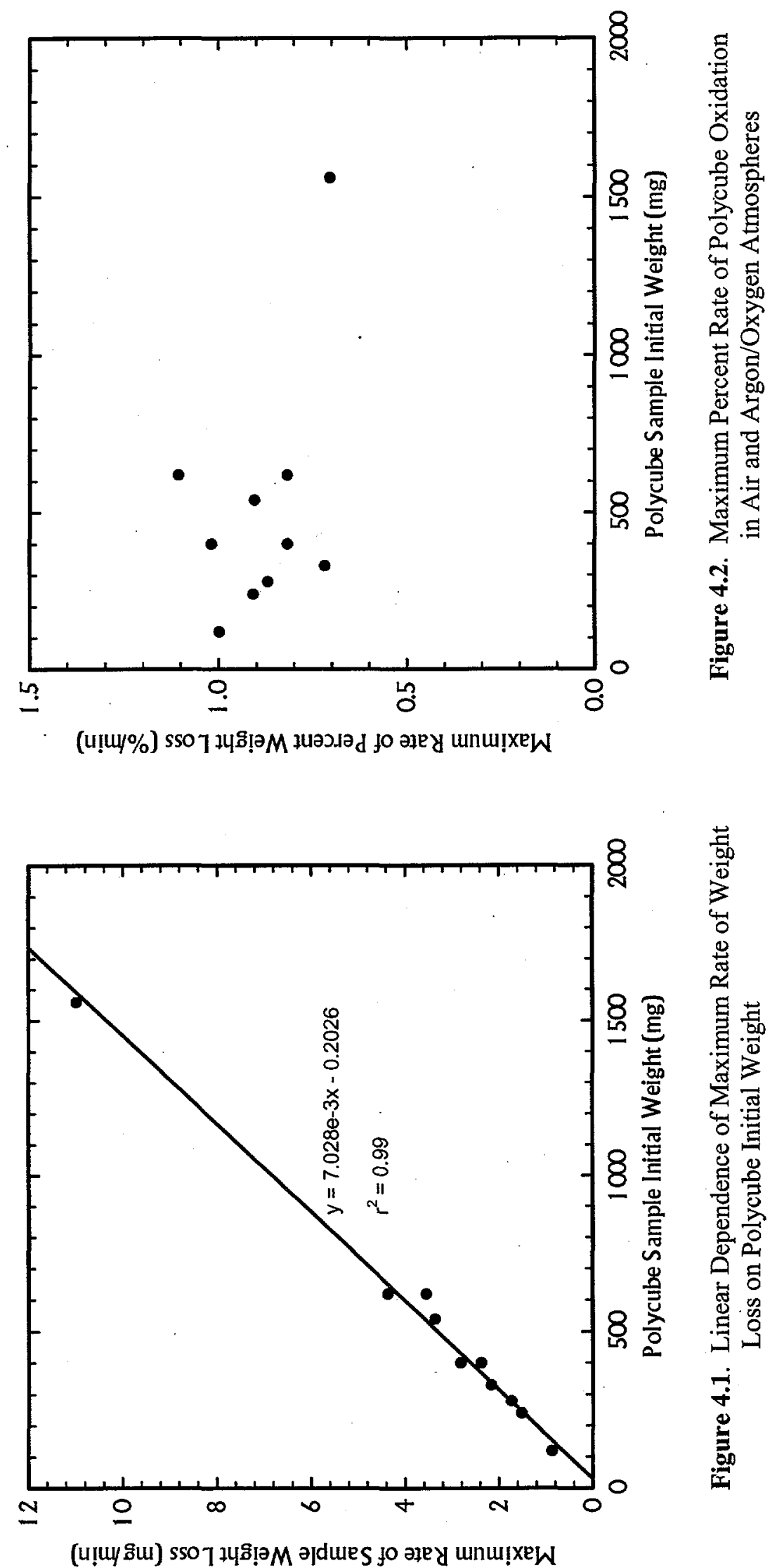


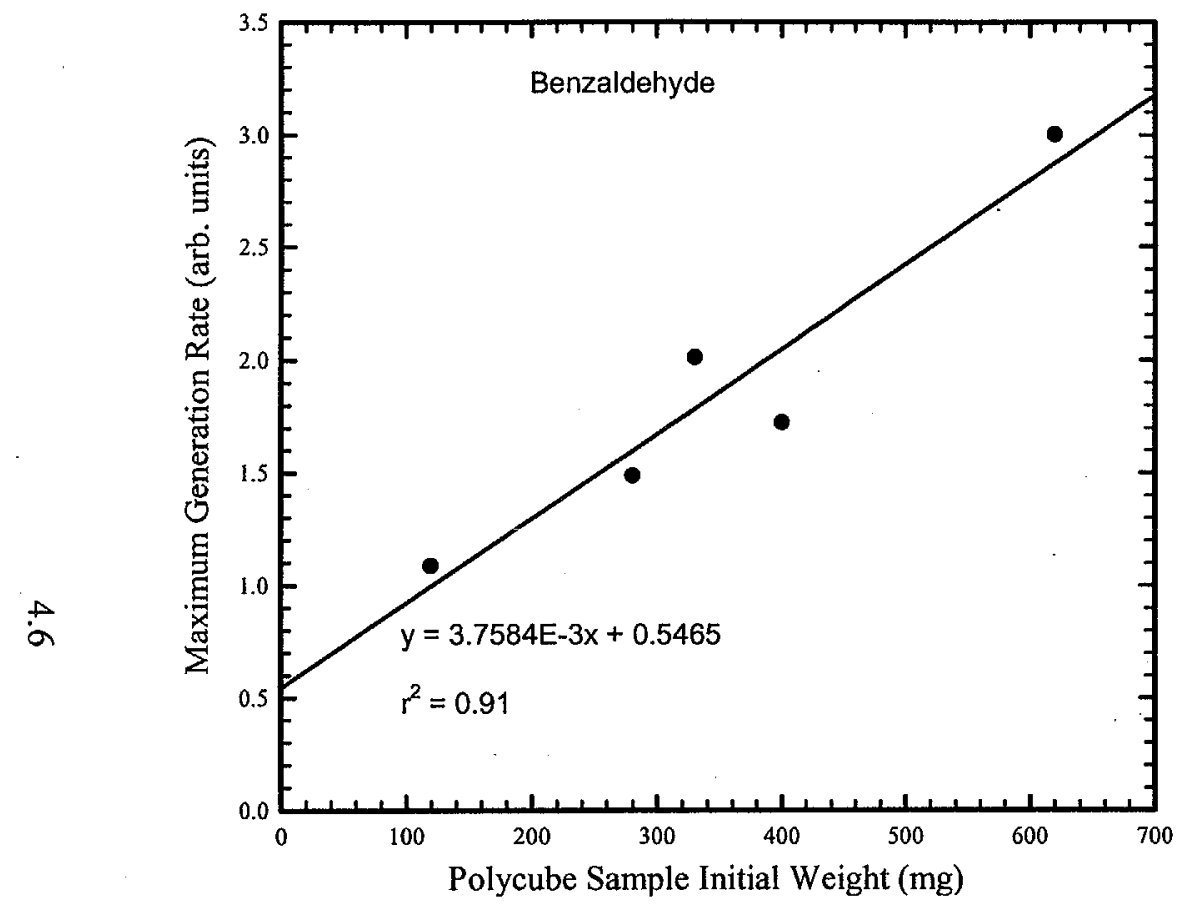

Figure 4.3. Effect of Polycube Weight on the Maximum Generation Rate of Benzaldehyde (a major flammable gas)

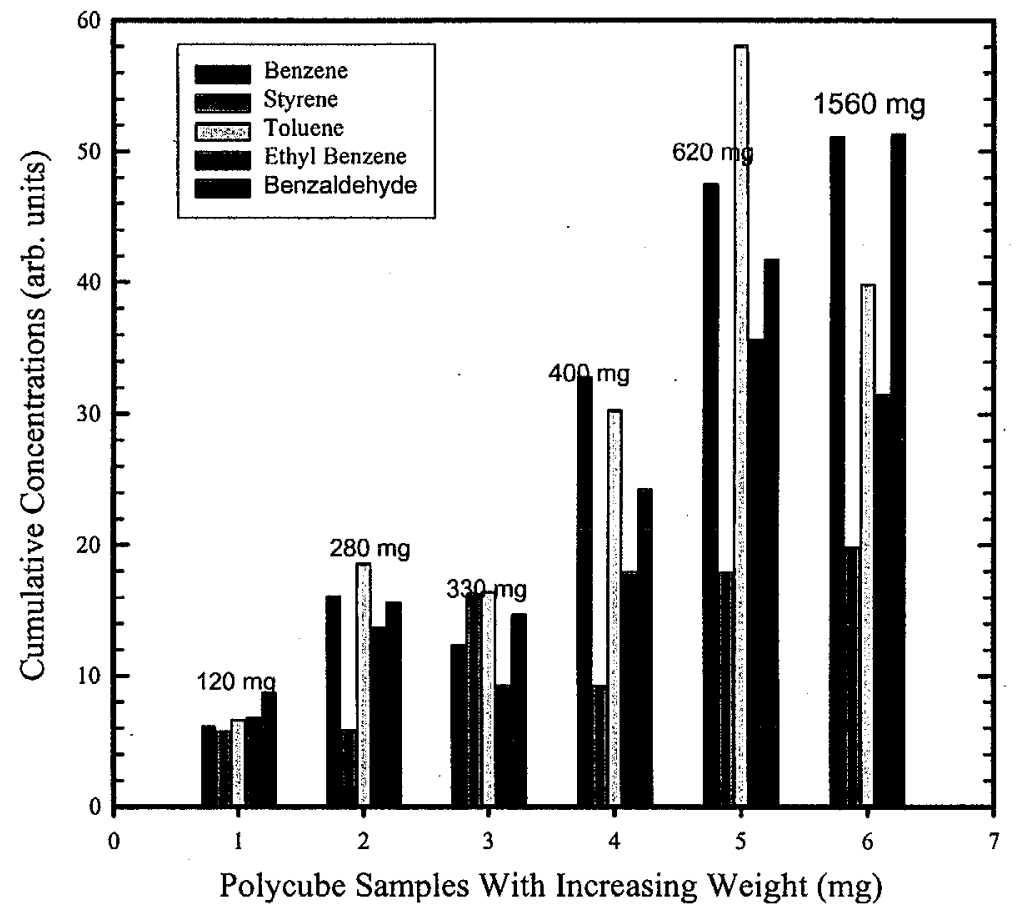

Figure 4.4. Major Flammable Products for Polycube Oxidation in Argon/Oxygen 


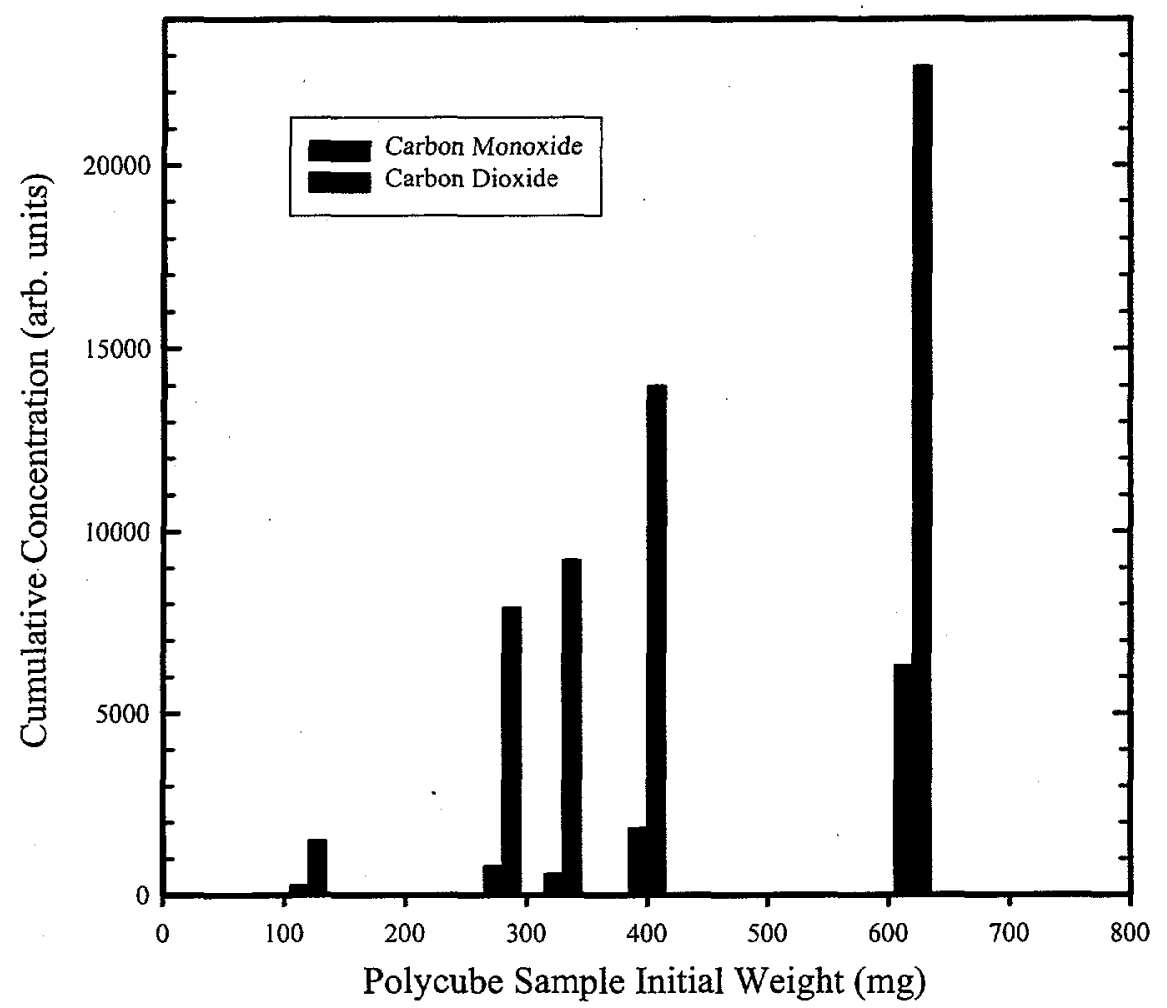

Figure 4.5. Cumulative $\mathrm{CO}_{2}$ and $\mathrm{CO}$ Concentrations in the Off-Gas Stream 


\subsection{Conclusions}

The test results show that the highly degraded polycubes can be thermally stabilized in an air atmosphere without generating flammable gases in concentrations that exceed their LFLs in the off-gas stream. The process occurring during the tests usually started with an initial slow oxidation, a faster rate of weight loss in the temperature range of $550 \mathrm{~K}$ to $790 \mathrm{~K}$, and finally, the oxidation of all the carbonaceous products, yielding an end product of $\mathrm{PuO}_{2}$ powder.

The maximum rate of weight loss for the polycube samples occurred in the region where pyrolysis plus oxidation thermally decomposed the organic phase of the polycube material, and therefore, corresponded to the maximum rate of flammable gas species concentrations in the off-gas stream. The maximum rate of weight loss (i.e., maximum flammable species concentrations) increased linearly with increasing polycube sample size. The extrapolation of the polycube size effect to an actual muffle furnace charge size of about $400 \mathrm{~g}$ gave about $2.8 \mathrm{~g} / \mathrm{min}$ as the maximum rate of weight loss.

A normalized percent maximum rate of weight loss data for the polycube tested, on the other hand, showed no dependence on increasing size of the polycube. An average value of the normalized percent maximum weight loss rate was estimated to be $0.87 \pm 0.14 \% / \mathrm{min}$, which translates to $3.5 \mathrm{~g} / \mathrm{min}$ as a maximum rate of weight loss for the $400 \mathrm{-g}$ polycube. This rate is higher than the previous value calculated using the linear extrapolation of the maximum rate of weight loss. The upper bound of flammable gas concentrations during the processing of a $400-\mathrm{g}$ polycube in the muffle furnace was calculated using a maximum rate of weight loss of $3.5 \mathrm{~g} / \mathrm{min}$. That calculation showed the peak flammable gas generation rates in the off-gas stream, for all the major identified products, stayed below their LFLs.

The irregular-shaped polycube fragment samples used in the testing made it difficult to analyze the data for direct correlation between geometrical surface area and the flammable gas generation rates. However, the two experiments (Runs 38 and 45) performed with polycube powder samples yielded data that conclusively showed no measurable increasing effect of the high surface area particulates on the flammable gas species concentrations.

The composition in the off-gas stream during the thermal treatment of polycube in air includes major flammable organic species such as benzene, styrene, toluene, ethyl benzene and benzaldehyde, and the oxidation products of water, $\mathrm{CO}$ and $\mathrm{CO}_{2}$. The organic products showed a peak generation rate during the pyrolysis/oxidation reactions in the temperature range of about $550 \mathrm{~K}$ to $790 \mathrm{~K}$. The peak rates of flammable organic gases occurred at the same temperature where the polycube showed maximum rate of weight loss.

The oxidation of the carbonaceous residue generated by far the higher concentrations of $\mathrm{CO}$ and $\mathrm{CO}_{2}$ in the off-gas stream. The $\mathrm{CO}$ concentrations throughout the runs were below the concentrations of the $\mathrm{CO}_{2}$ (assuming similar MS sensitivity). The cumulative yield of $\mathrm{CO}$ constitutes only about 10 volume percent of the total concentration of $\mathrm{CO}$ and $\mathrm{CO}_{2}$. This yield confirms an adequate flow of air through the furnace system; the CO generated can be kept well below its LFL, especially if the total product concentration in the off-gas stream is designed to be below 10 volume percent of the total gas flow. Another significant observation was that during the pyrolysis and oxidation reactions segment, the CO concentration 
increased to the level of the $\mathrm{CO}_{2}$ concentration in the off-gas stream. This increase may have been a result of an additional barrier created by the sudden release of a plume of organic products during pyrolysis.

Based on these conclusions and observations, the following temperature/time profile is recommended for direct oxidation process of the polycube in the muffle furnace:

- Heat at a rate of 4 to $5 \mathrm{~K} / \mathrm{min}$ to a temperature of about $573 \mathrm{~K}$, as the reaction is slow within this temperature range and only a low concentration of gases is generated.

- Slow down the heating rate to $3 \mathrm{~K} / \mathrm{min}$ up to a temperature of $773 \mathrm{~K}$ and hold it for about 5 hours. This will reduce the flammable gas generation rate.

- Continue the heatup rate at $3 \mathrm{~K} / \mathrm{min}$ up to $1273 \mathrm{~K}$, hold it for 3 hours and allow to cool down to ambient conditions. This will convert the carbon residue to $\mathrm{CO}$ and $\mathrm{CO}_{2}$ to generate a pure form of $\mathrm{PuO}_{2}$ powder.

The above temperature/time profile can be optimized to increase the overall efficiency of the direct oxidation process. 


\subsection{Future Work}

A number of testing activities are planned to provide additional information that will support the preliminary conclusions in this report and further enhance the understanding of the process parameters for stabilizing polycubes by direct oxidation. These activities include, but are not limited to, the following:

- calibration of all the identified gaseous products in the off-gas stream to provide factors needed to convert the MS signal intensities to actual concentrations.

- characterization of products generated by the thermal treatment for total carbon content and other heavy metal impurities.

- independent verification of all the major organic species generated by pyrolysis of polycube samples. A GC/MS system will be used to perform the tests. The data will be used to determine the pyrolyzates that were generated during the tests discussed in this report.

- optimization of the thermal stabilization process by the variation of the temperature/time profiles. This activity will be coordinated with a similar effort at PPSL involving actual polycube size.

- determination of the heat of reaction during the thermal treatment of polycubes in air using the TG/DSC configuration of the Netzsch TGA/DSC/MS system. 


\subsection{References}

Abrefah, J., and R. L. Sell. 1999. Characteristics and Results of Polycube Thermal Stabilization Testing. PNNL-12262, Pacific Northwest National Laboratory, Richland, Washington.

Jones, S. A., G. S. Barney and J. Abrefah. 1999. White Paper on Muffle Furnace Stabilization of Polycubes. 15F00-99-130, B \& W Hanford, Richland, Washington.

Lewis, W. S., and C. D. Meng. 1996. Location Assessment for the Polycube Pyrolysis Process. WHC-SD-CP-TI-203, Westinghouse Hanford Company, Richland, Washington. 


\section{Appendix}

Thermogravimetric and MS Data for Polycube Oxidation in Air (Runs 35 through 40) and Argon/Oxygen (Runs 41 through 46) Atmospheres 


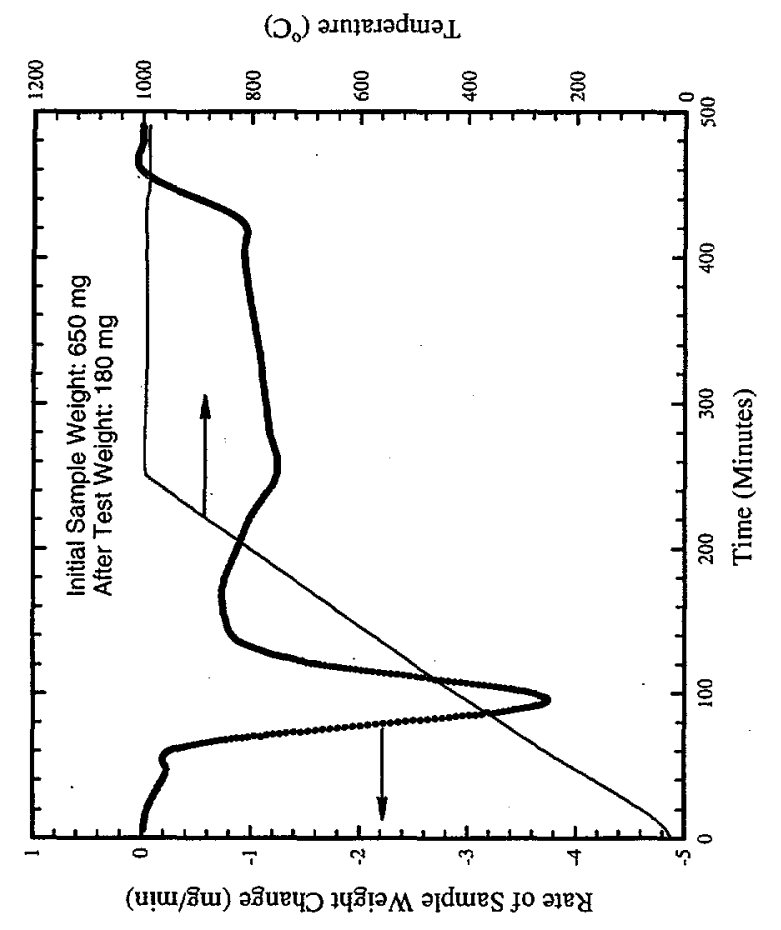

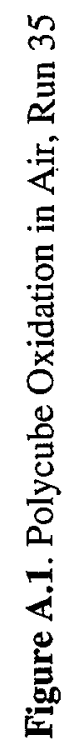

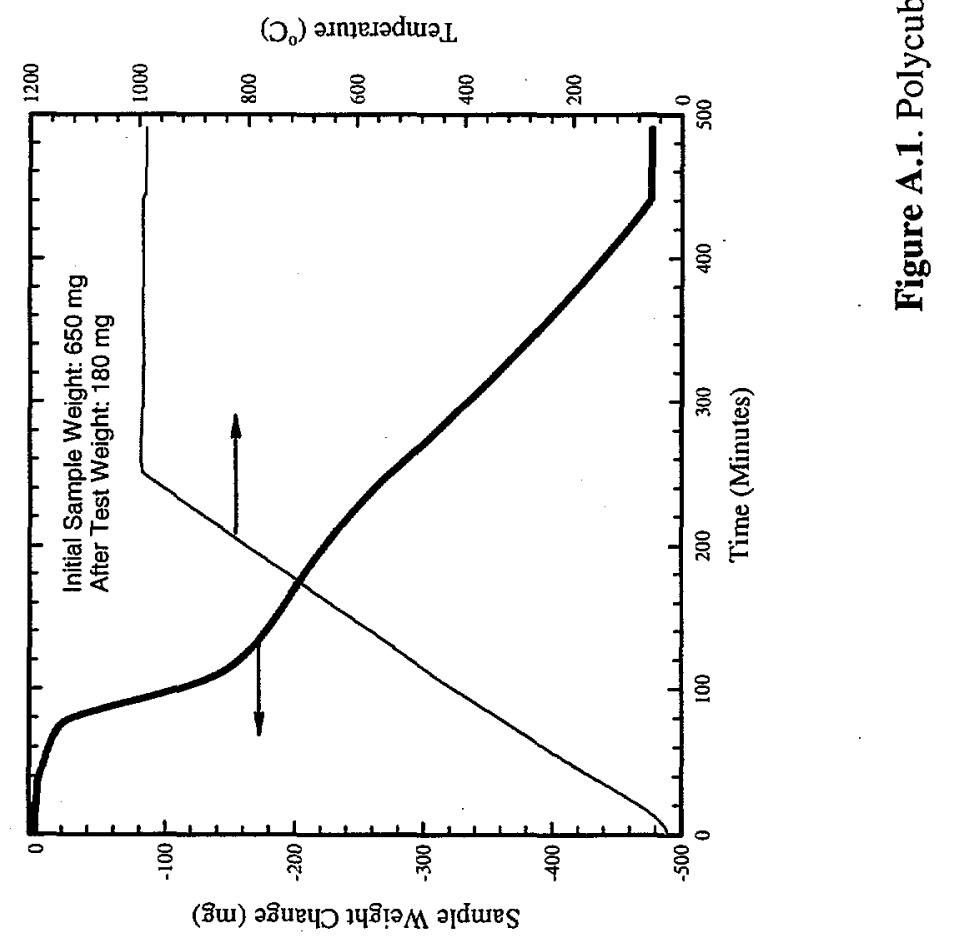

A. 1 

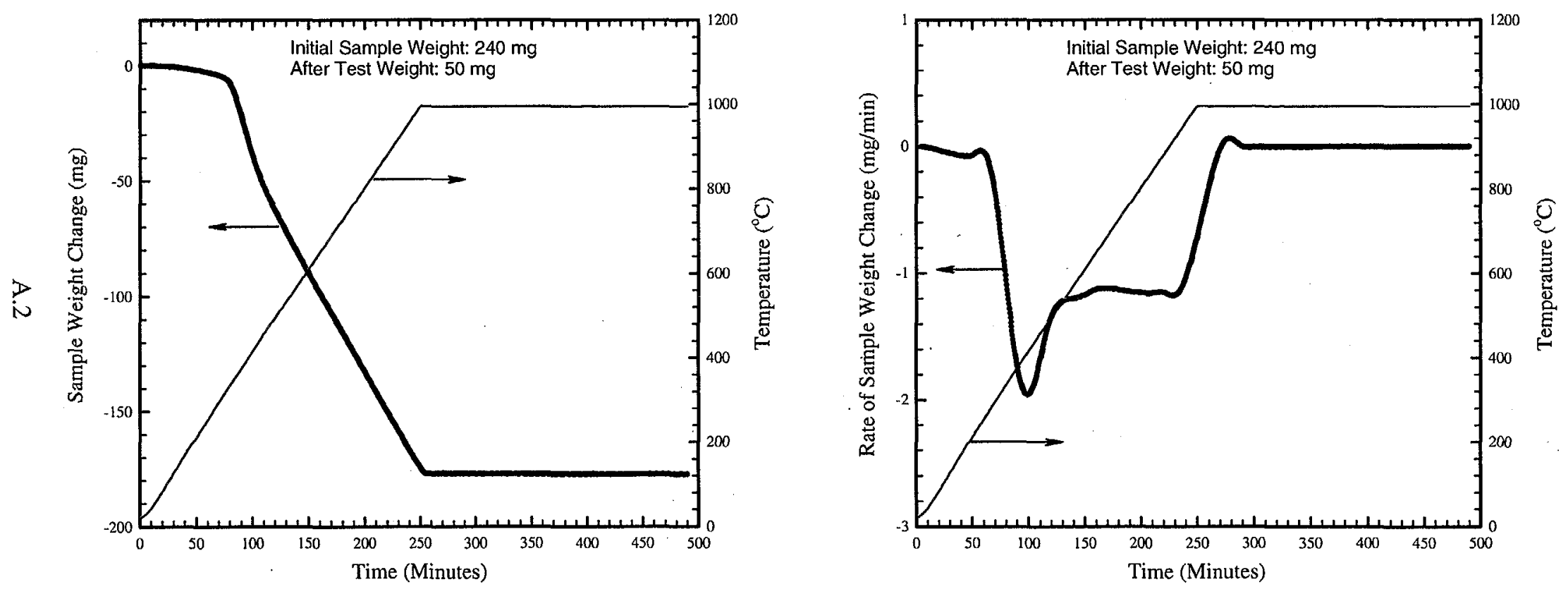

Figure A.2. Polycube Oxidation in Air, Run 36 
(D) ameraduจ

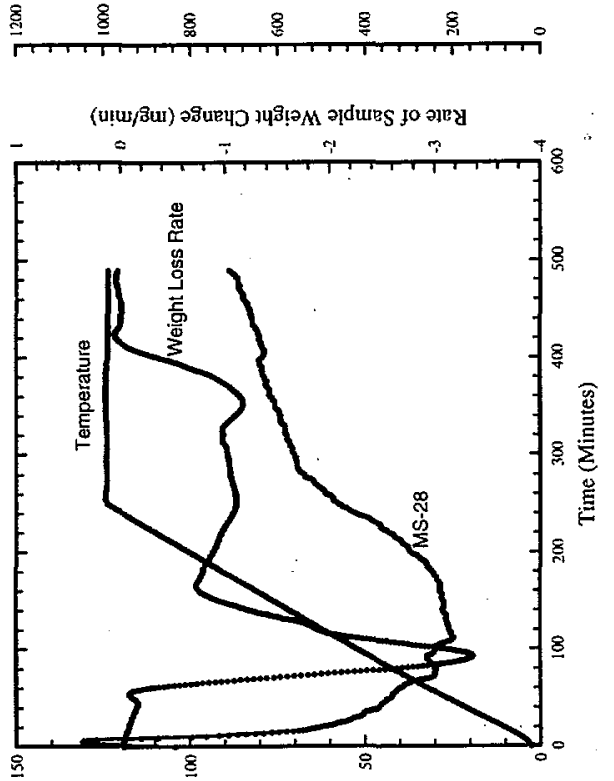

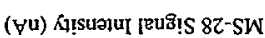

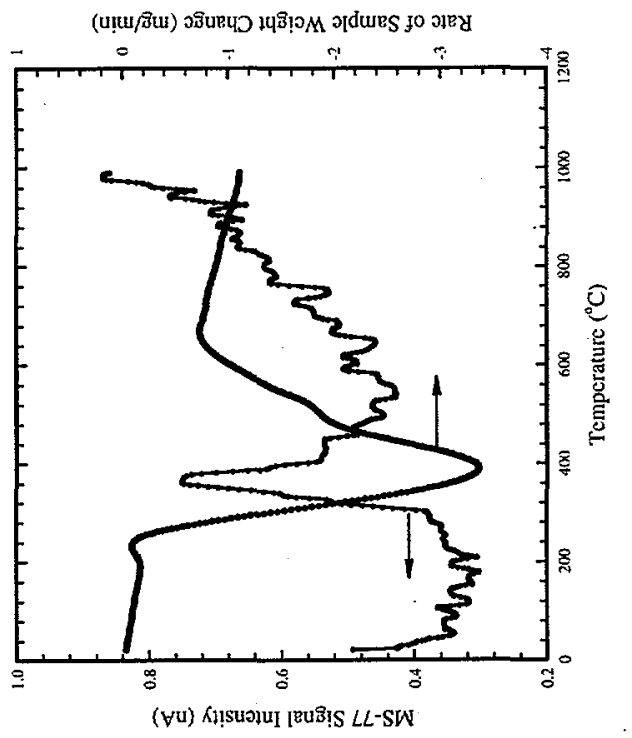

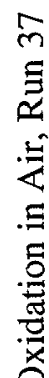

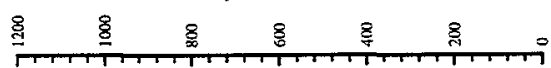

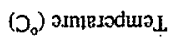
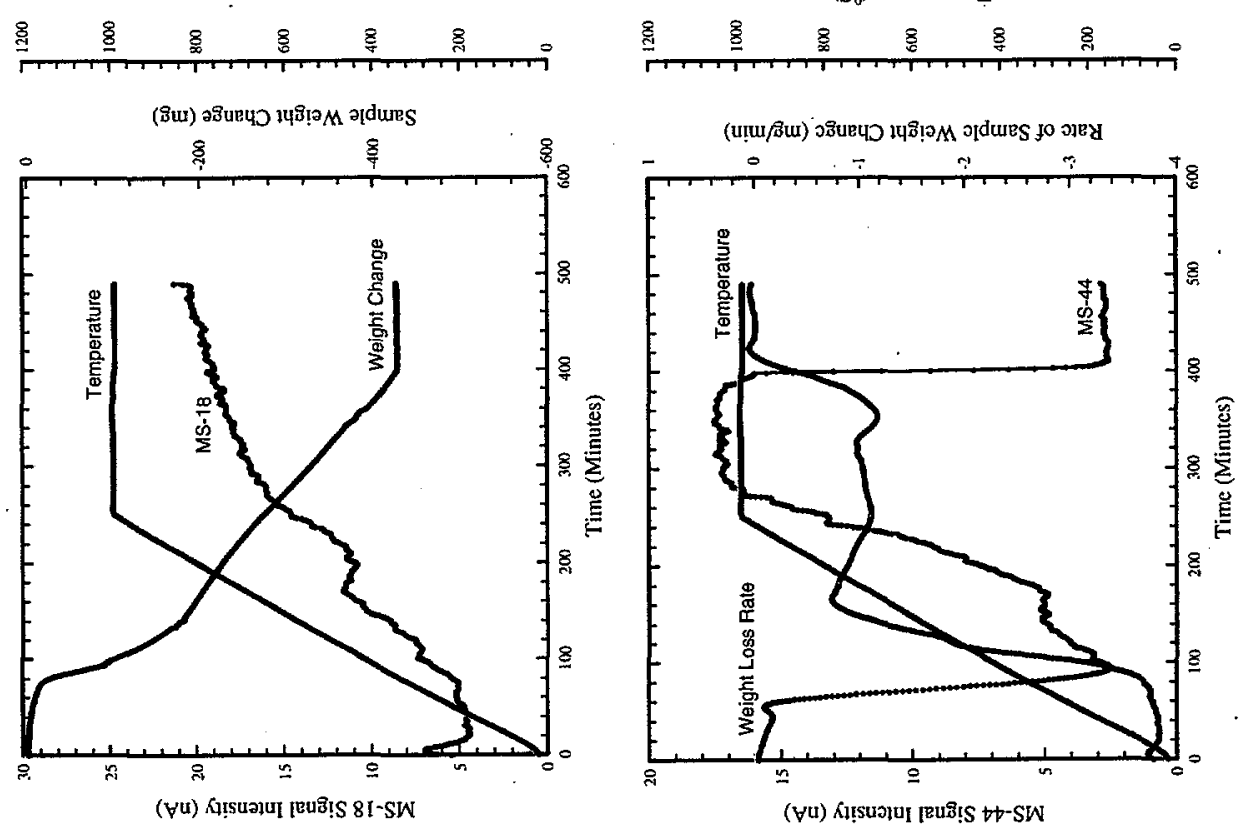

A. 3 

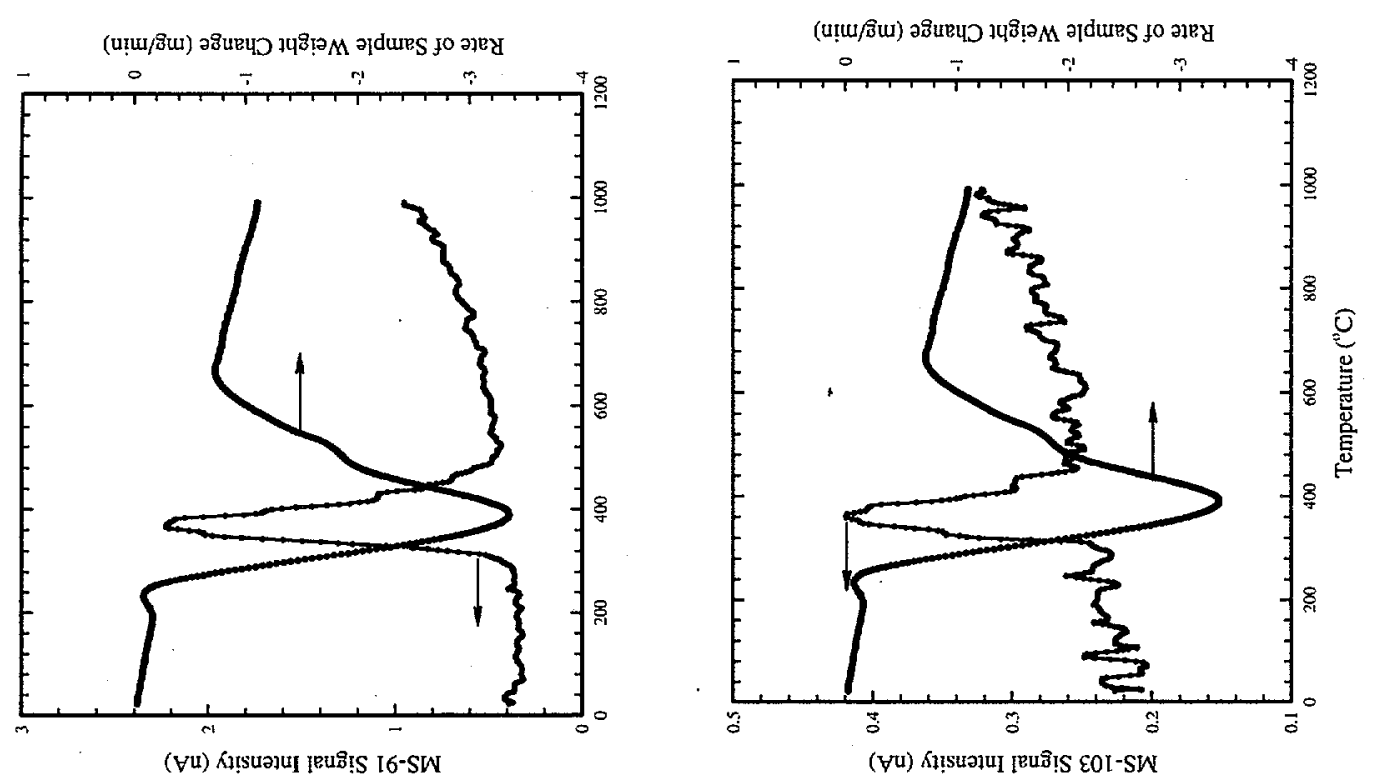

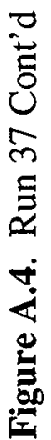
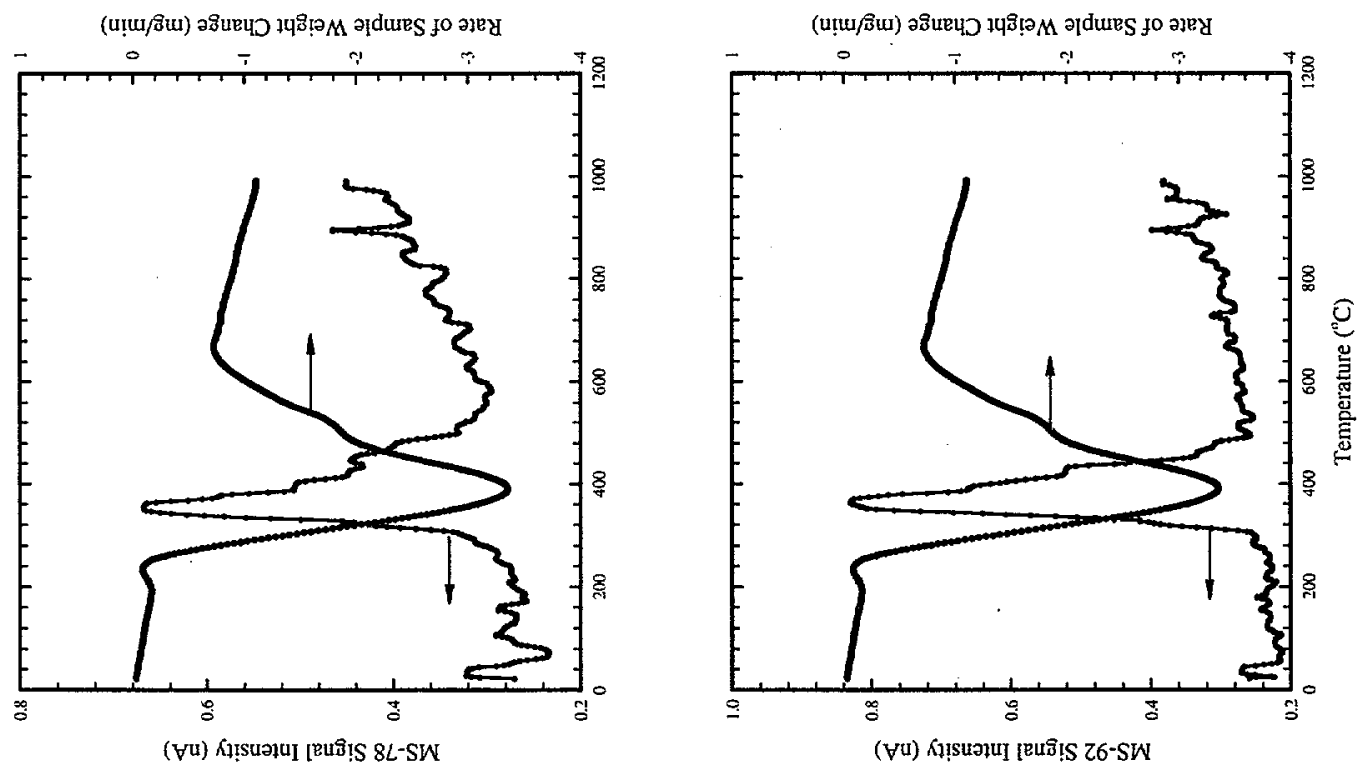

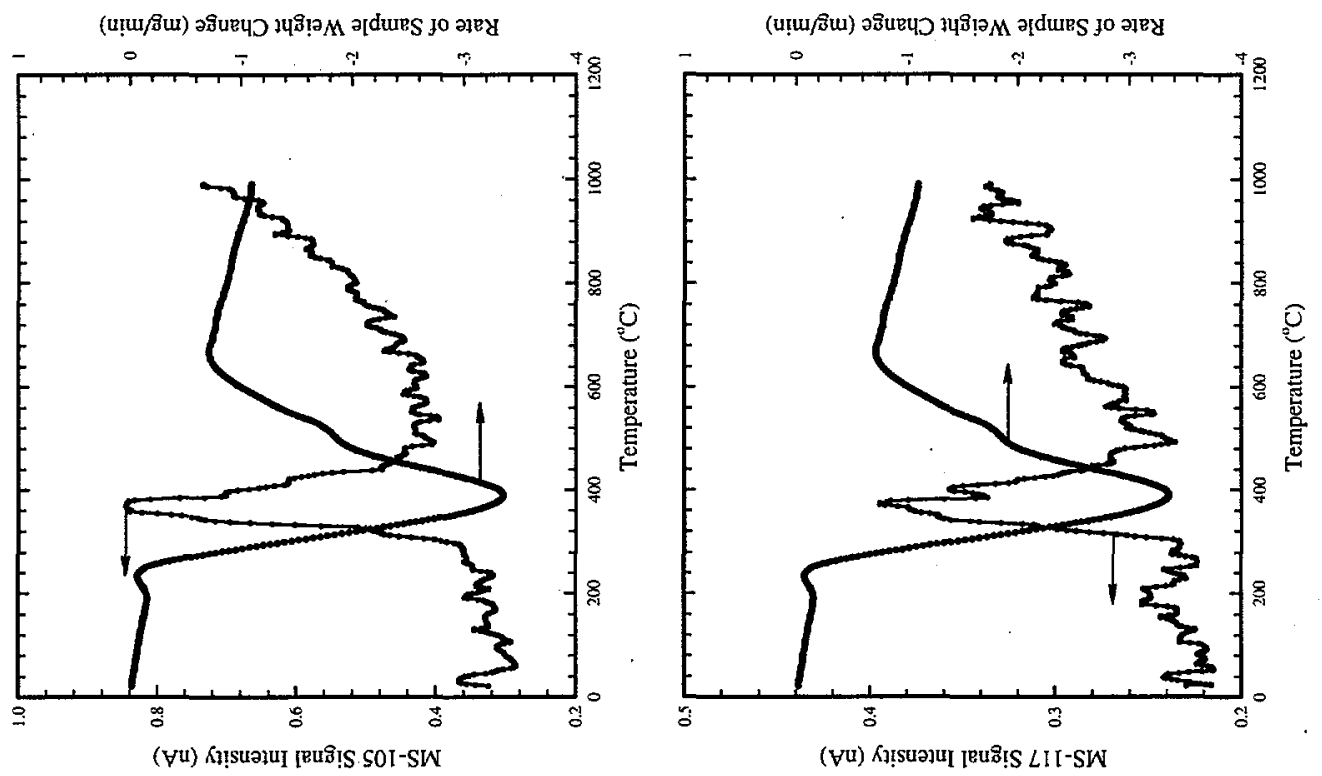

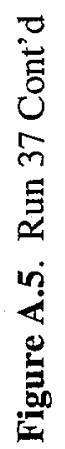
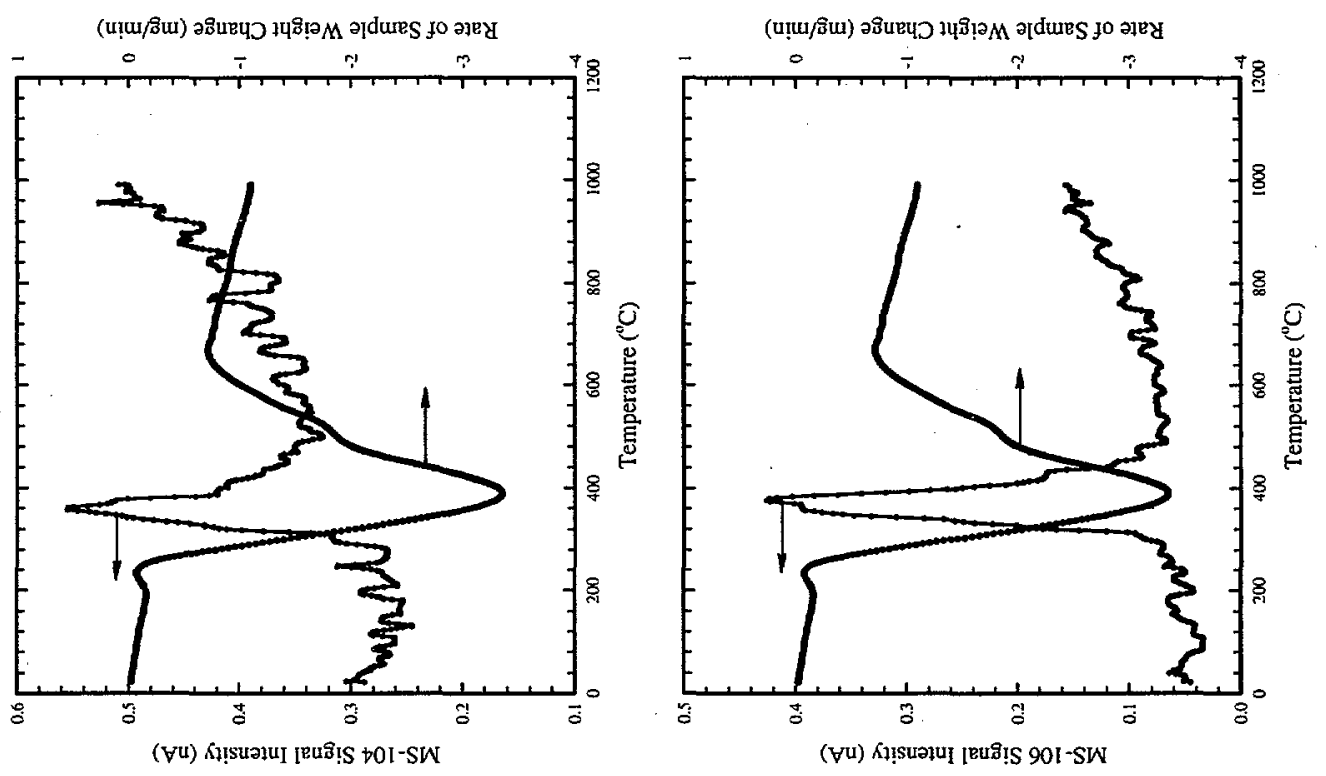
(D) amesduol
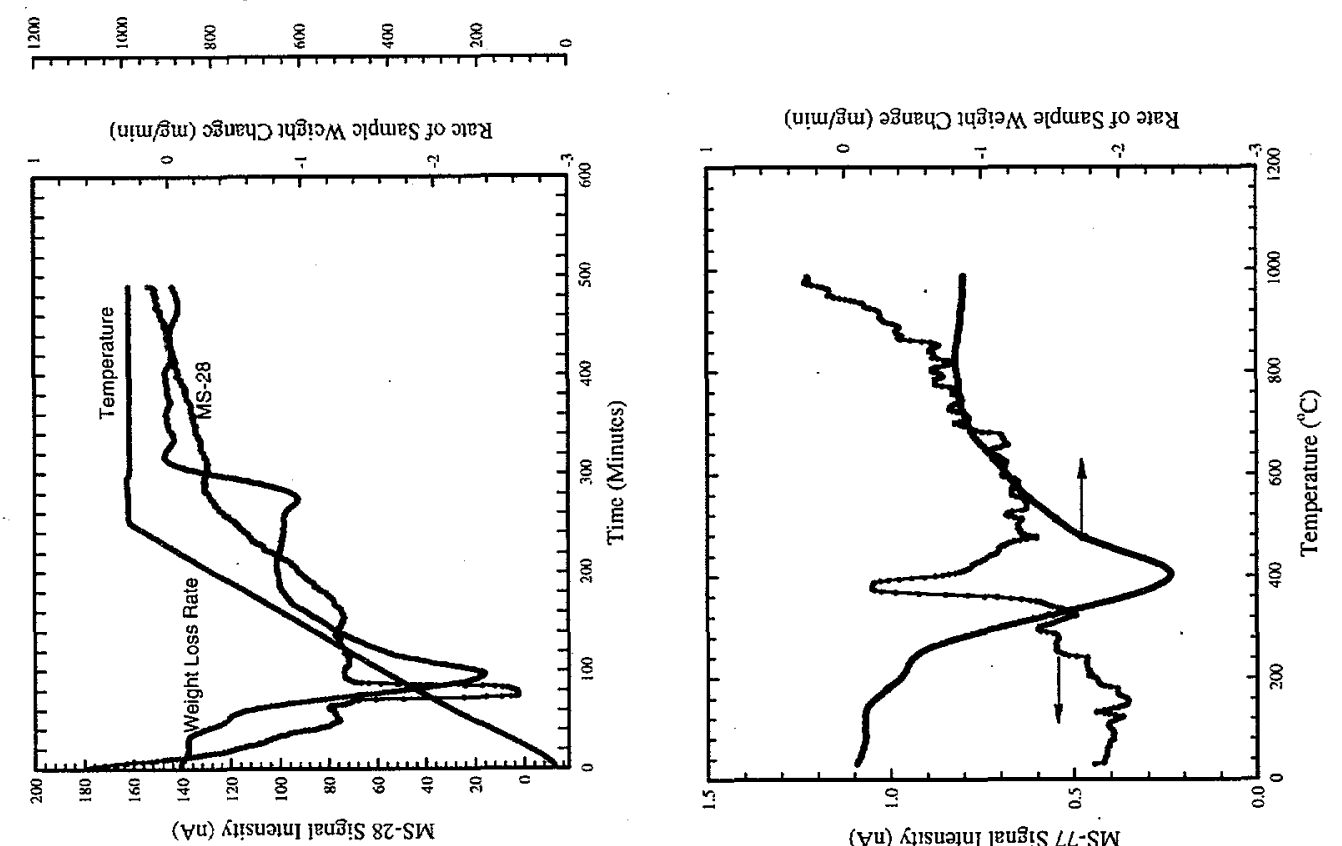

禹
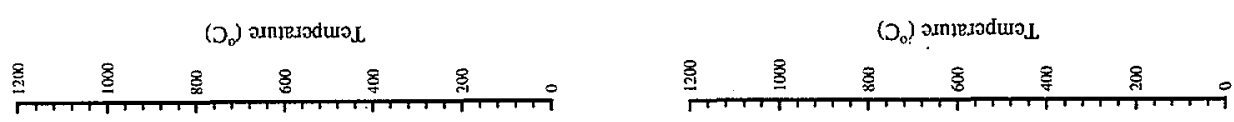

苛
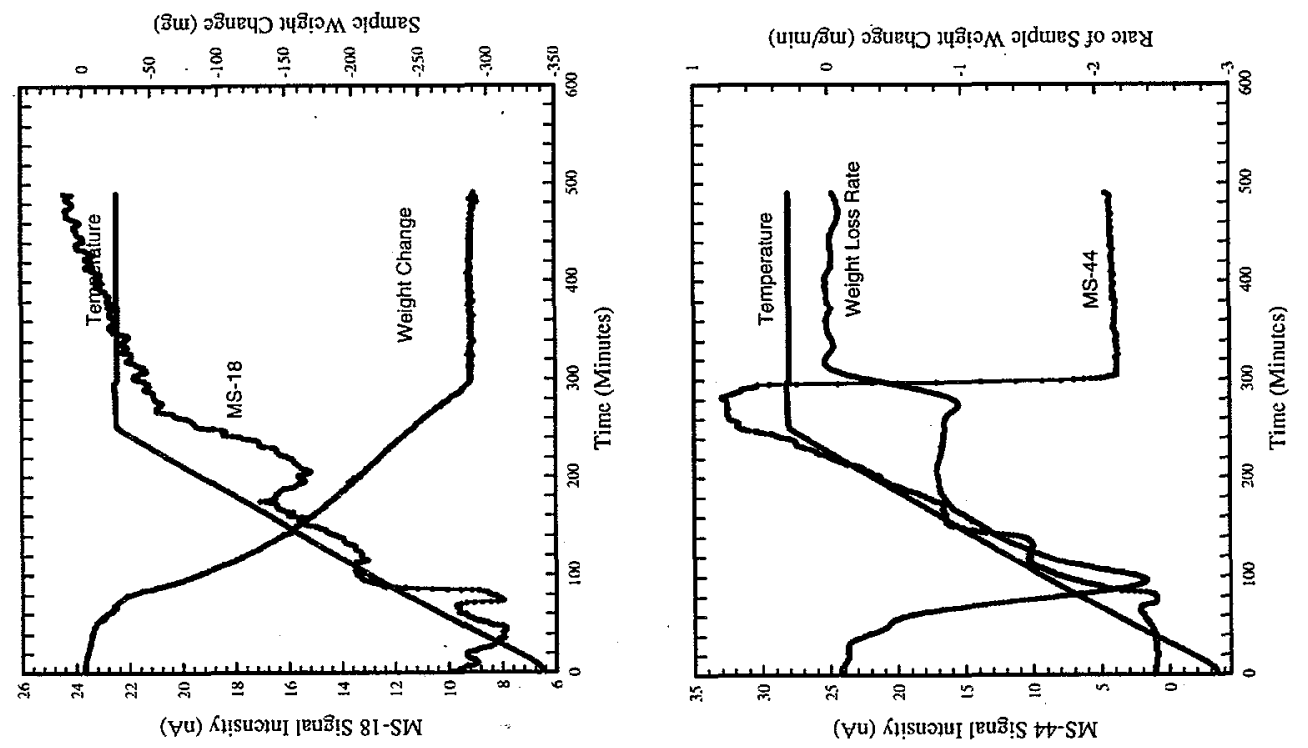

它 

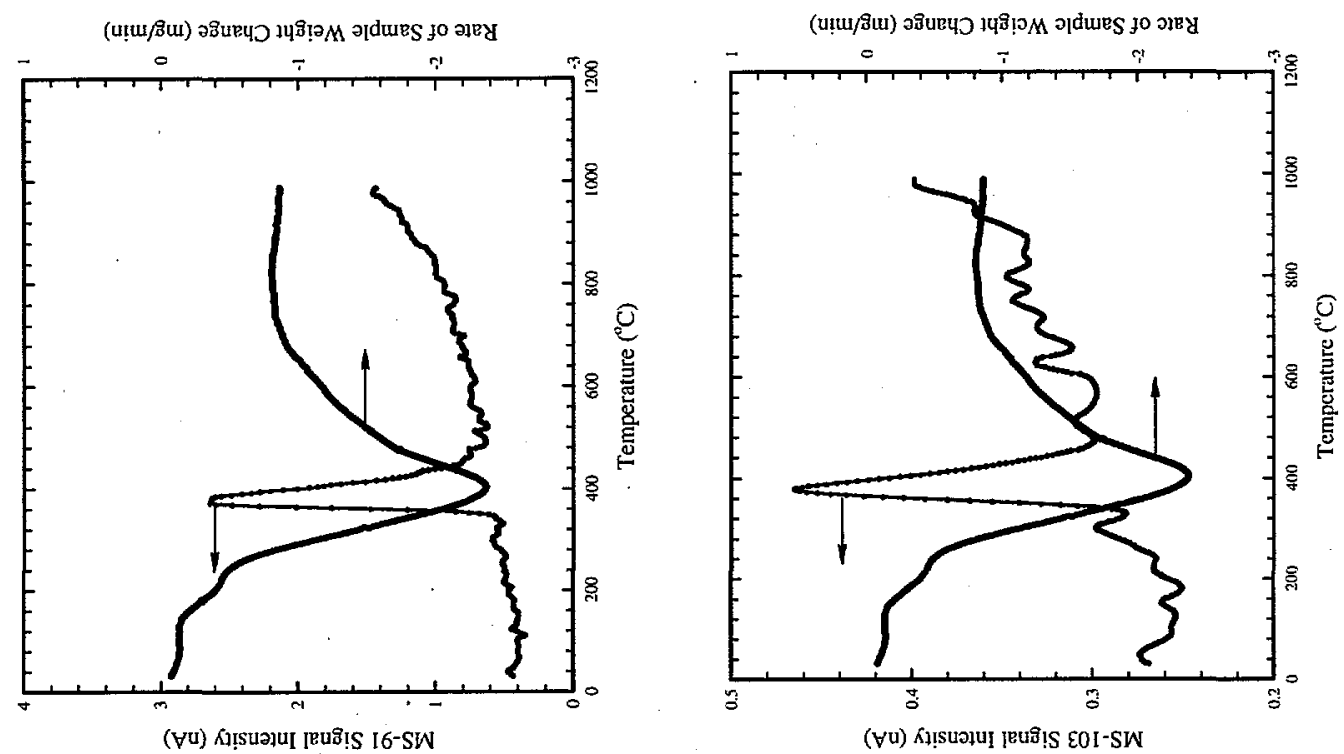

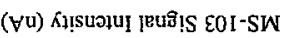

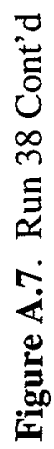
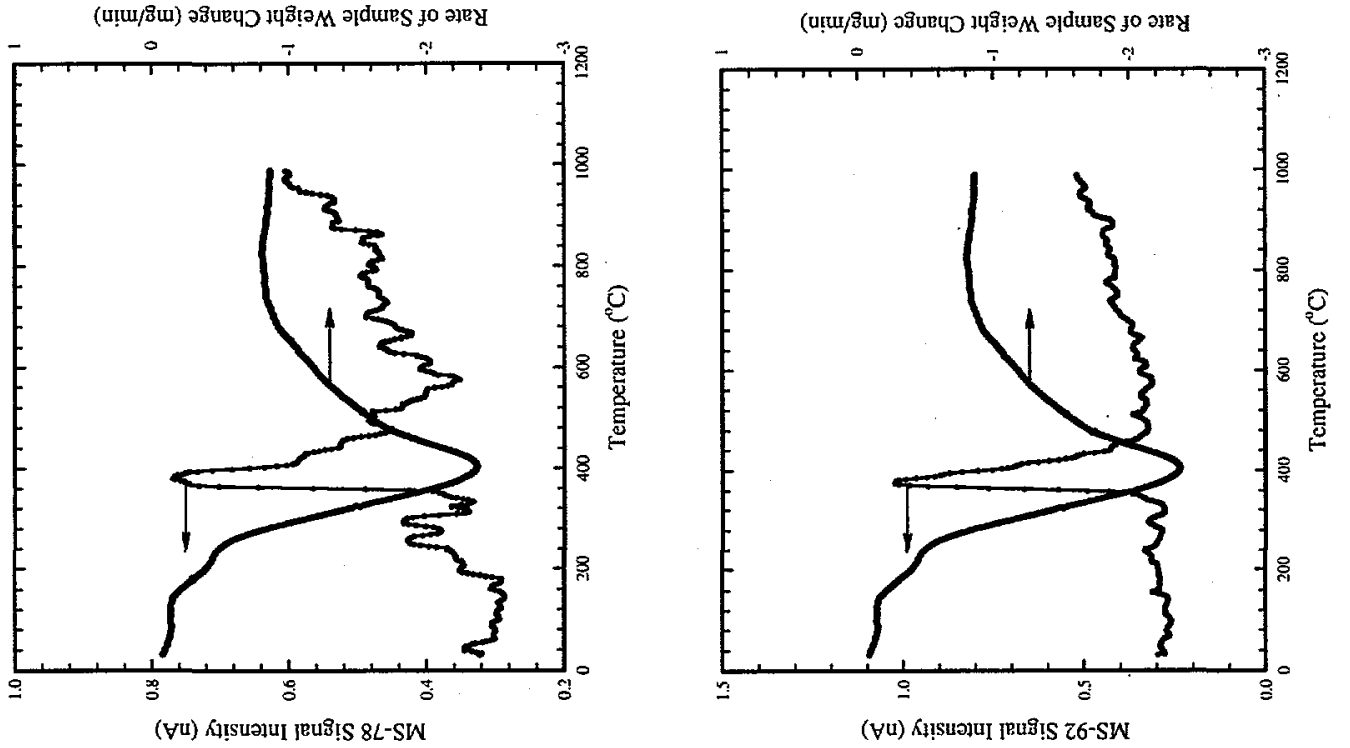

A. 7 

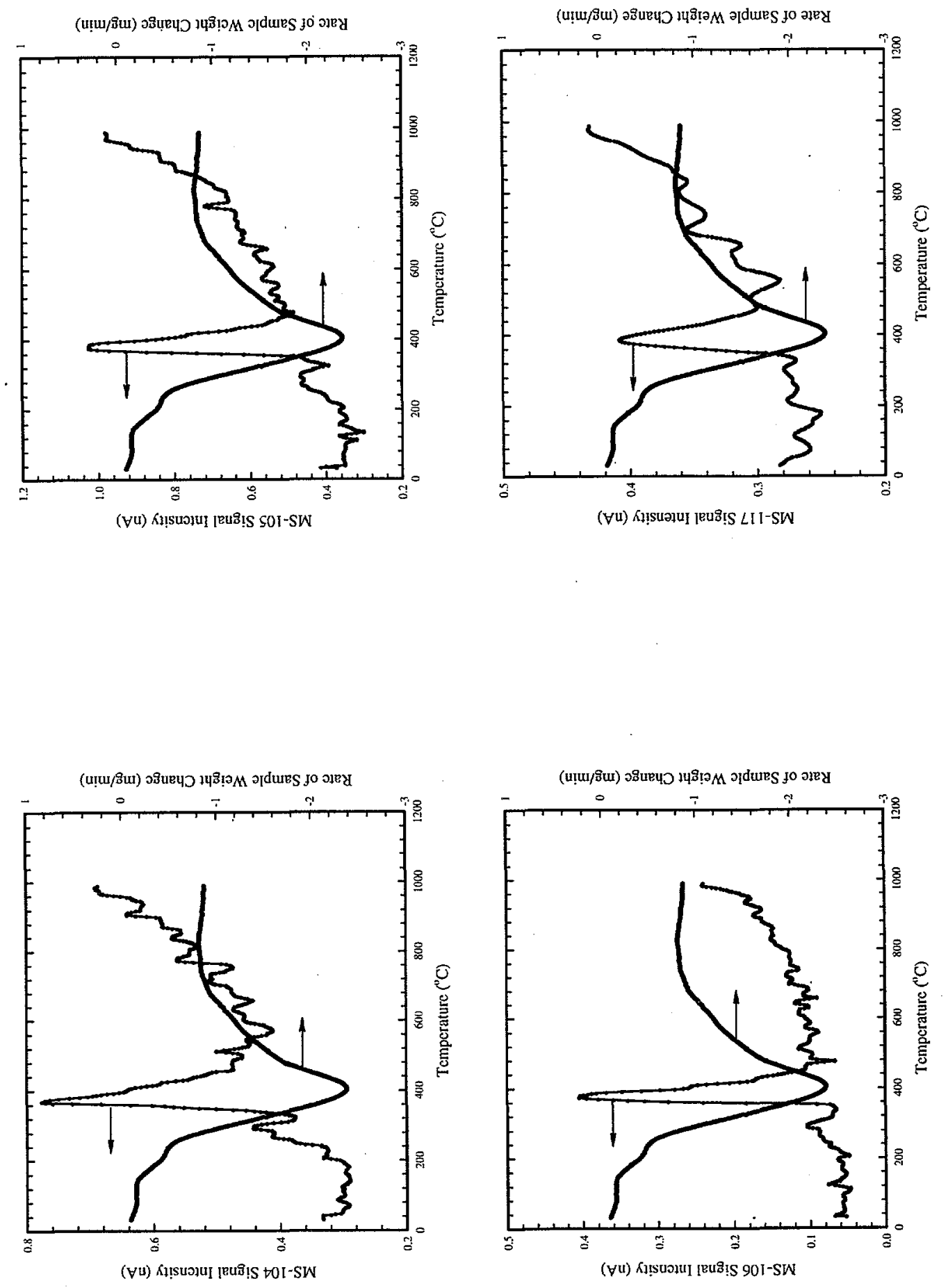

A. 8 


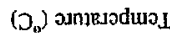
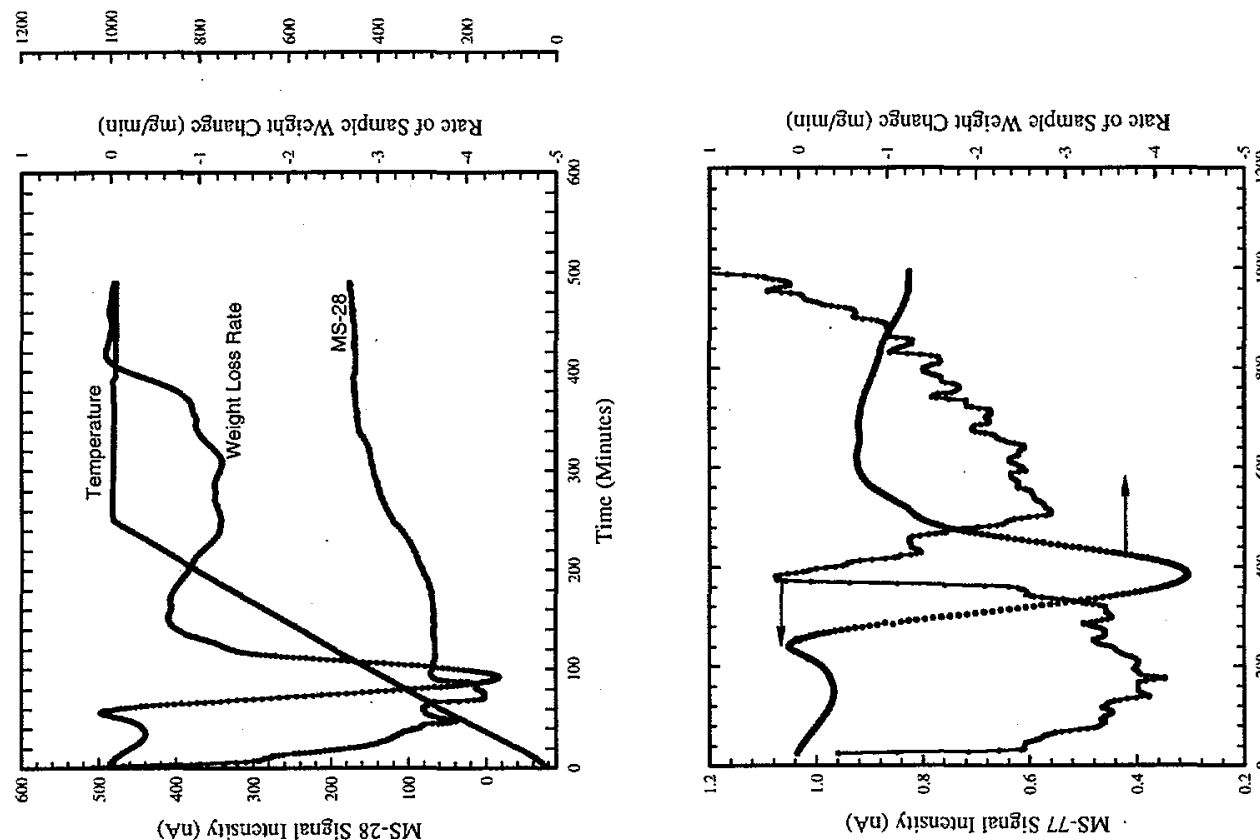

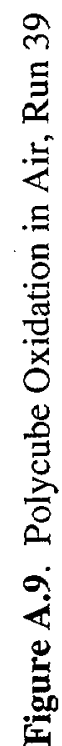
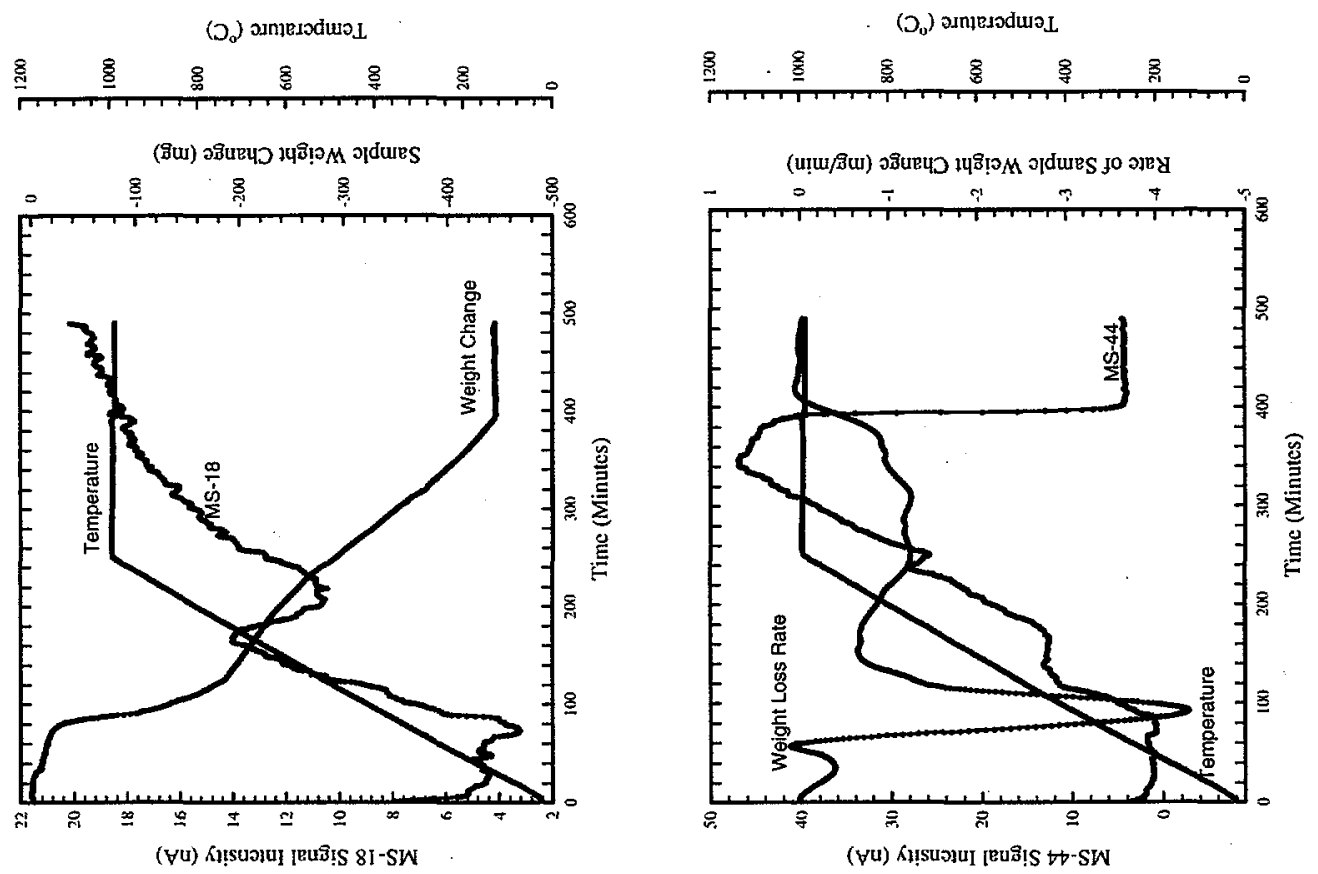

A. 9 

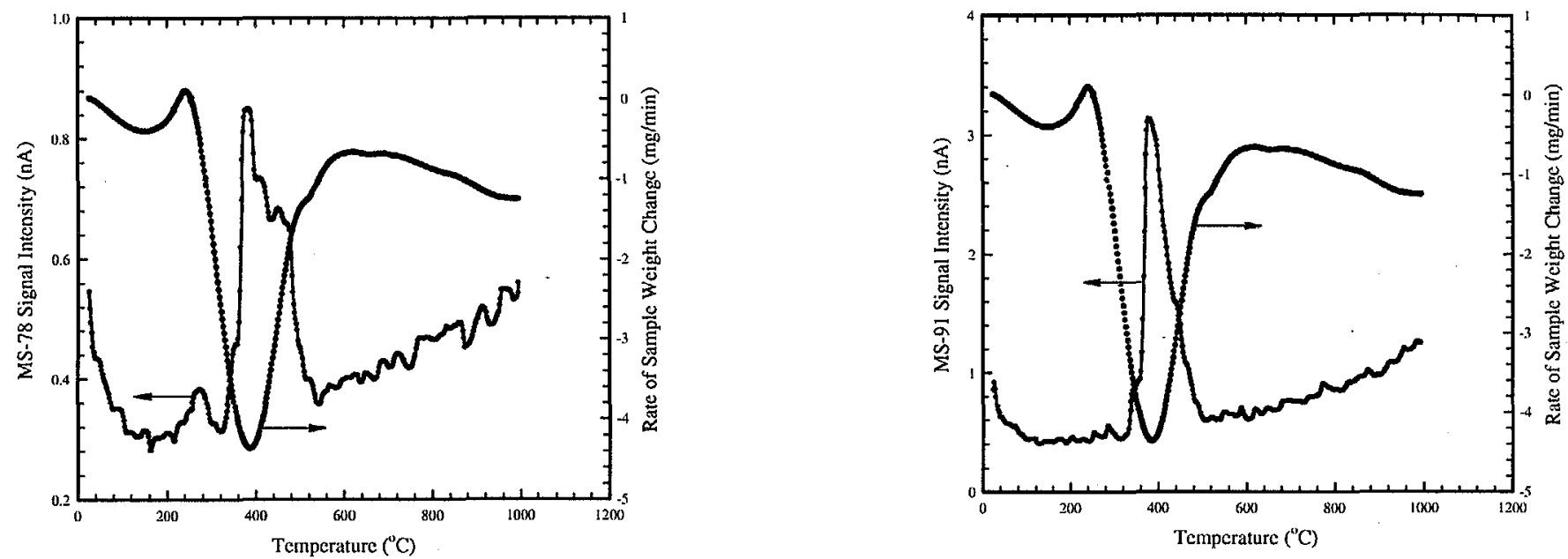

$\stackrel{?}{0}$
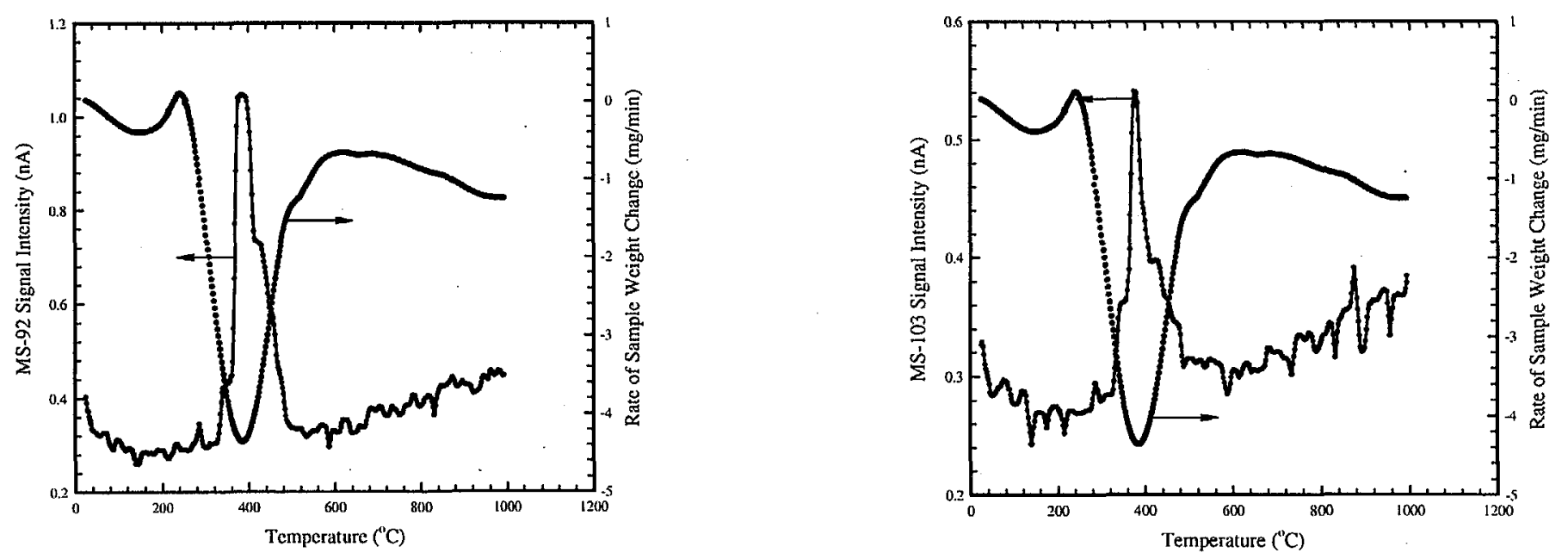

Figure A.10. Run 39 Cont'd 

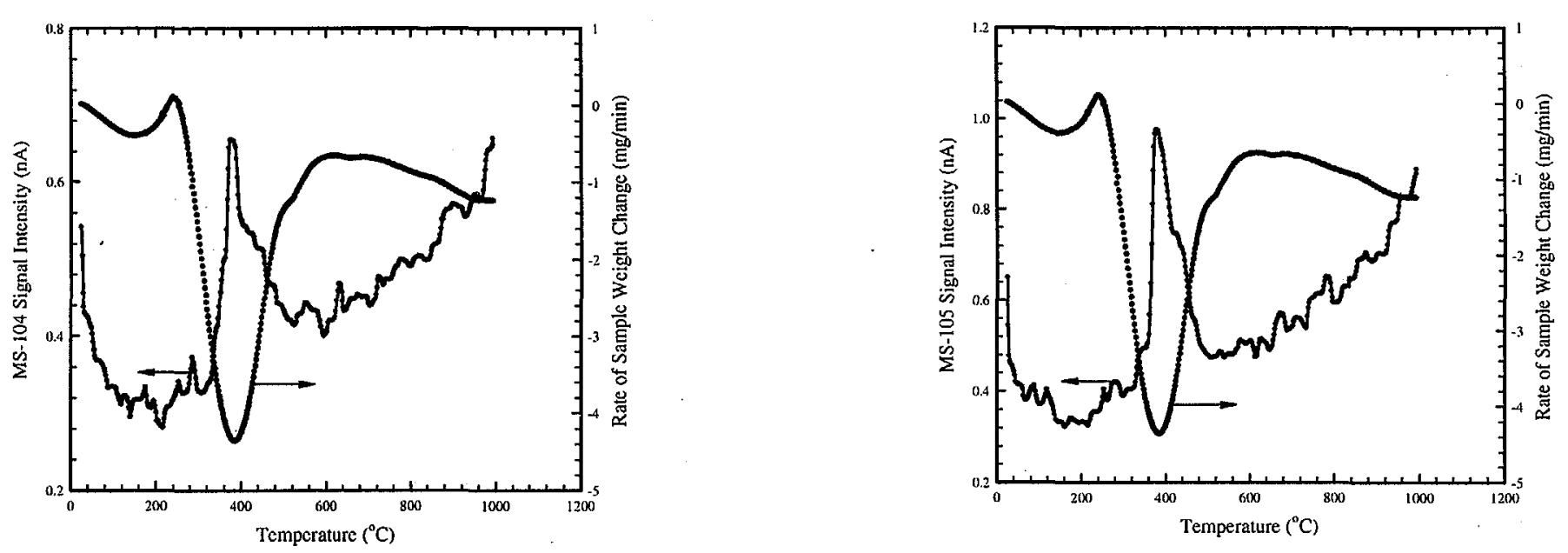

$\stackrel{D}{=}$
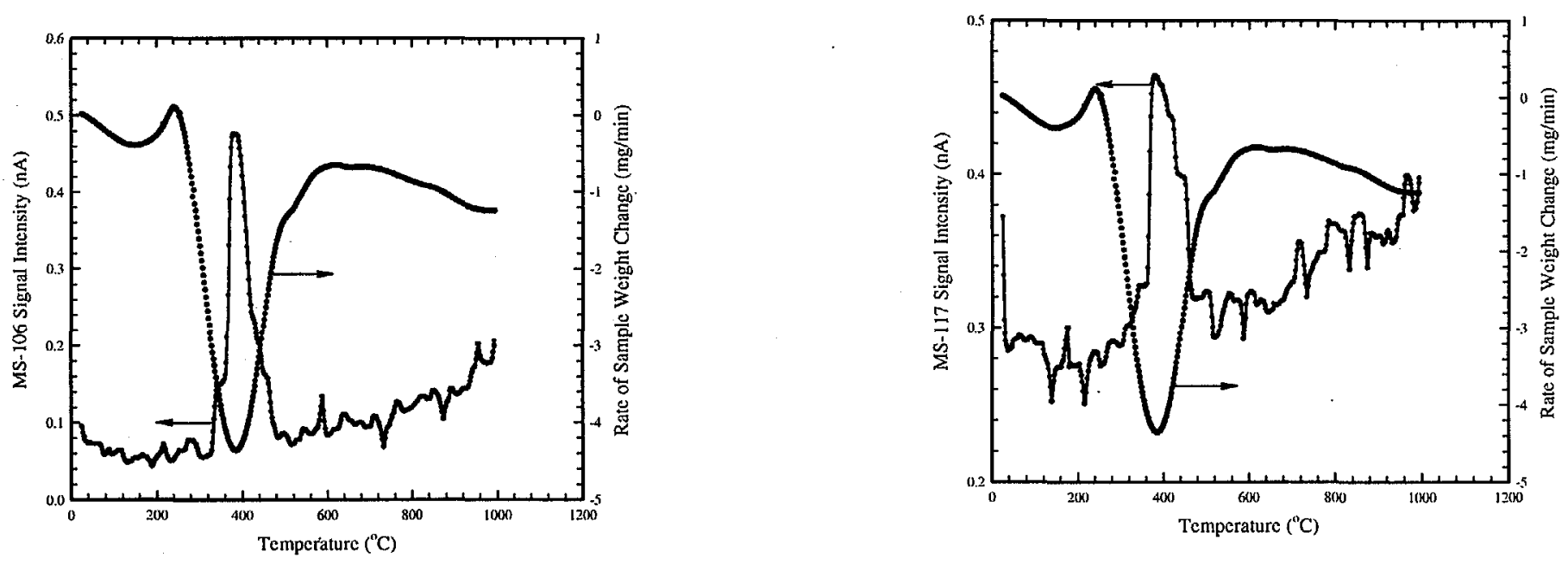

Figure A.11. Run 39 Cont'd 

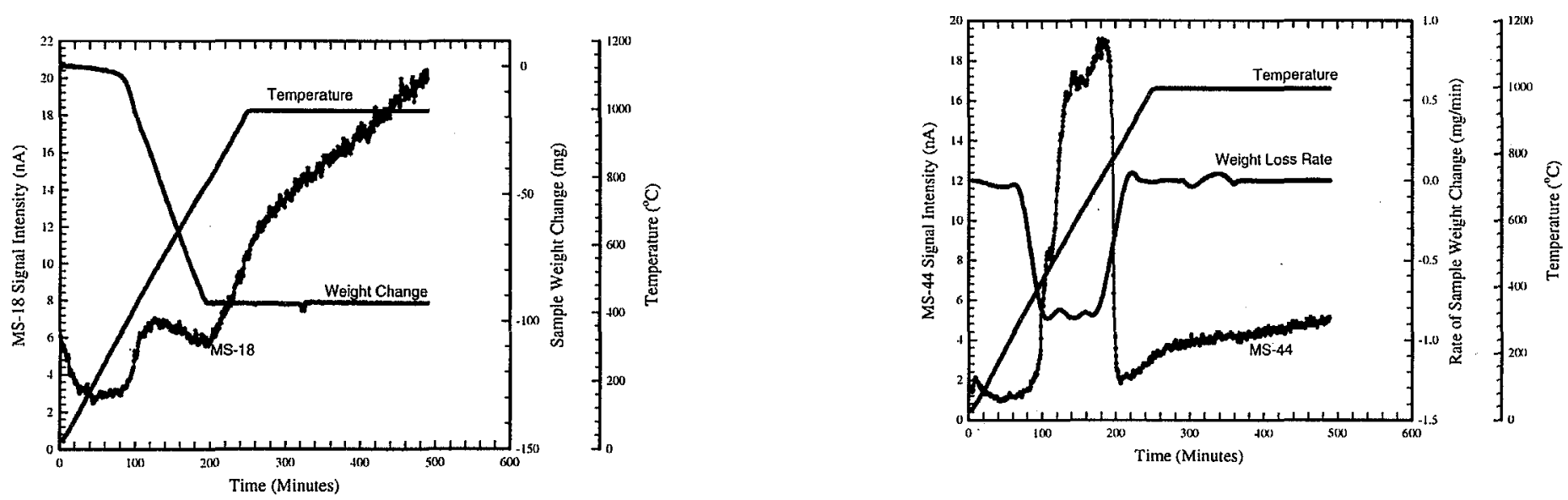

$\frac{p}{N}$
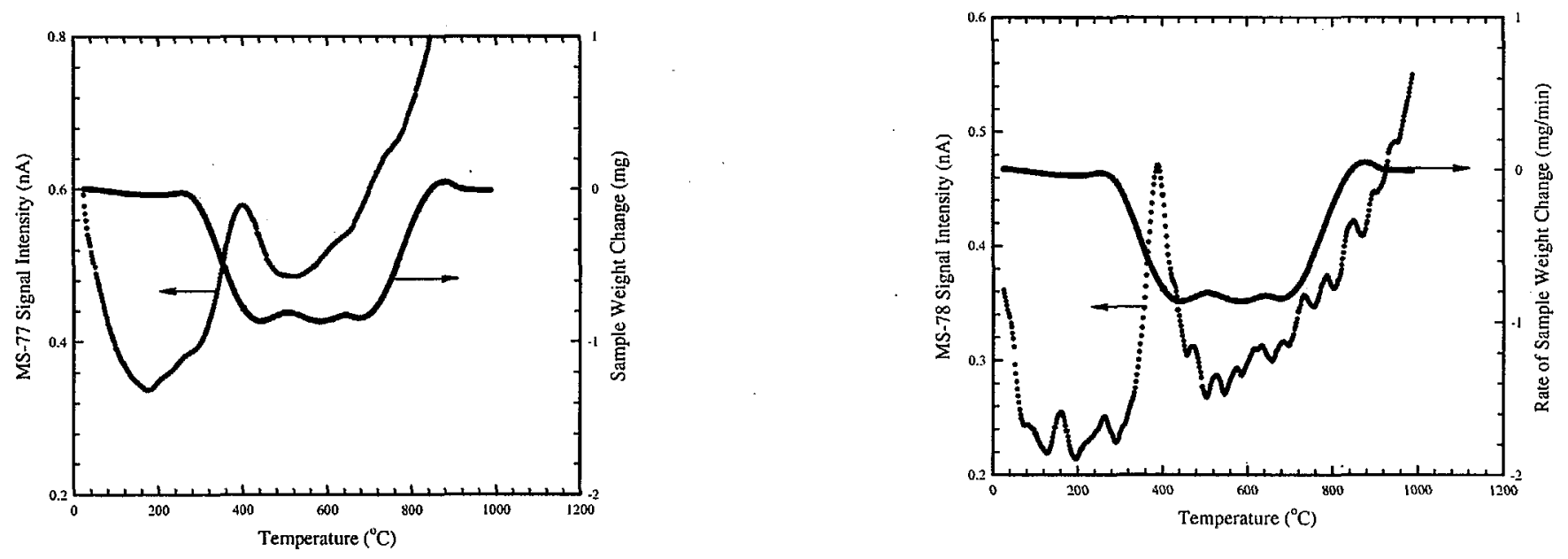

Figure A.12. Polycube Oxidation in Air, Run 40 

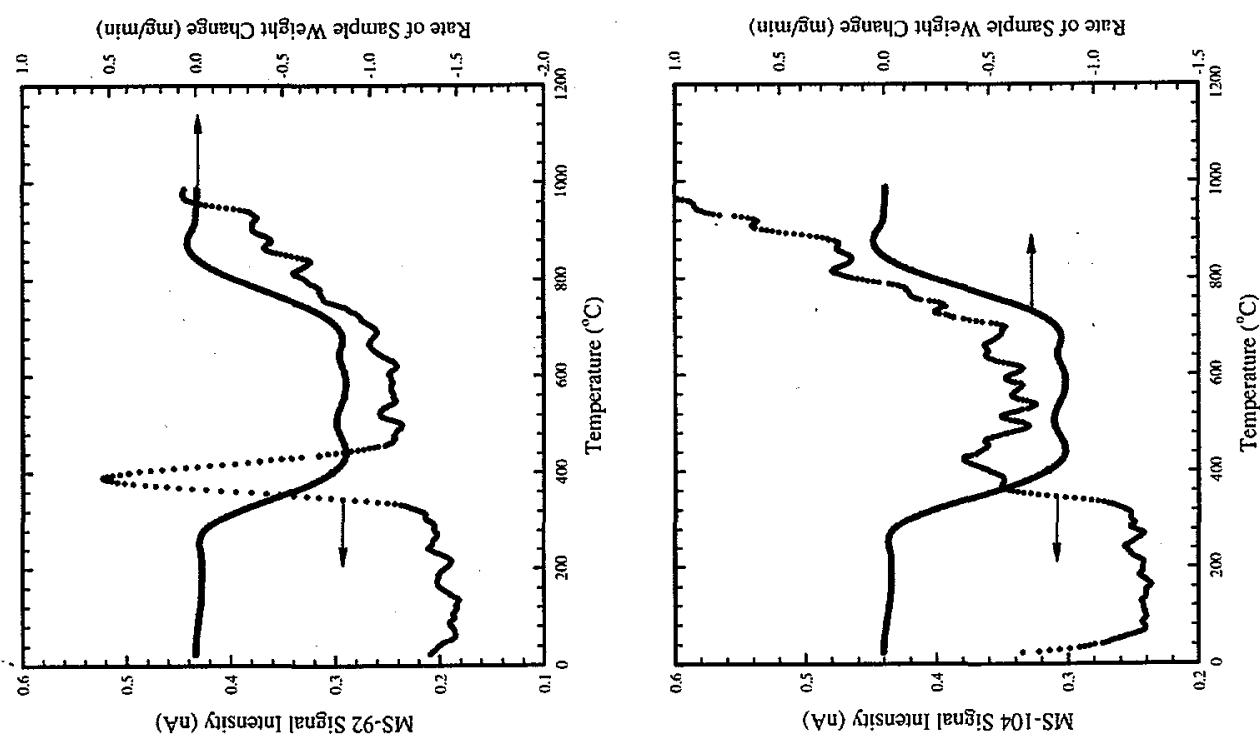

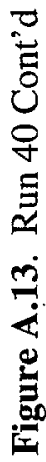
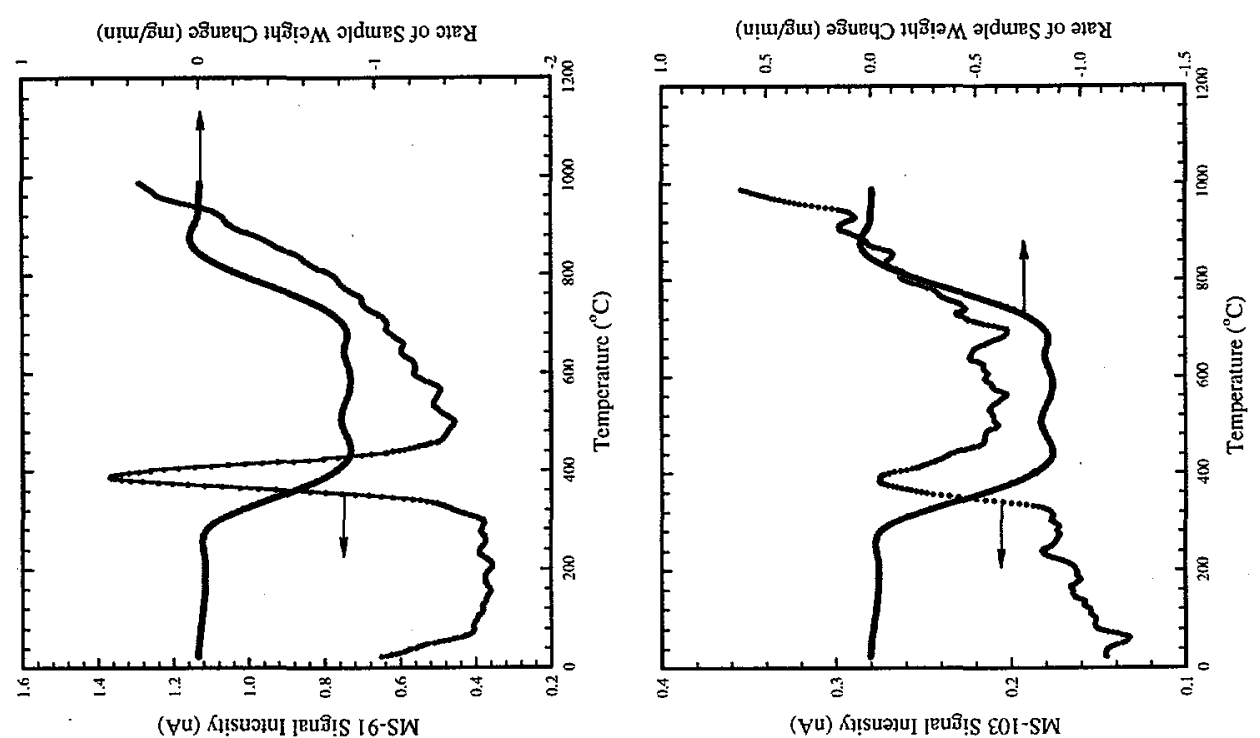

A.13 

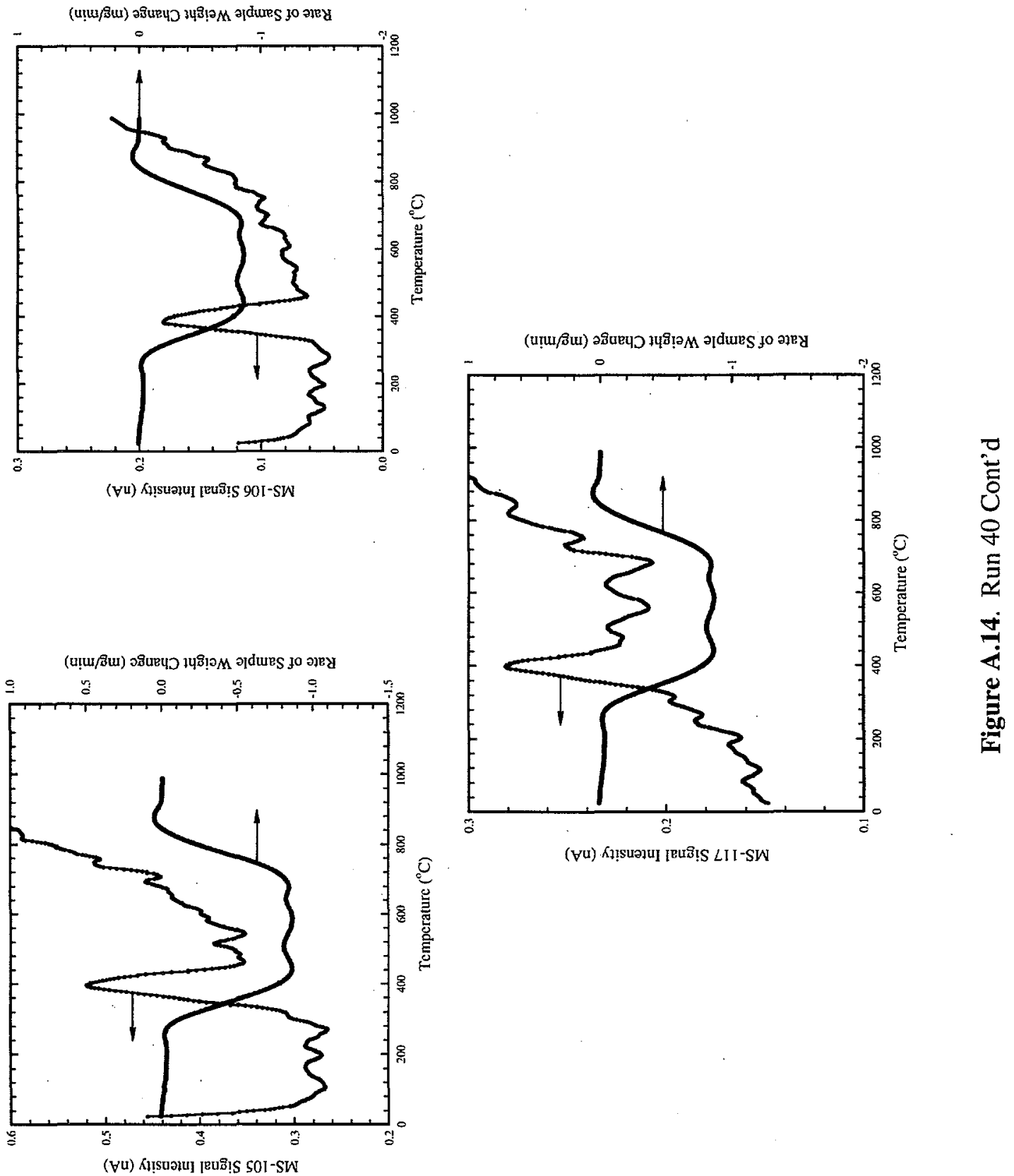

A. 14 

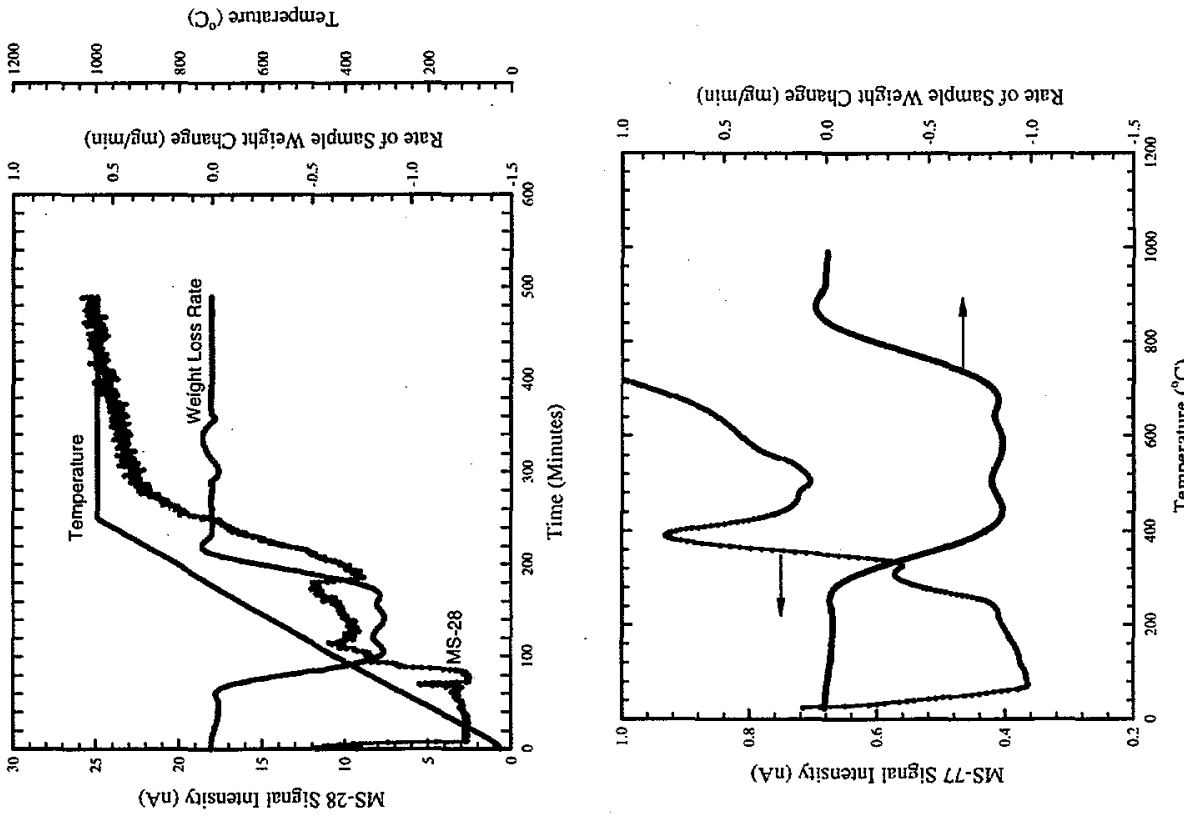

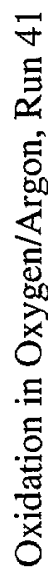
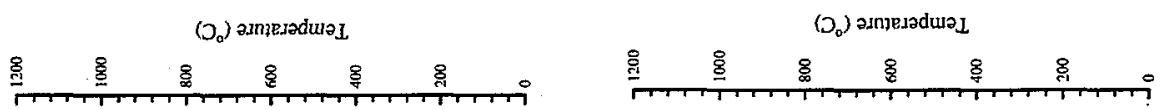

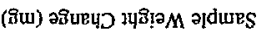

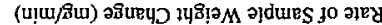
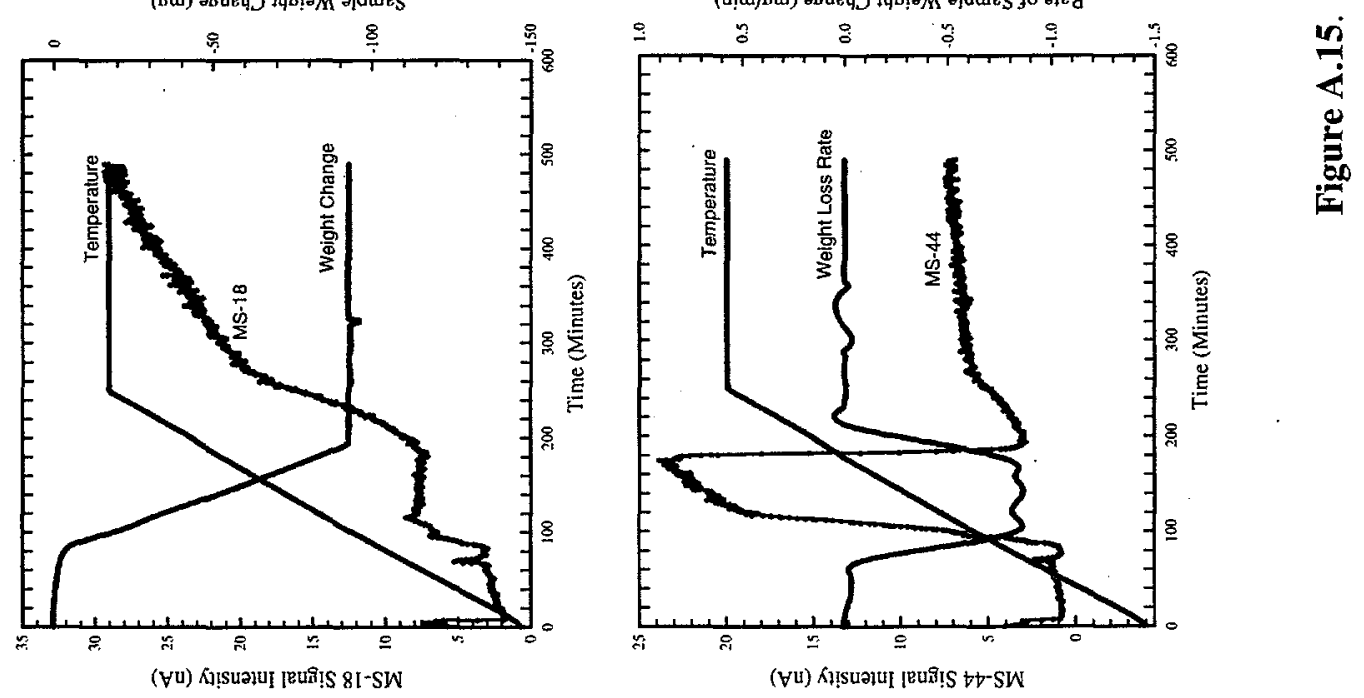

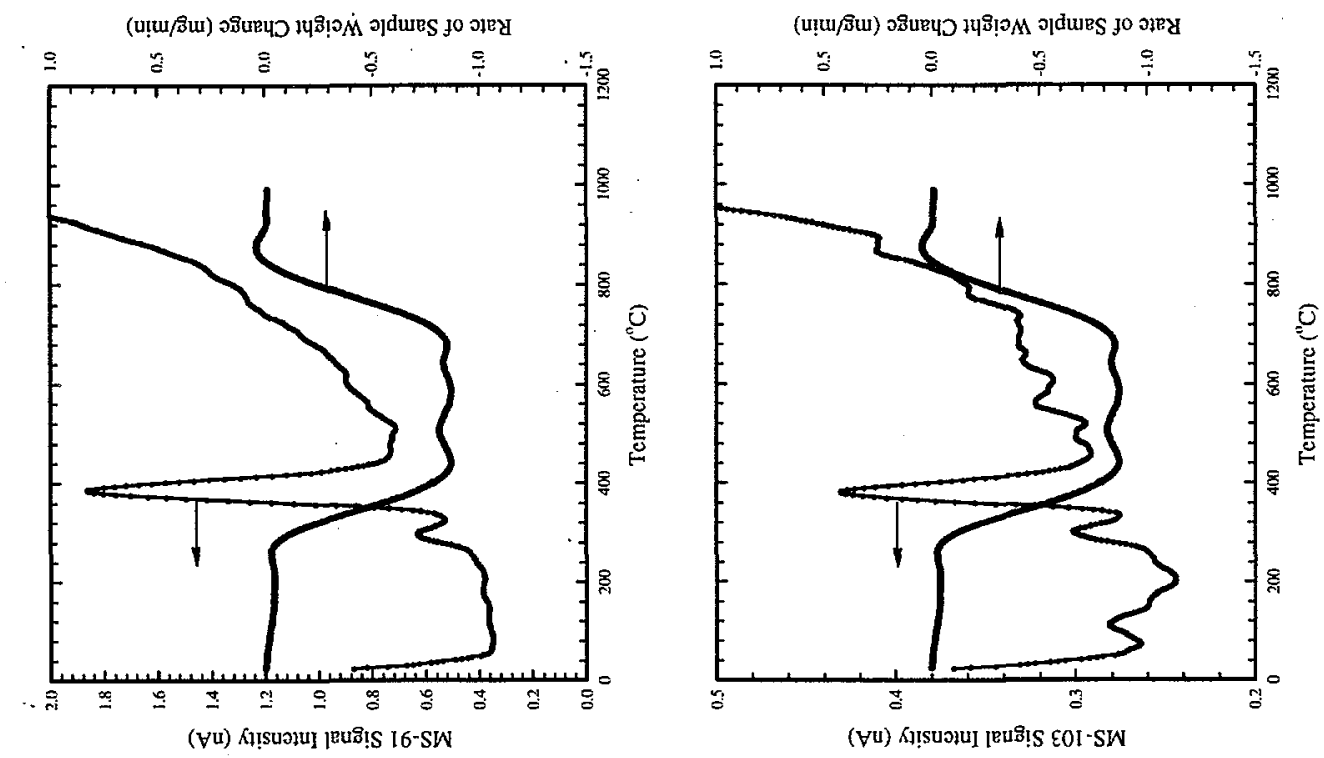

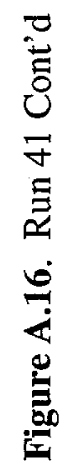
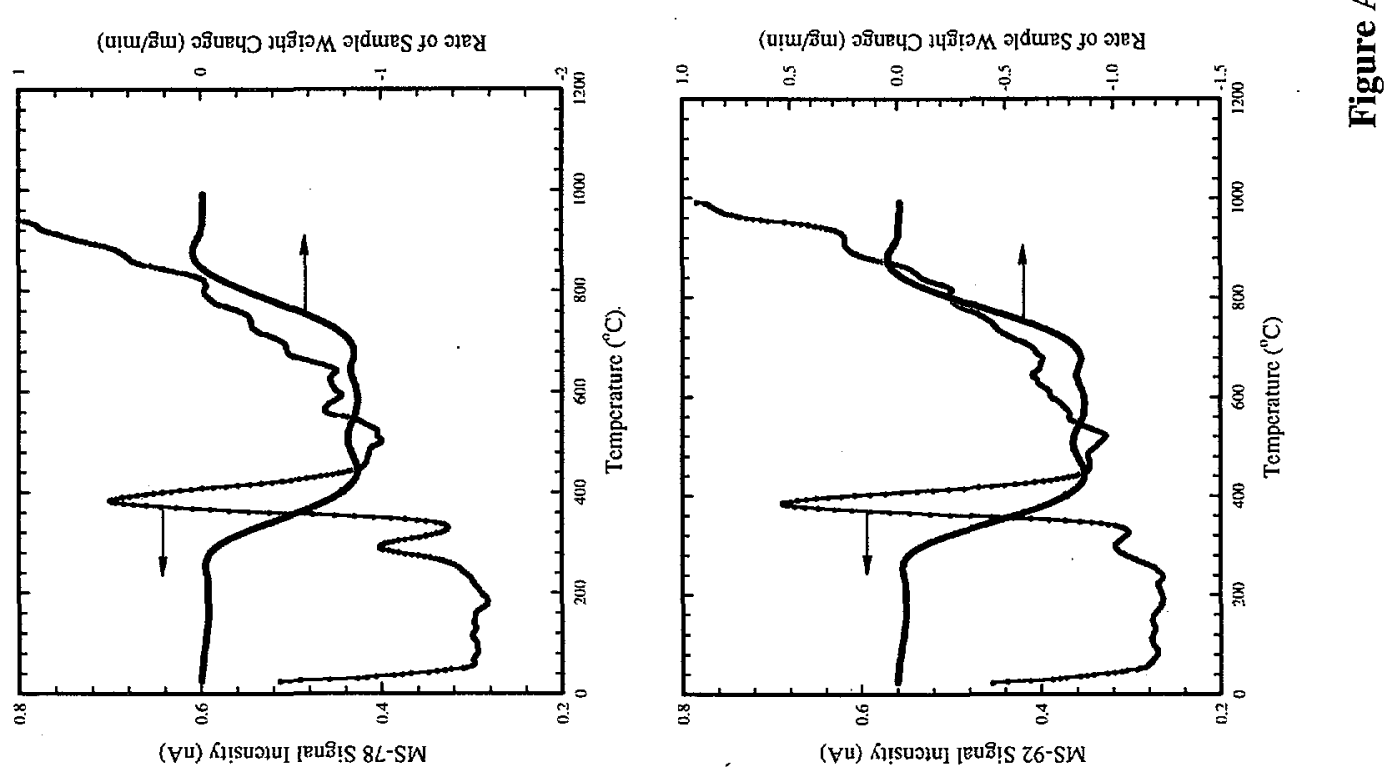

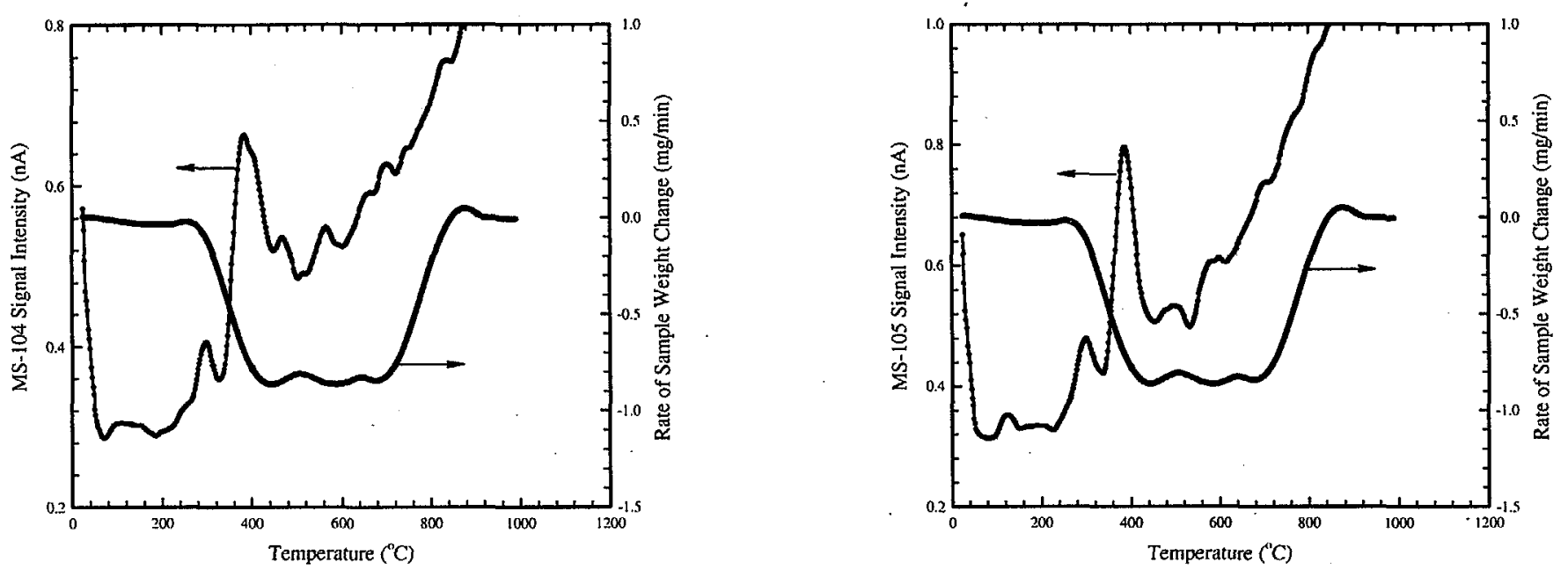

$\stackrel{D}{v}$
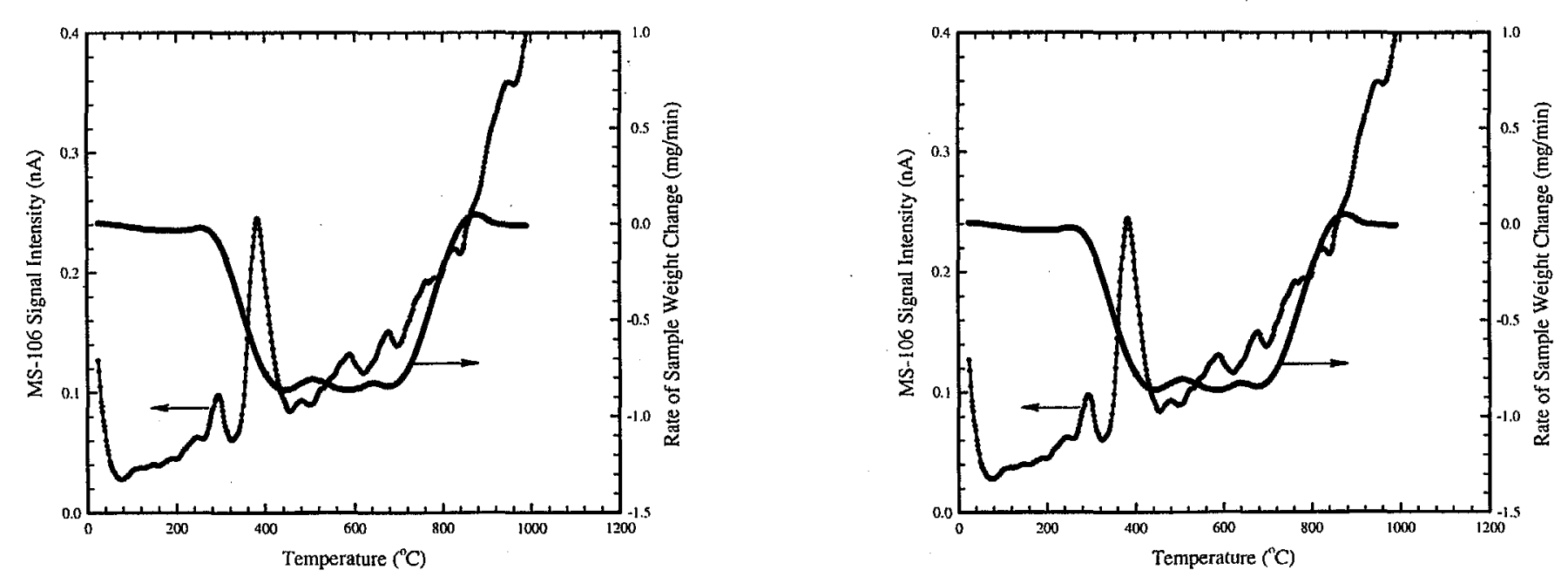

Figure A.17. Run 41 Cont'd 

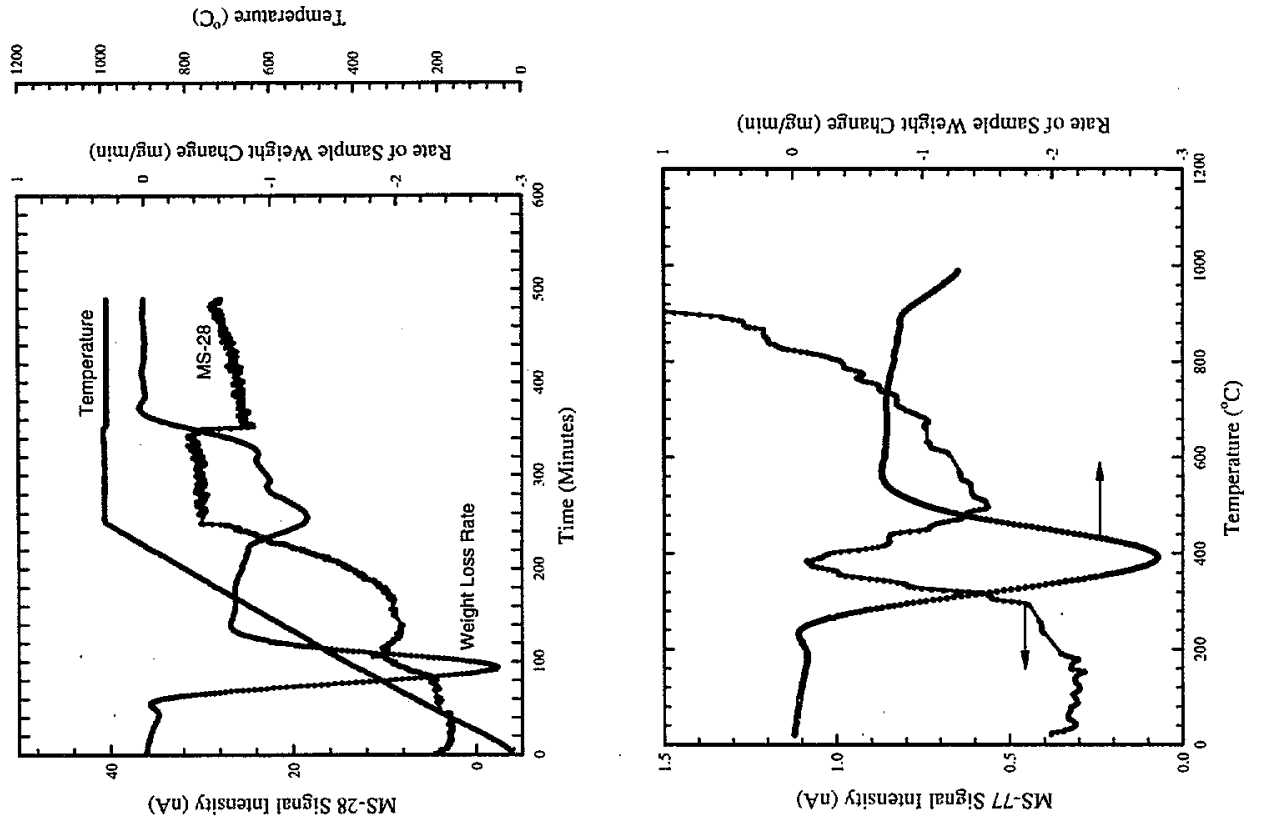

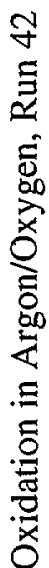
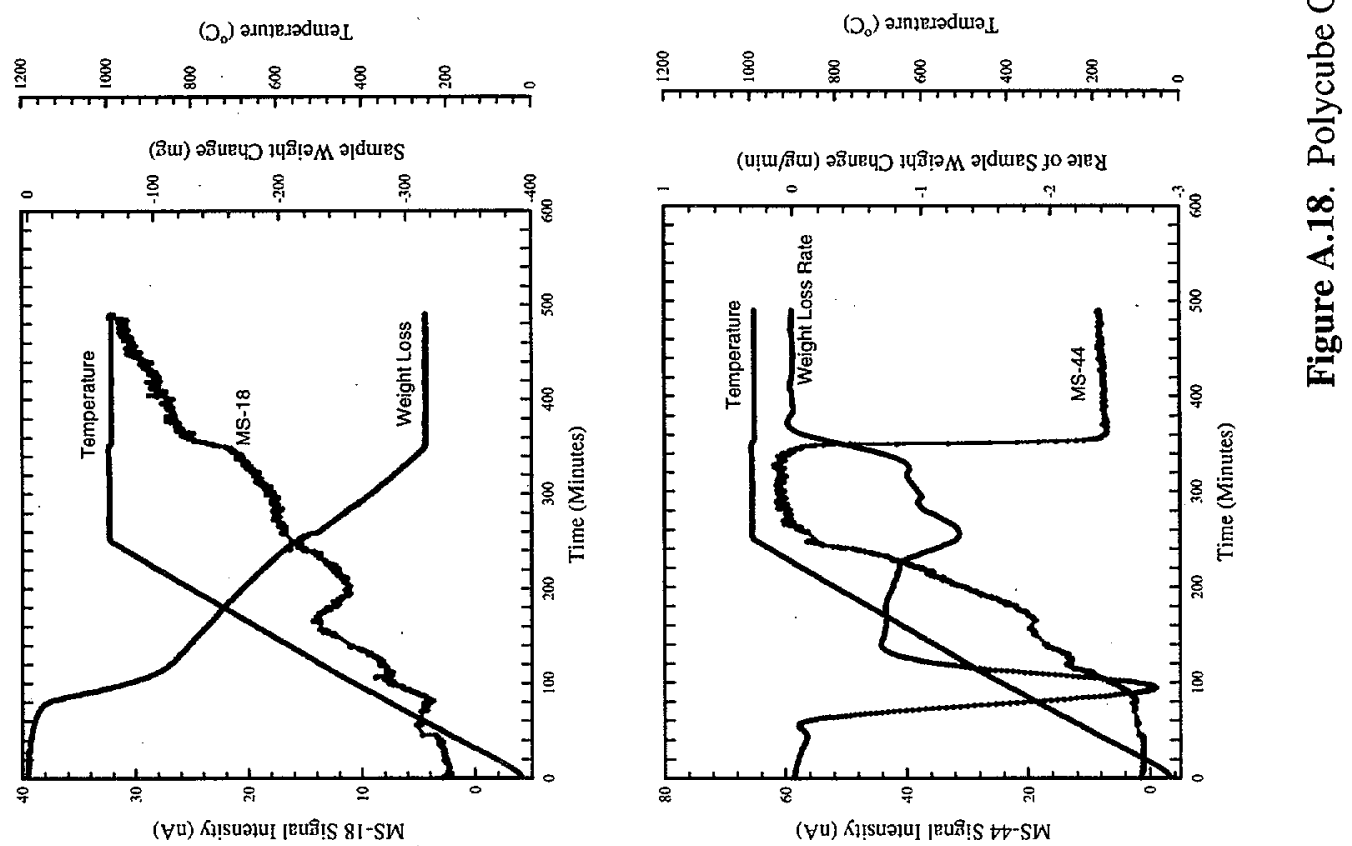

A.18 


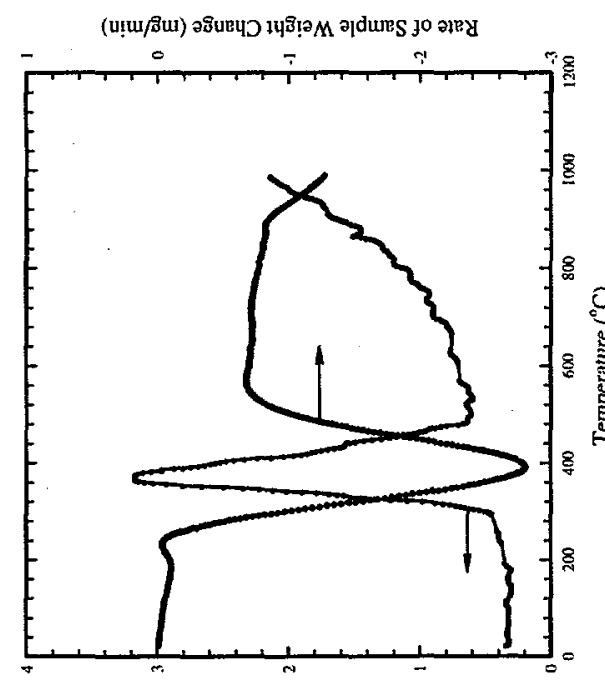

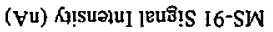

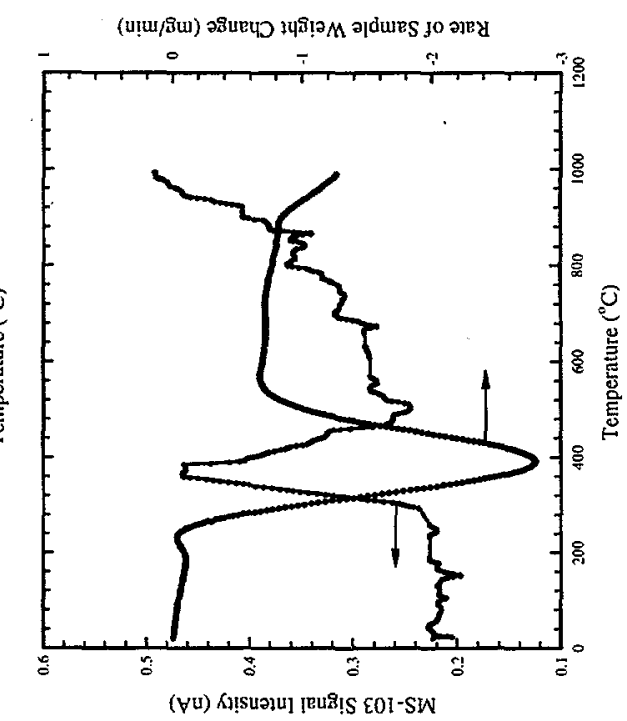

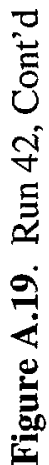

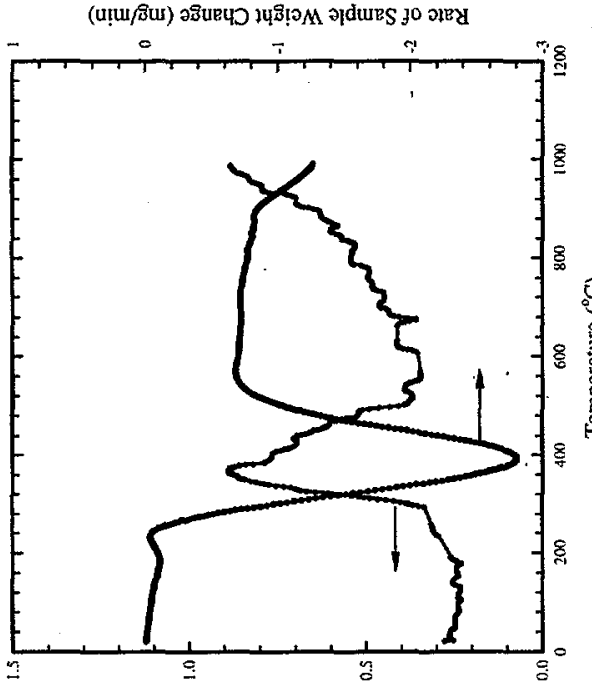

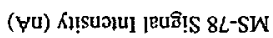

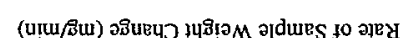

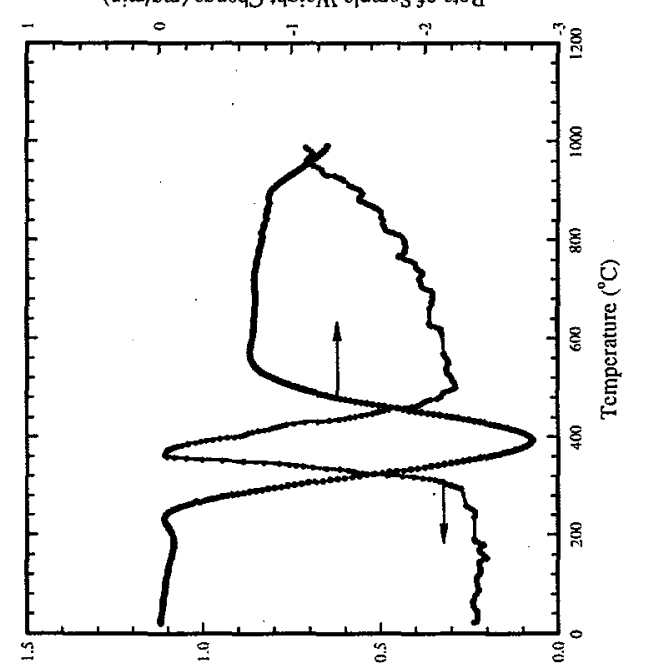

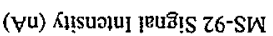



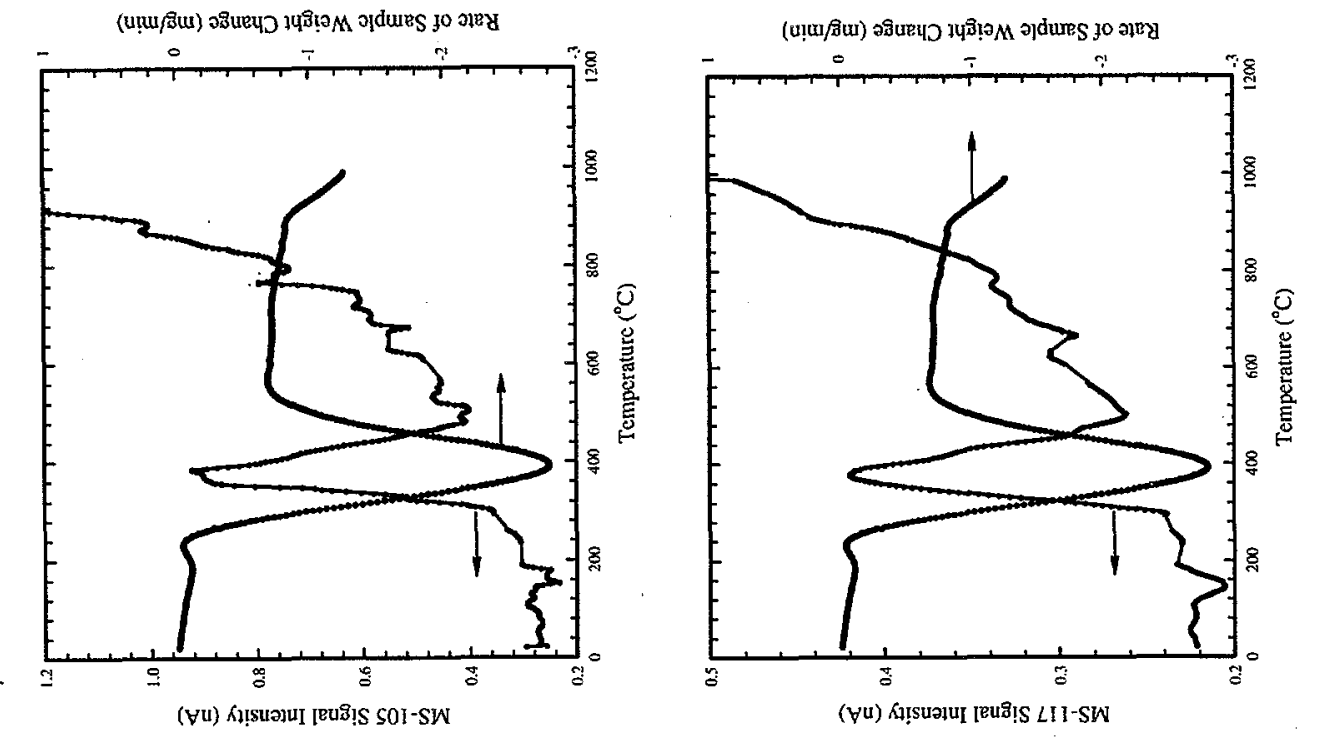

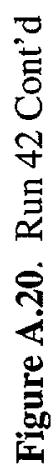
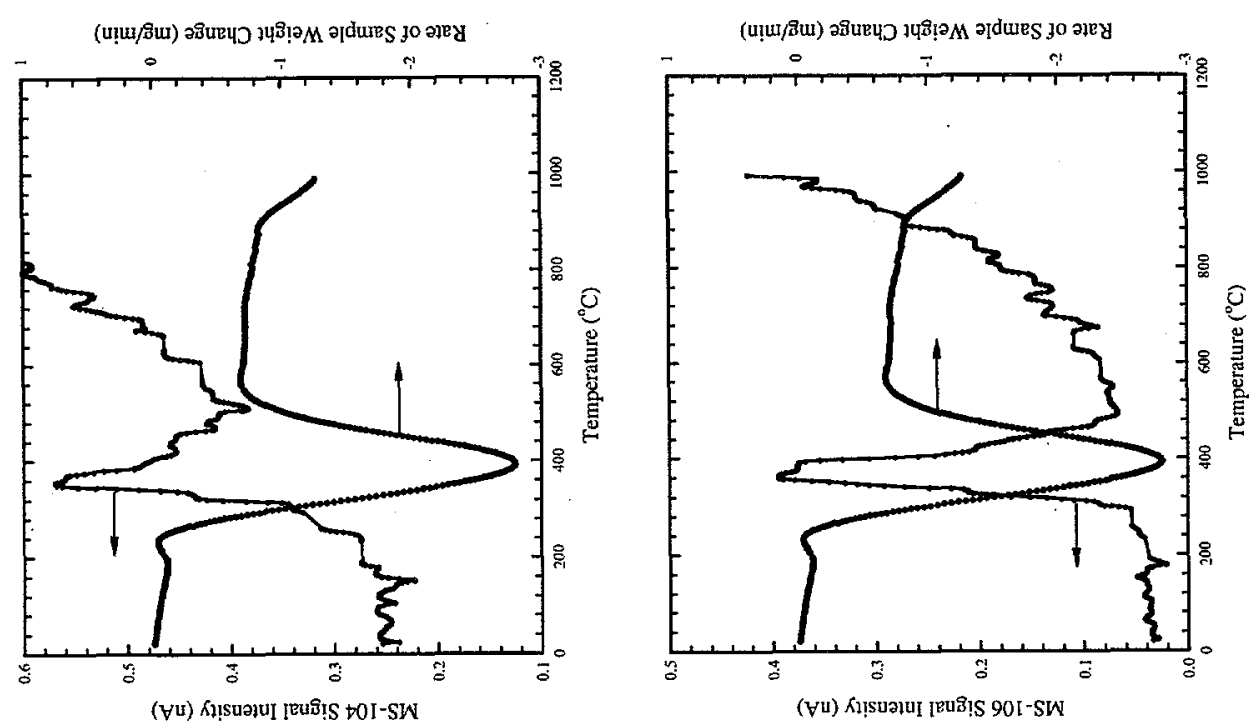

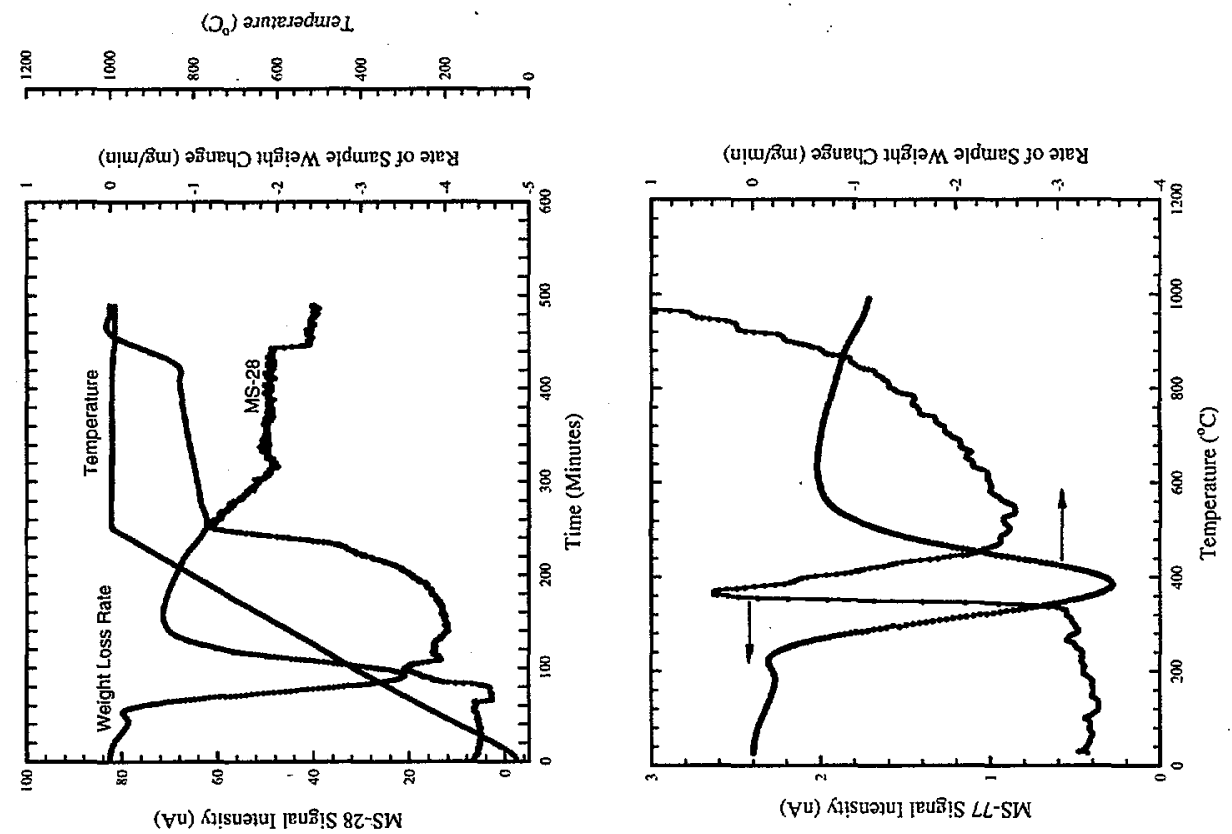

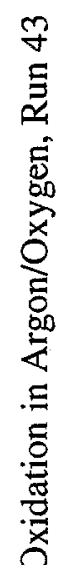

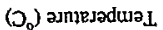
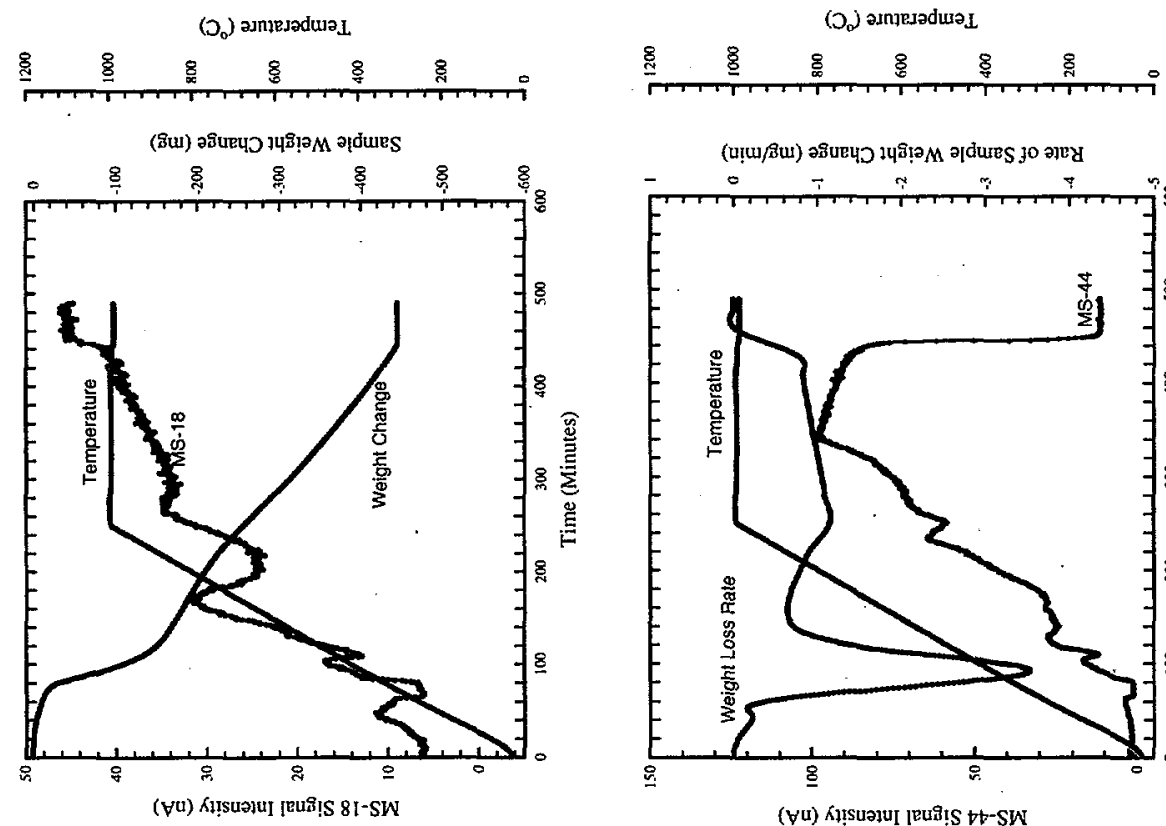

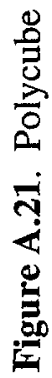



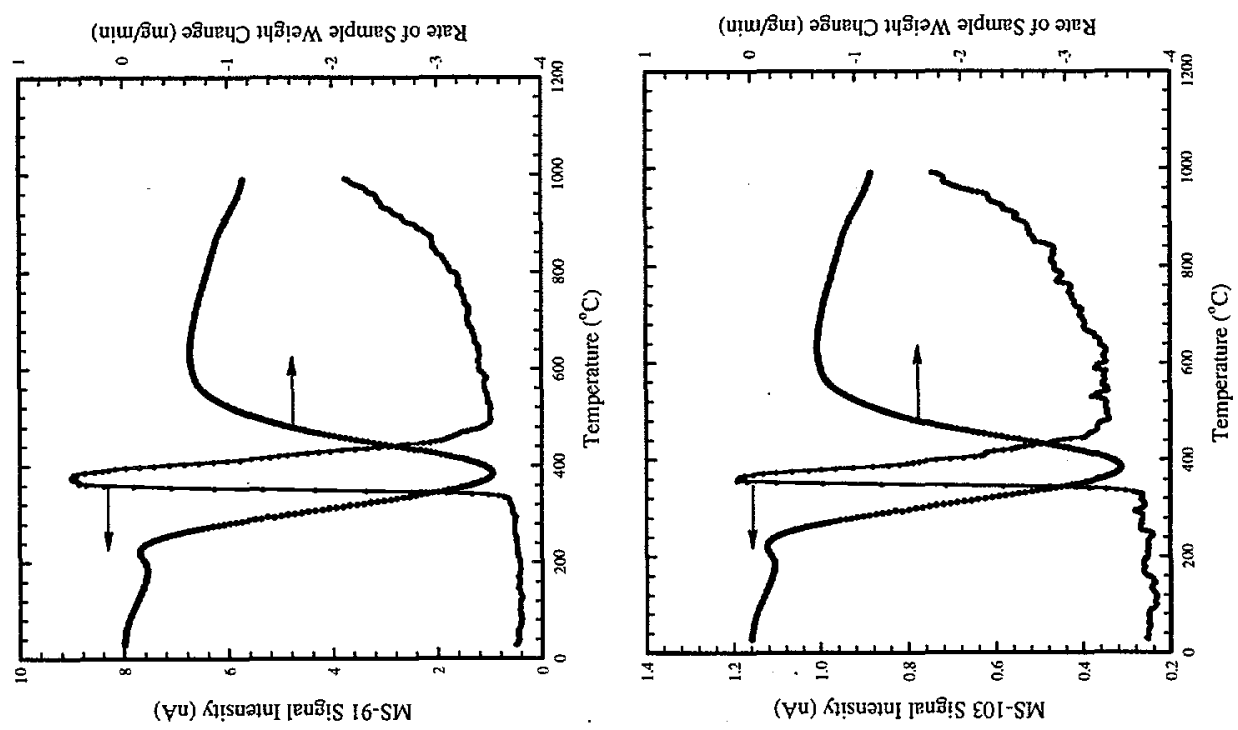

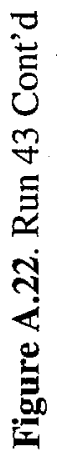
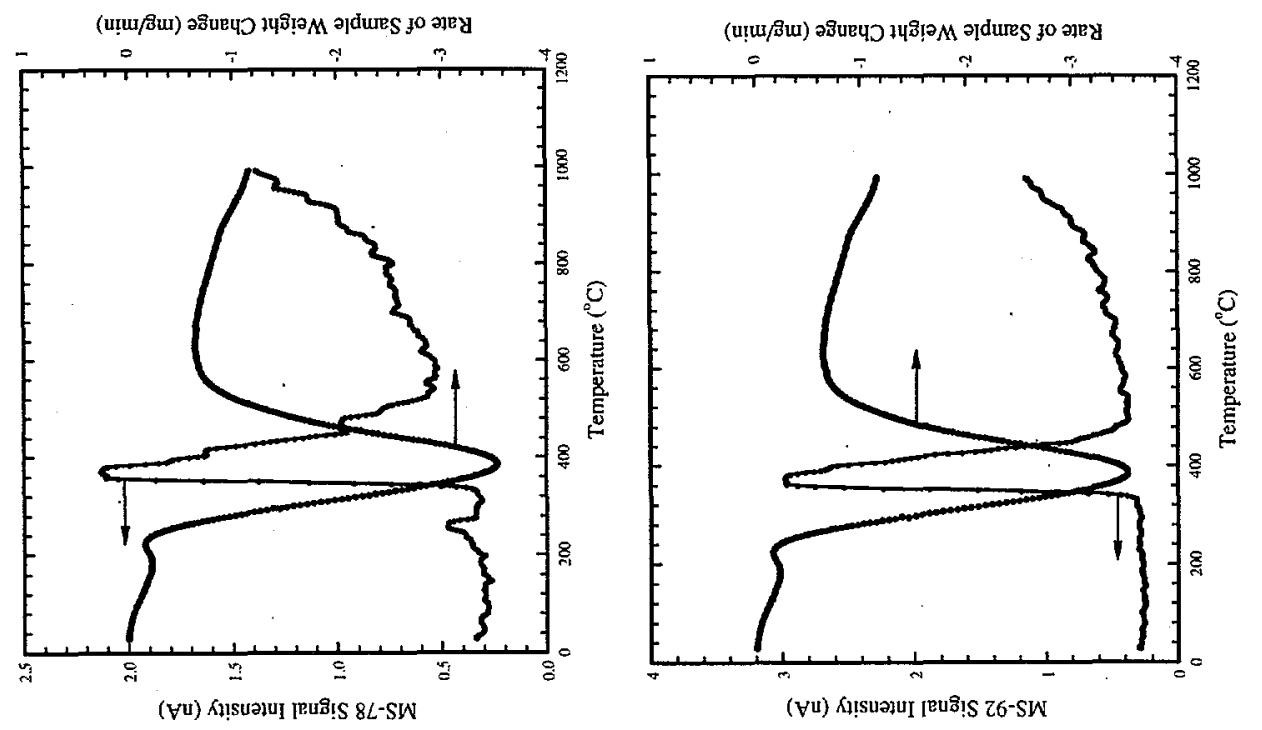

A. 22 

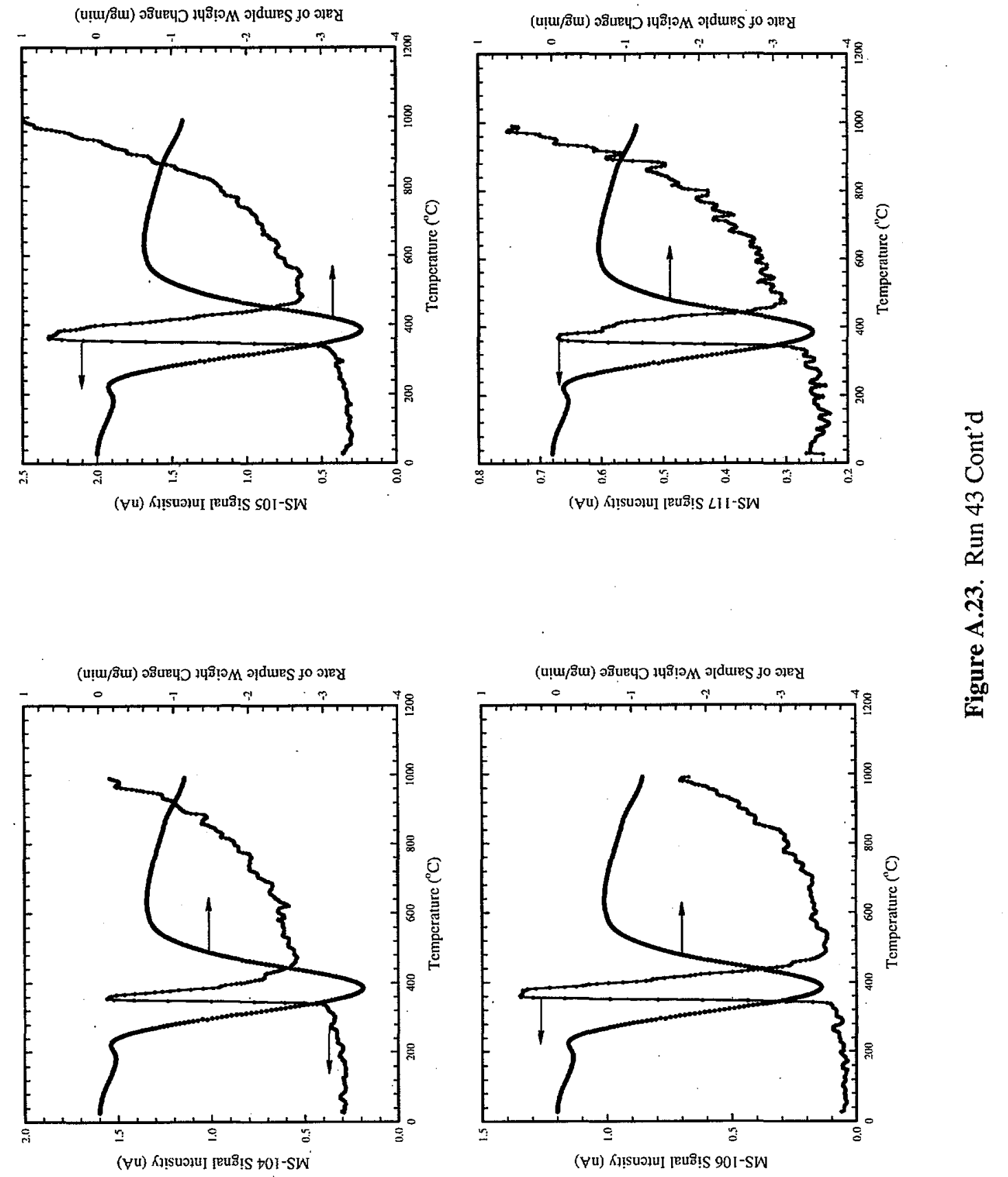

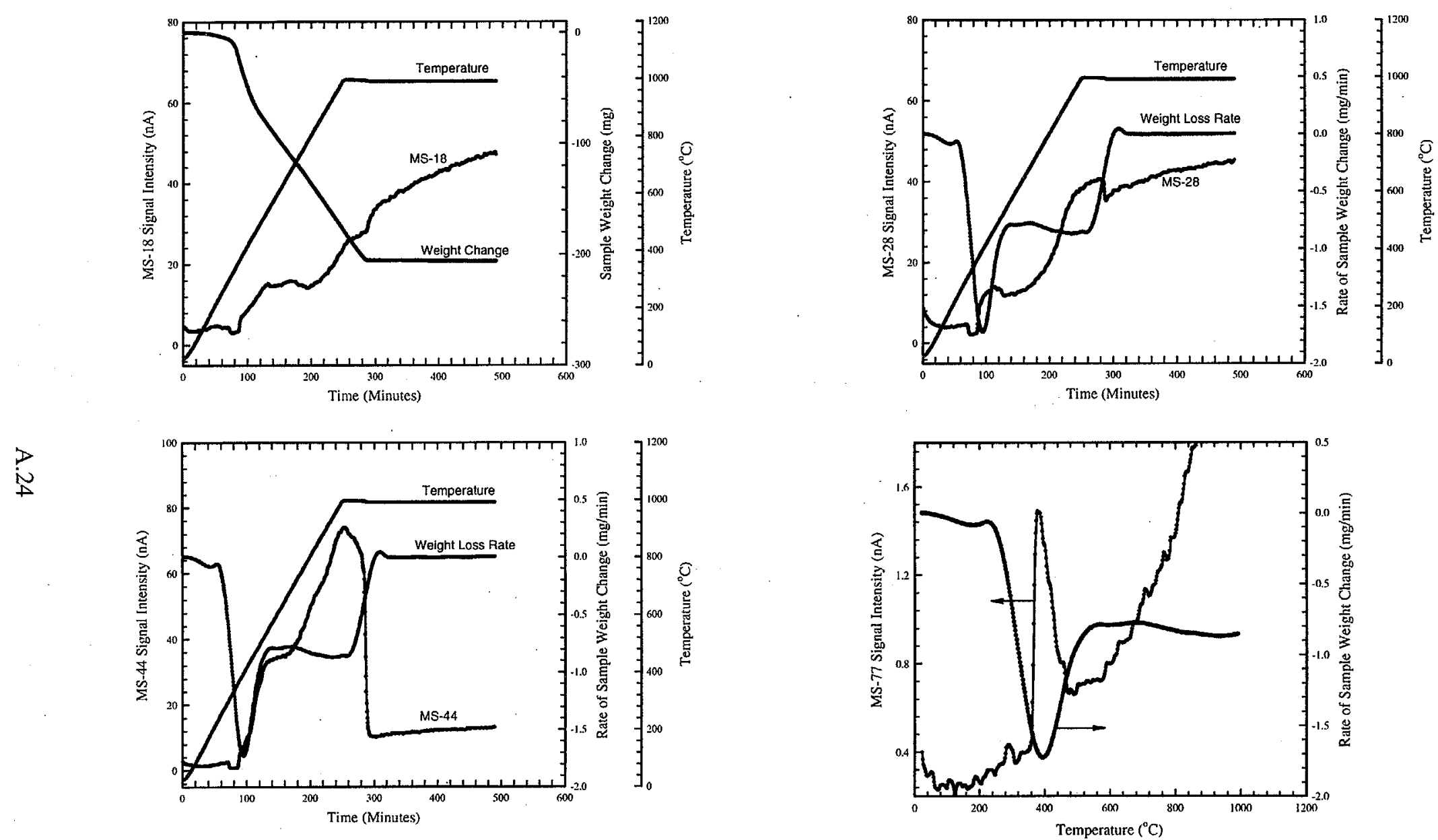

Figure A.24. Polycube Oxidation in Argon/Oxygen, Run 44 

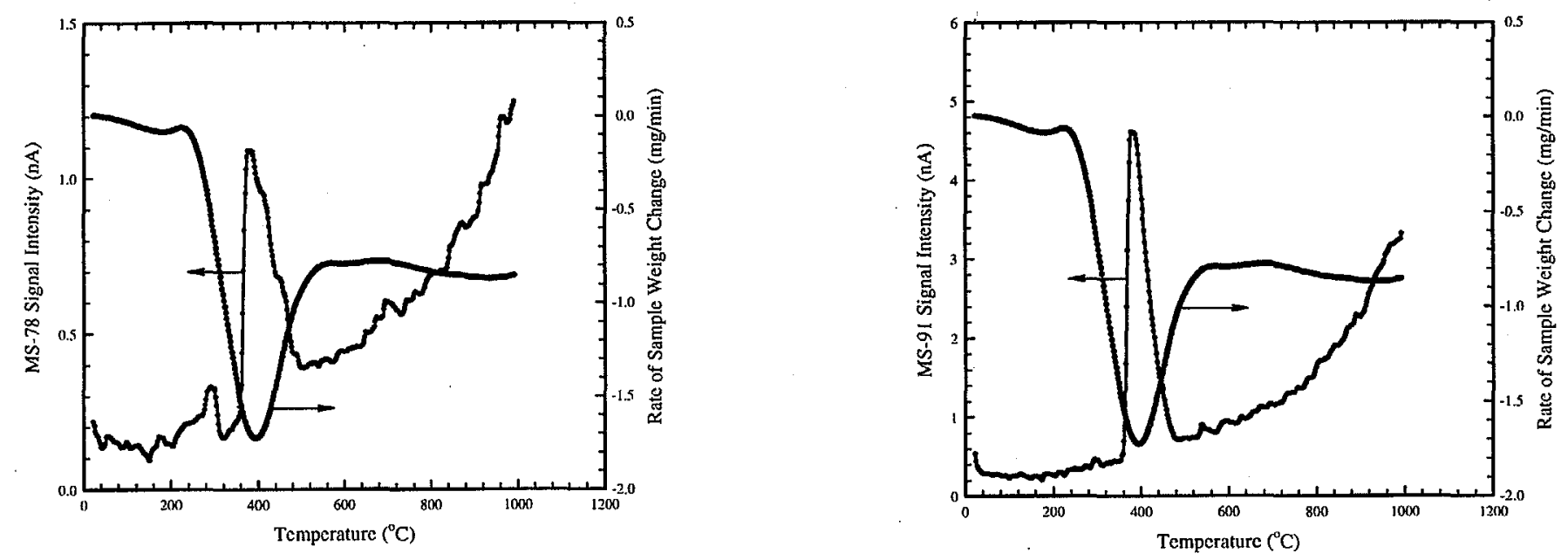

录
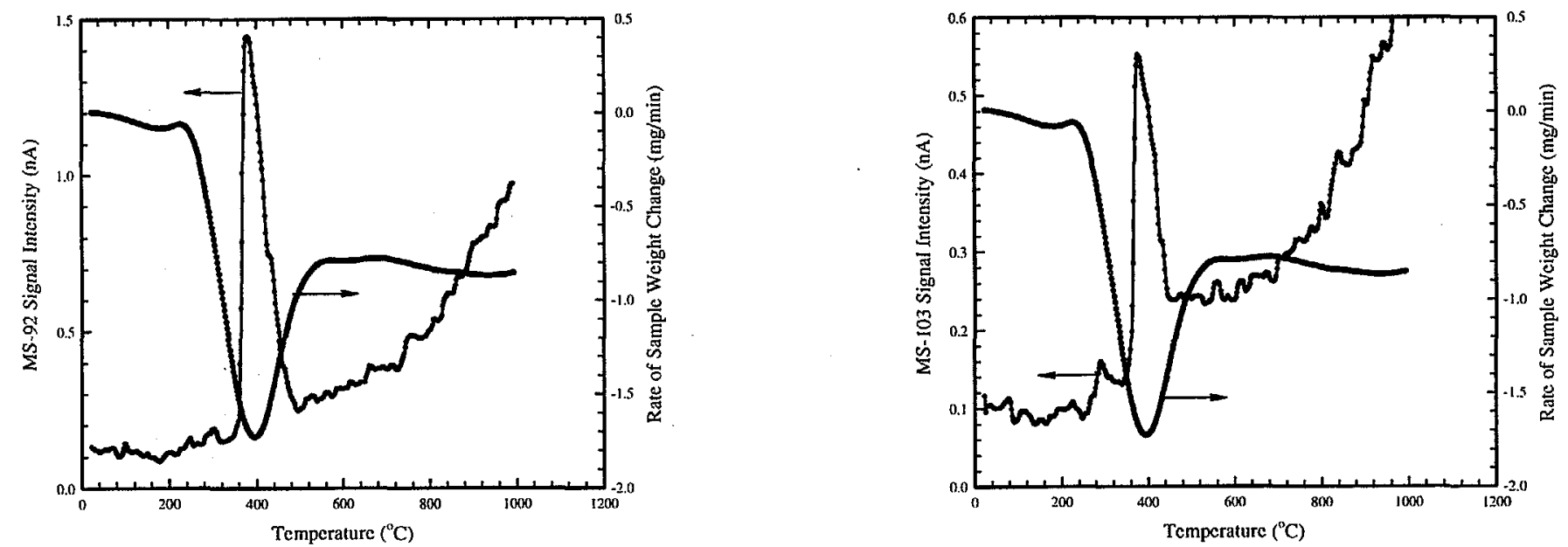

Figure A.25. Run 44 Cont'd 

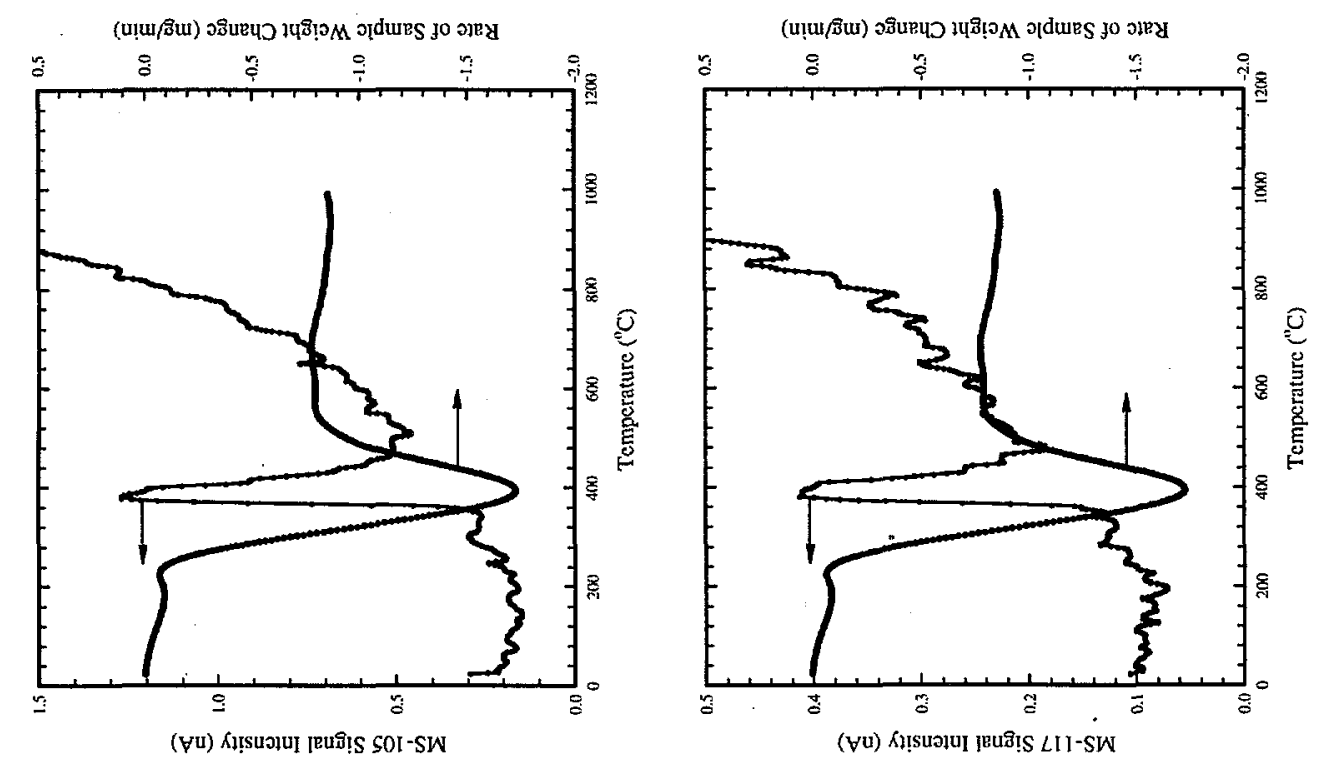

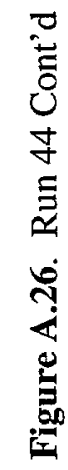
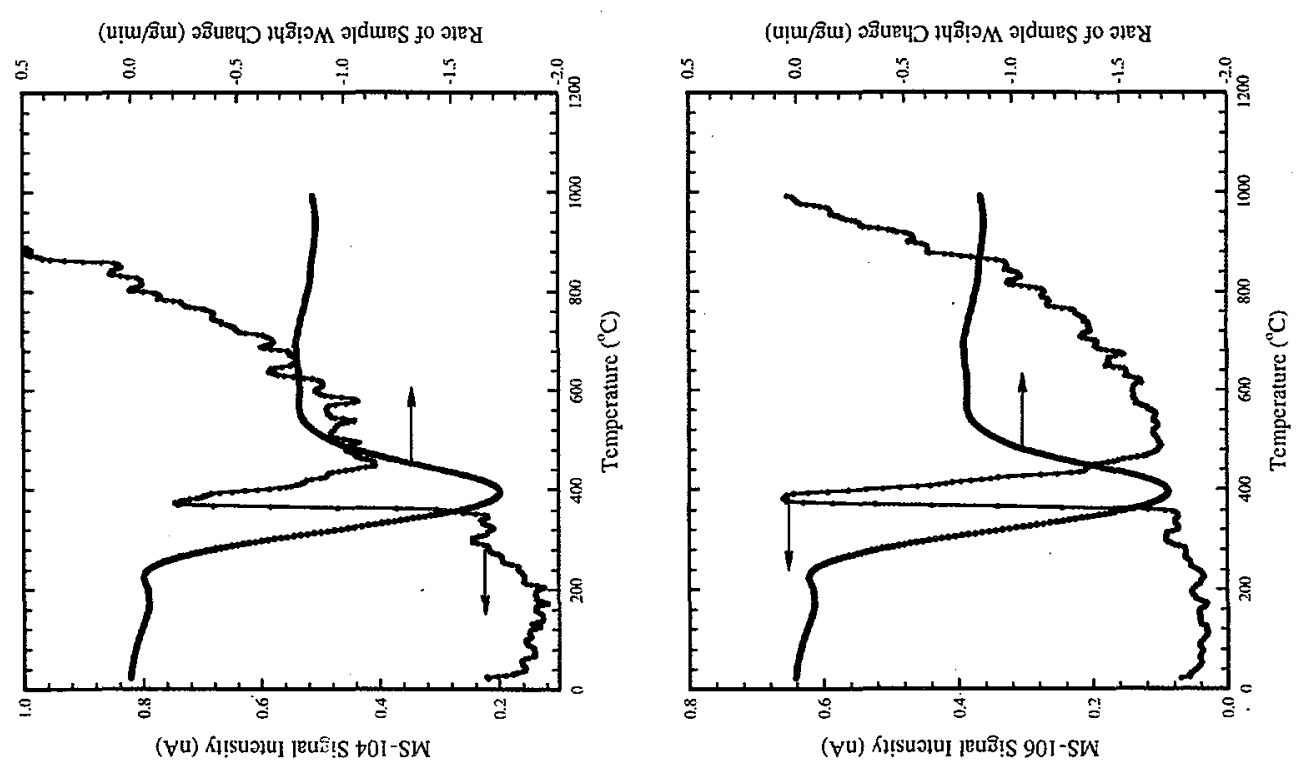

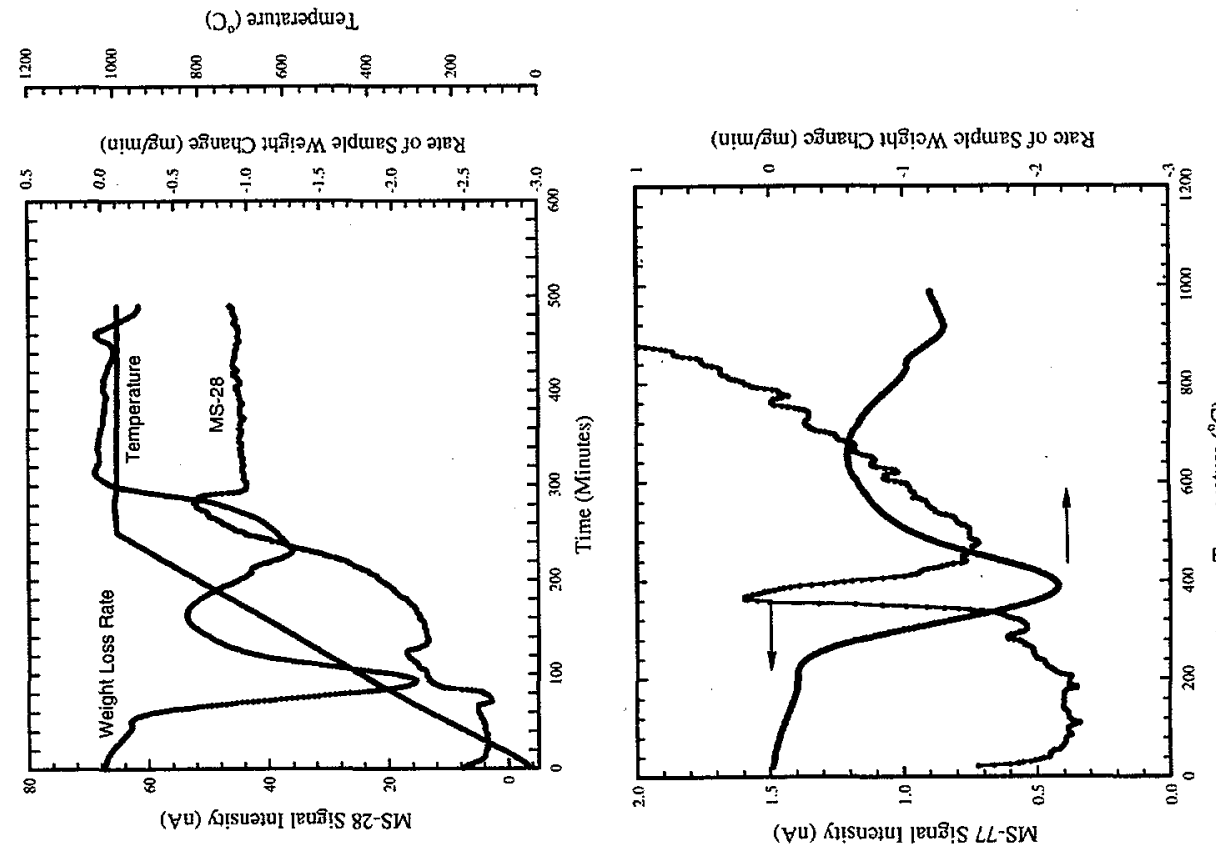

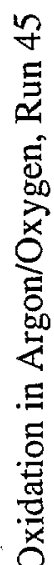
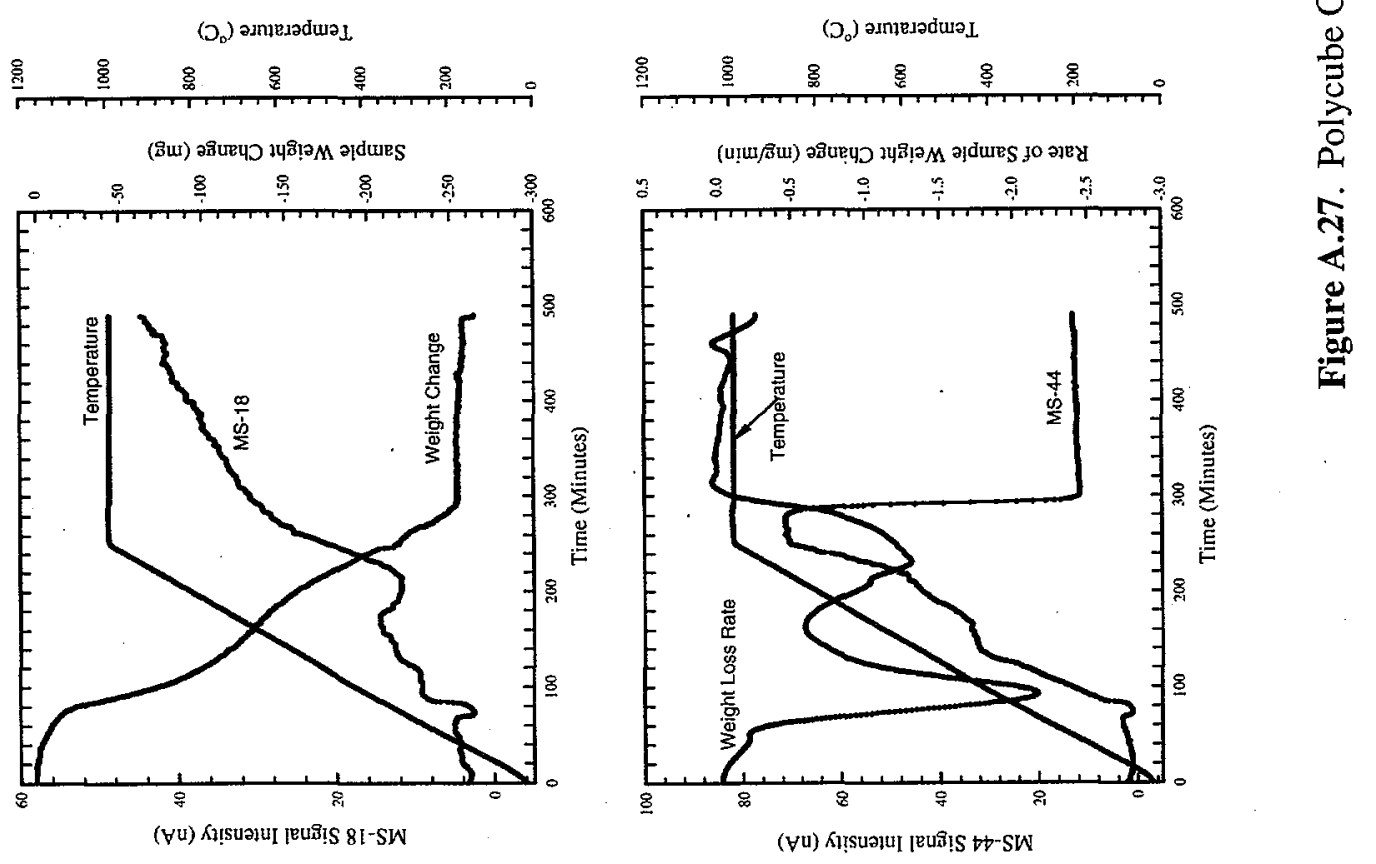


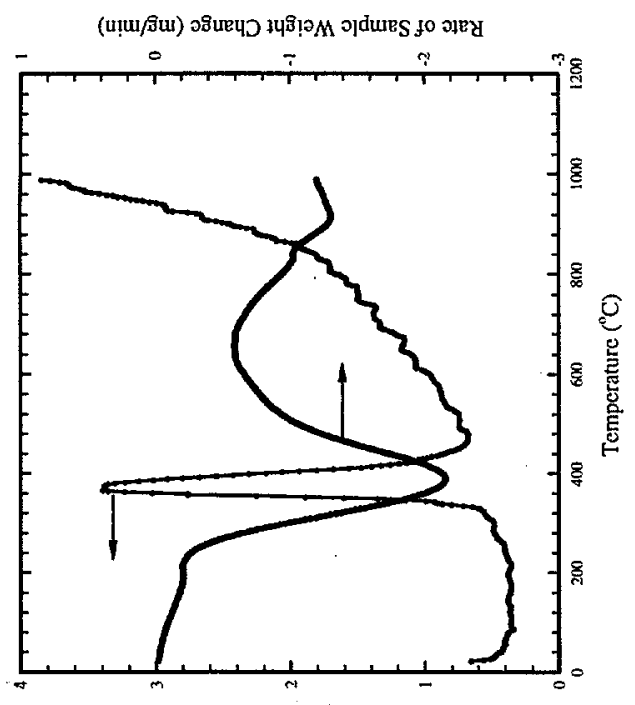

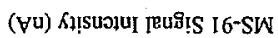

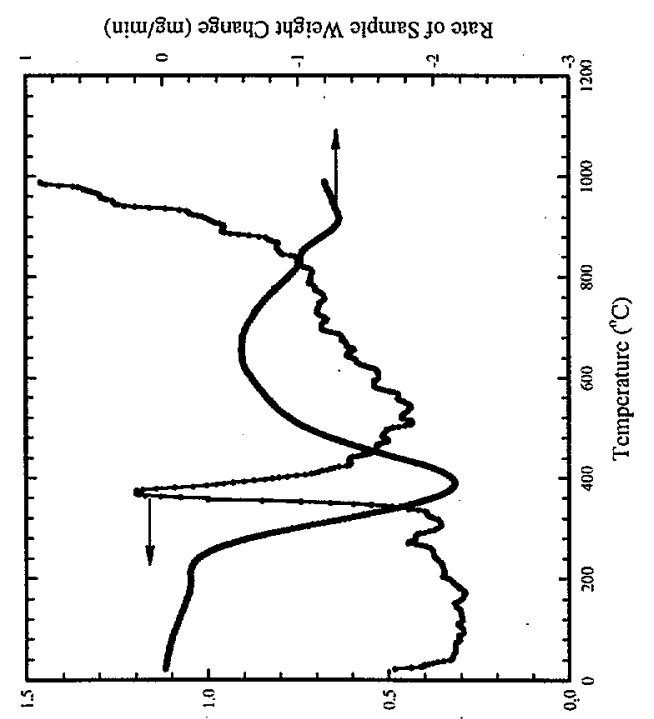

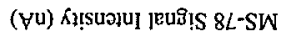

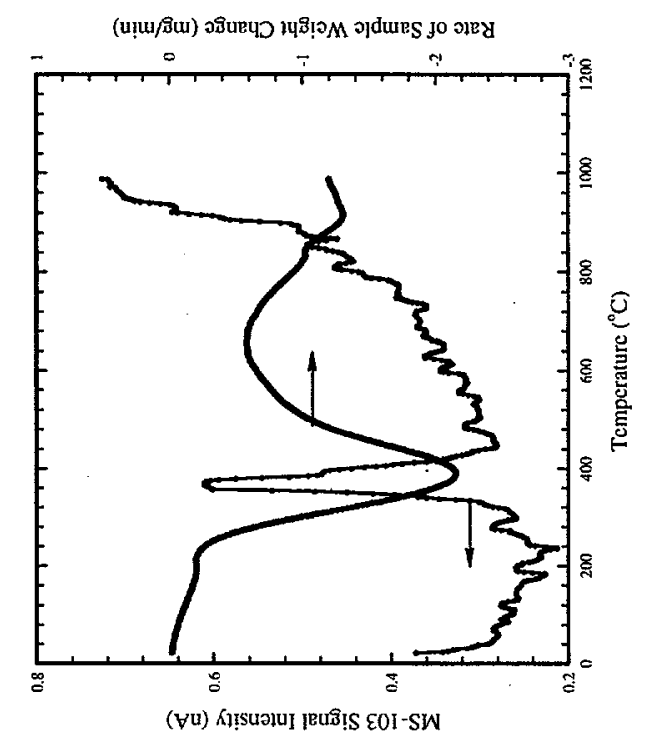

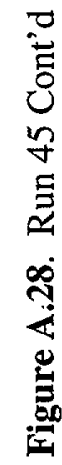



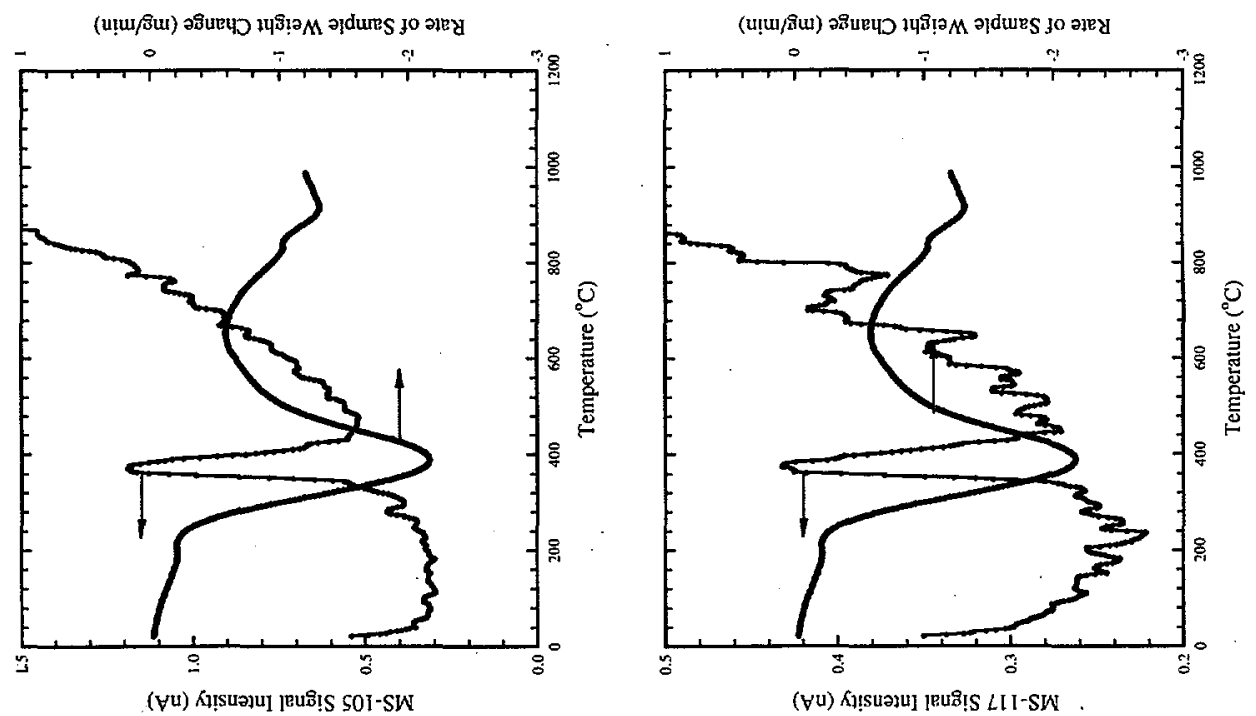

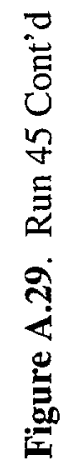

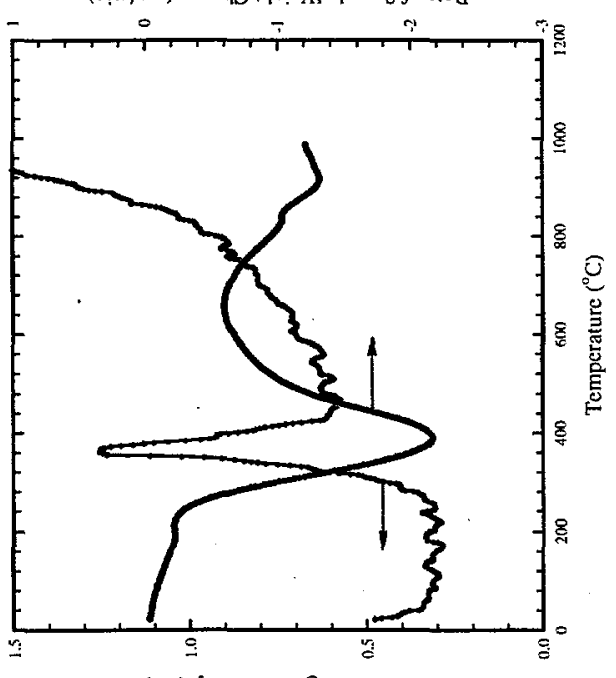

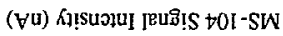

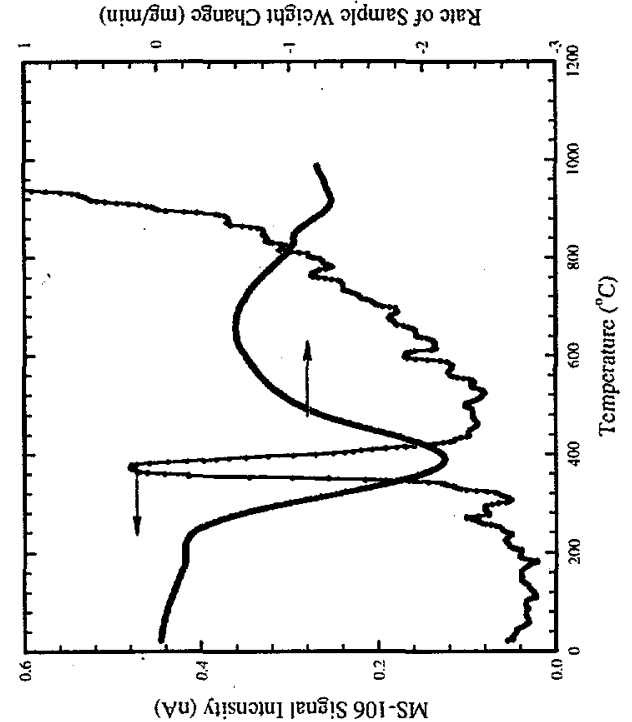



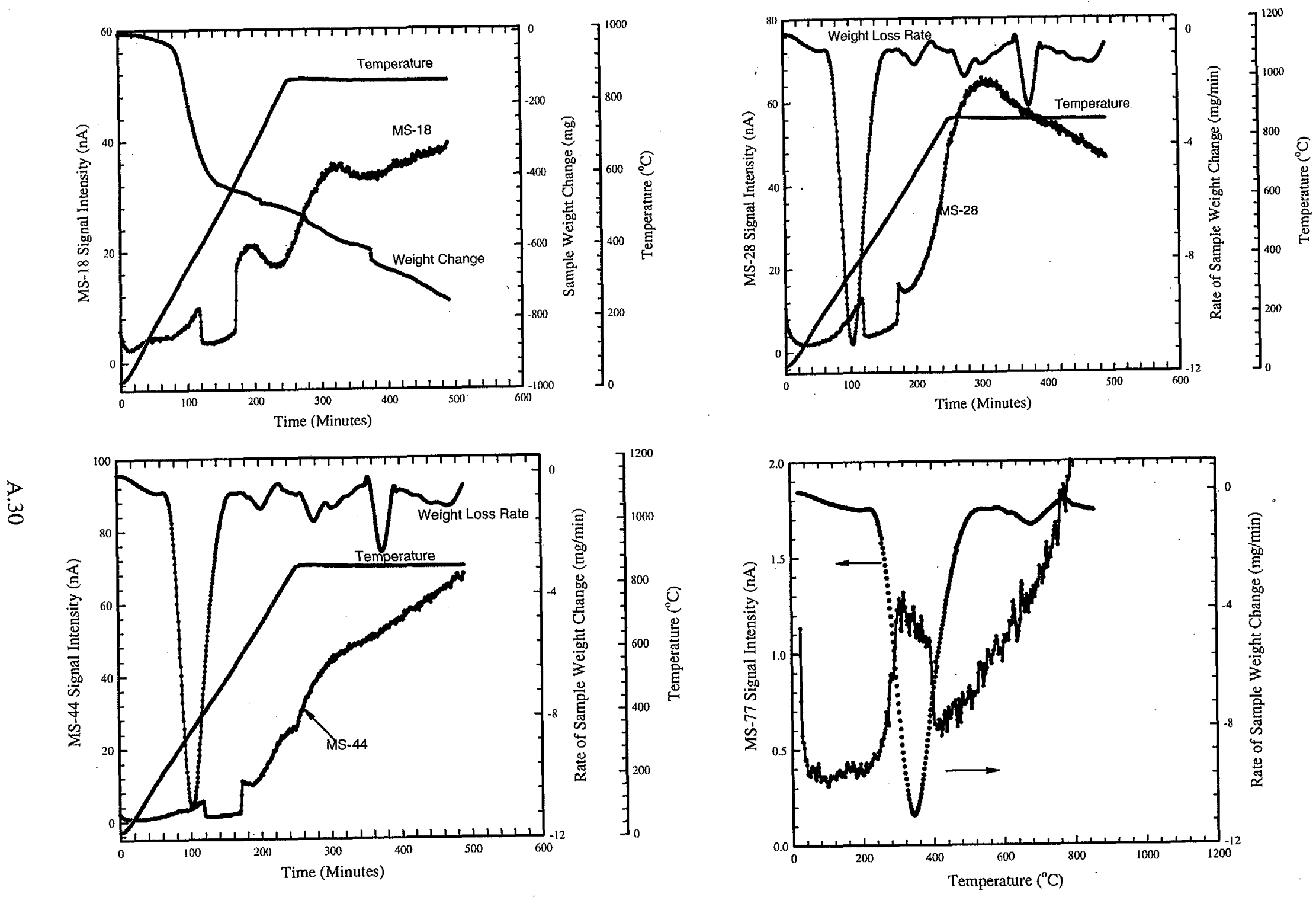

Figure A.30. Polycube Oxidation in Argon/Oxygen, Run 46 


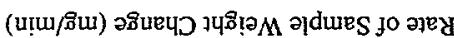

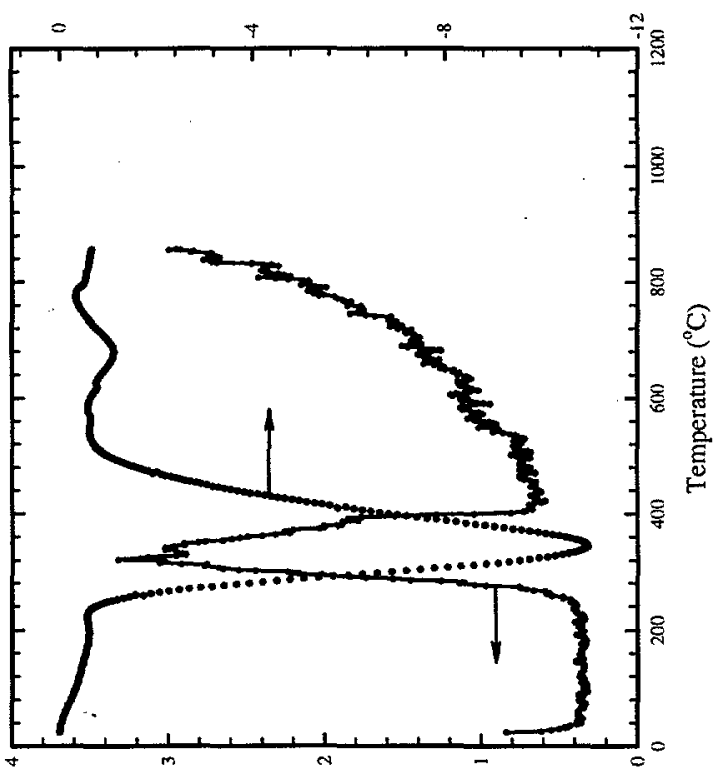

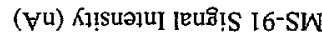

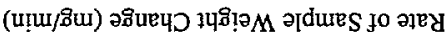

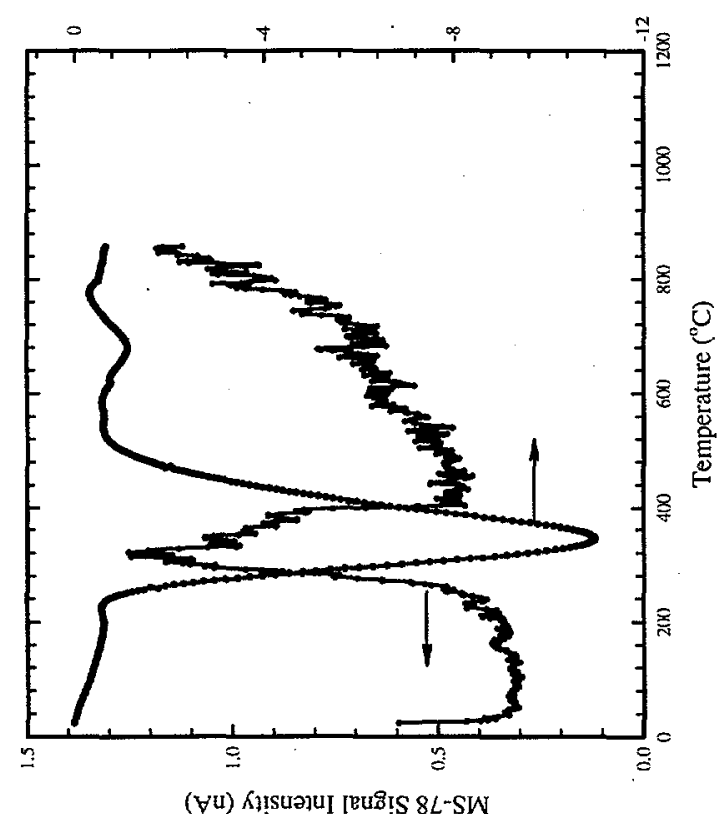

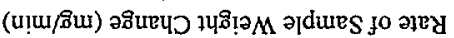

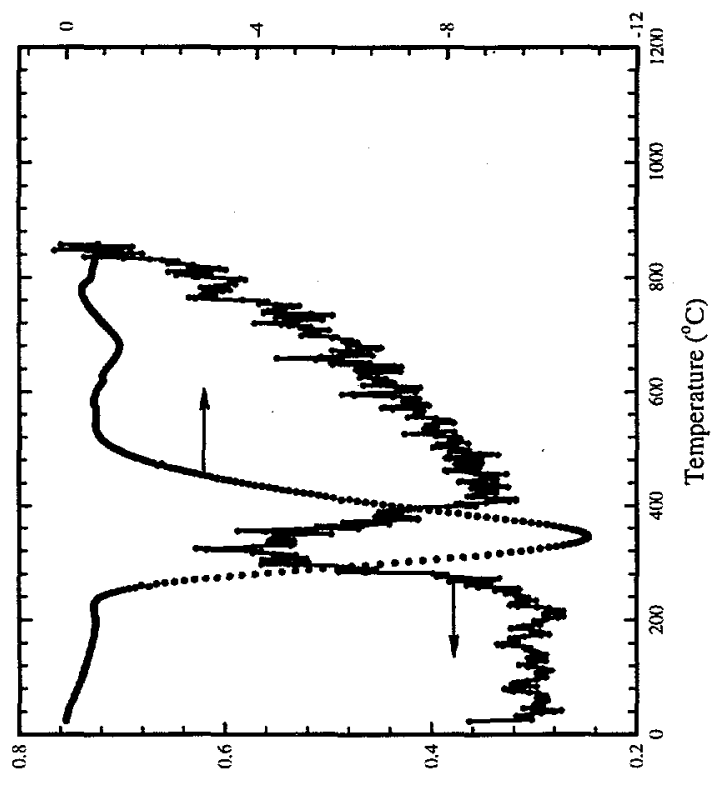

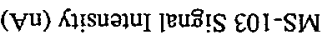

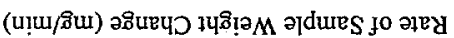

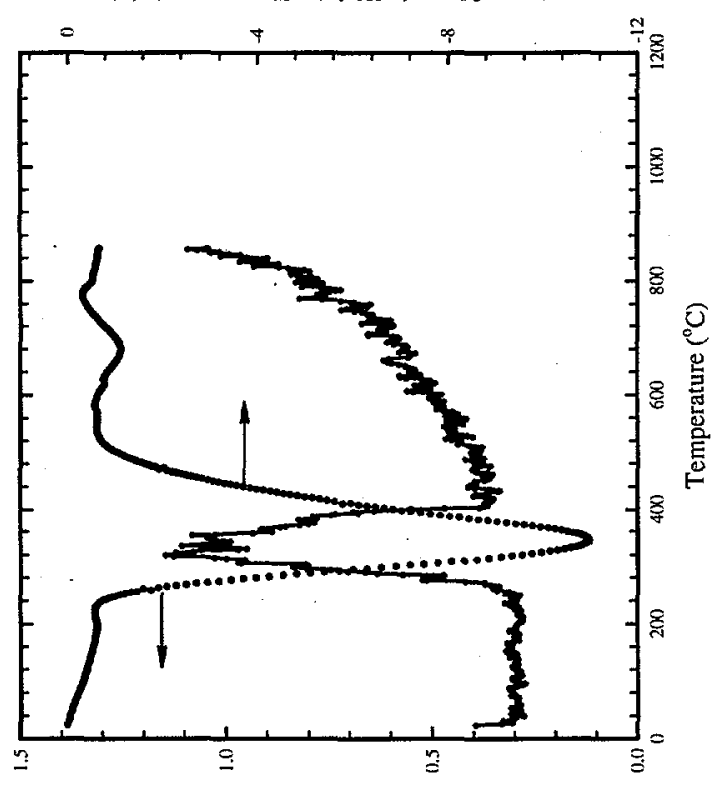

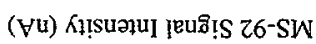




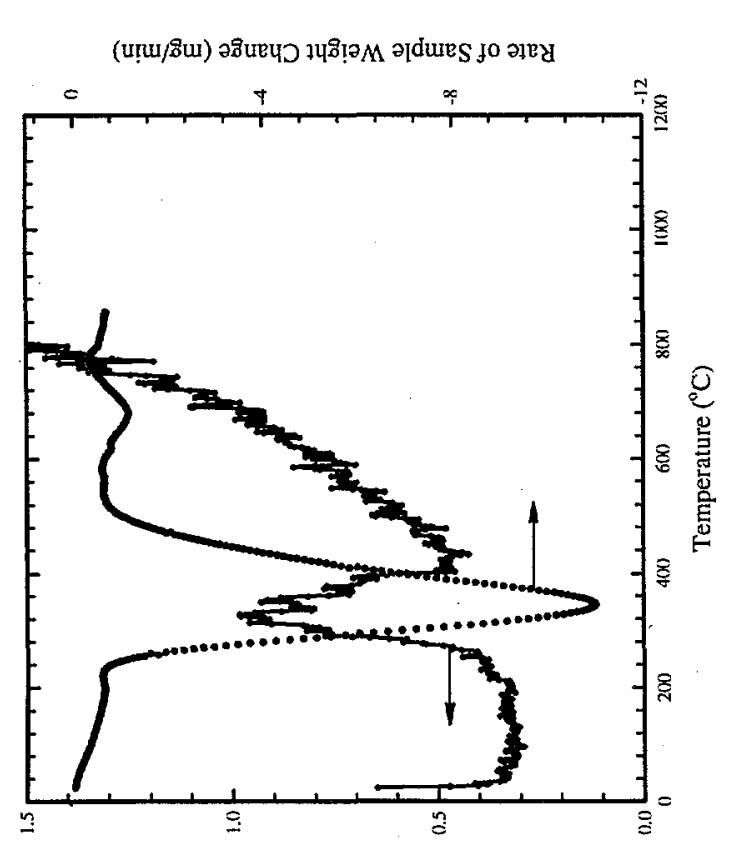

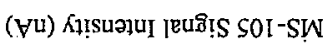

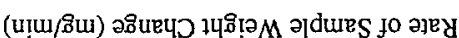

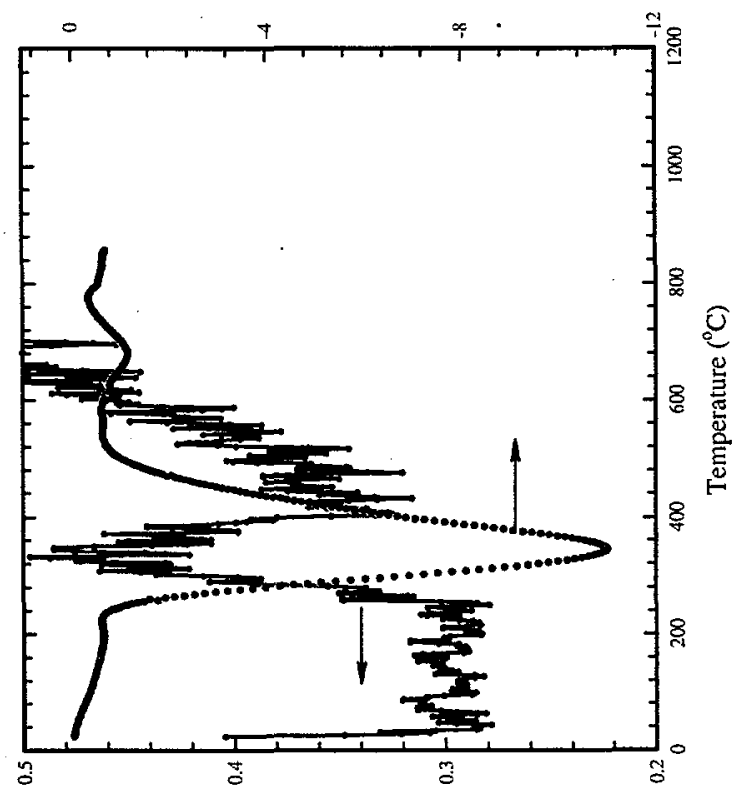

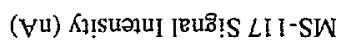

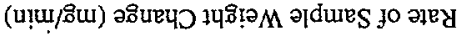

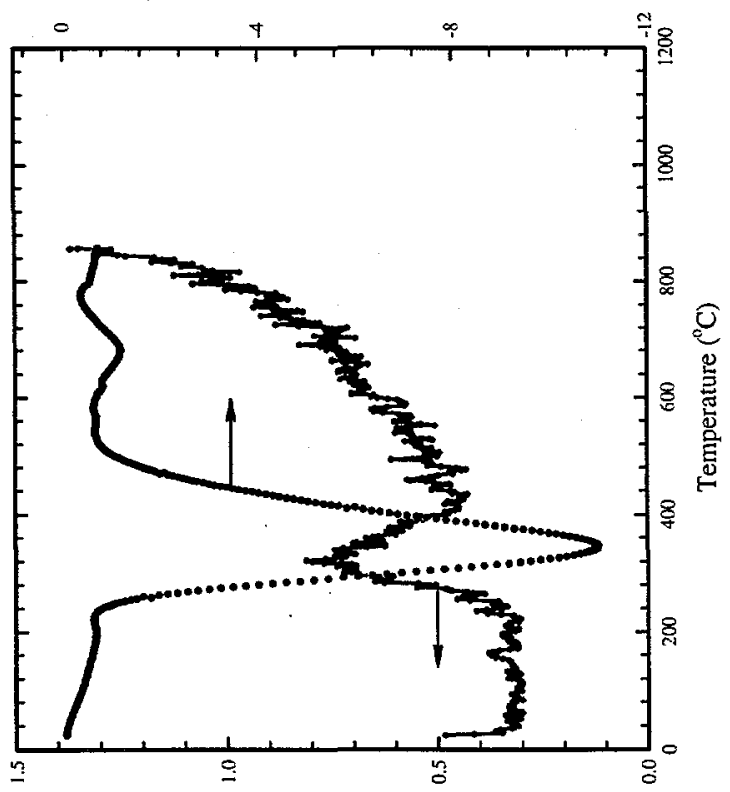

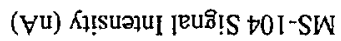

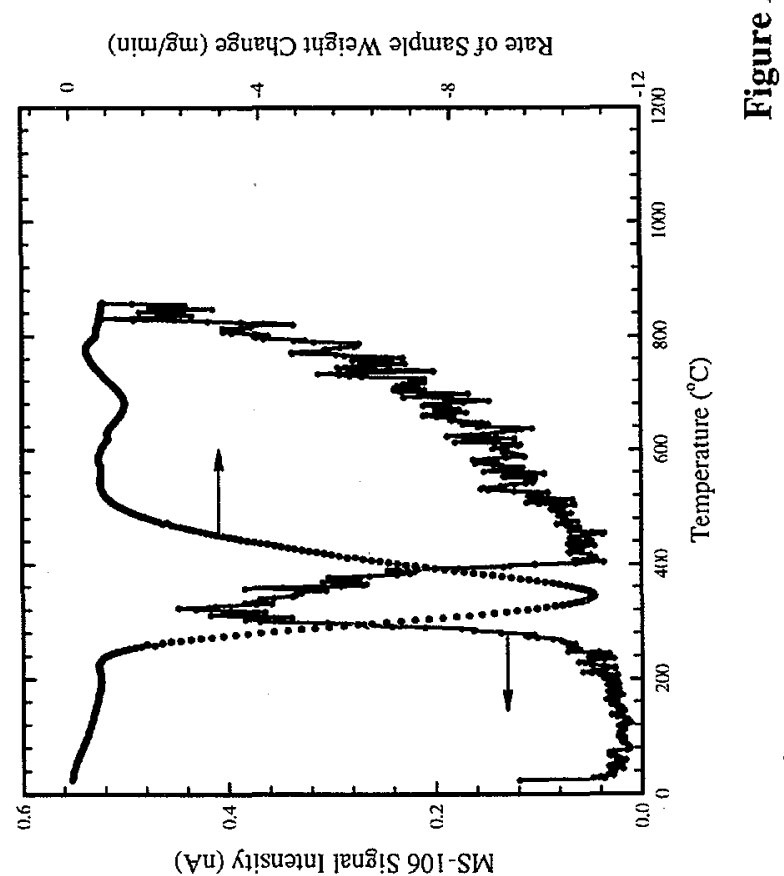

A.32 


\section{Distribution}

No. of

Copies

Offsite

J. D. Psaras

U.S. Department of Energy

1000 Independence Avenue, S.W.

Washington, D.C. 20585

\section{Onsite}

3 DOE Richland Operations Office
H. E. Bell
R3-79
M. R. Hahn
R3-79
L. D. Romine
R3-79

10 Fluor Hanford, Inc.

G. S. Barney

T5-12

T. D. Cooper

T5-12

T. W. Halverson (4)

R3-56

S. A. Jones

T5-12

H. R. Risenmay

T5-55

G. W. Reddick, Jr.

R2-12

C. S. Sutter

T5-12

19 Pacific Northwest National Laboratory

J. Abrefah (4) P7-27

J. L. Buelt K9-09

R. W. Goles K6-24

D. E. Knutson P7-25

P. A. Scott K9-46

K. L. Silvers (3) K9-08

T. L. Waiton K9-46

Information Release (7) K1-06

Distr.1 